\title{
Generic revision of the Microhoriini with new species and synonymies from the Palaearctic Region (Coleoptera: Anthicidae)
}

\author{
Zbyněk KEJVAL ${ }^{1)}$ \& Donald S. CHANDLER ${ }^{2)}$ \\ ${ }^{1)}$ Muzeum Chodska, Chodské náměstí 96, Domažlice, CZ-344 01 Czech Republic; e-mail: anthicid@seznam.cz \\ ${ }^{2)}$ Department of Biological Sciences, University of New Hampshire, Durham, NH 03824, U. S. A.; e-mail: Donald.Chandler@unh.edu
}

Accepted:

$31^{\text {st }}$ January 2020

Published online: $10^{\text {th }}$ March 2020

\begin{abstract}
The classification of Microhoriini Bonadona, 1974 is revised. Five genera are recognized: Aulacoderus LaFerté-Sénectère, 1849, Falsophilus Kejval, 2015, Liparoderus LaFertéSénectère, 1849, Microhoria Chevrolat, 1877, and Neocrohoria Telnov, 2019. (i) New species: Microhoria almukalla Kejval, sp. nov. (Yemen), M. anahita Kejval, sp. nov. (Iran), M. antalya Kejval, sp. nov. (Turkey), M. bacillisternum Kejval, sp. nov. (Iran), M. cervi Kejval, sp. nov. (Oman), M. fergana Kejval, sp. nov. (Kyrgyzstan), M. garavuti Kejval, sp. nov. (Tajikistan), M. gibbipennis Kejval, sp. nov. (Turkey), M. halophila Kejval, sp. nov. (Turkey), M. hazara Kejval, sp. nov. (Afghanistan), M. heracleana Kejval, sp. nov. (Greece), M. impavida Kejval, sp. nov. (Turkey), M. kabulensis Kejval, sp. nov. (Afghanistan), M. kermanica Kejval, sp. nov. (Iran), M. pahlavi Kejval, sp. nov. (Iran), M. persica Kejval, sp. nov. (Iran), M. strejceki Kejval, sp. nov. (Tajikistan), M. sawda Kejval, sp. nov. (Saudi Arabia), and M. sulaimanica Kejval, sp. nov. (Pakistan, Uzbekistan). (ii) New synonymies: Microhoria Chevrolat, 1877 = Clavicomus Pic, 1894 syn. nov. = Tenuicomus Pic, 1894 syn. nov.; Microhoria depressa (LaFerté-Sénectère, 1849) = Anthicus mollis Desbrochers des Loges, 1875 syn. nov.; Microhoria edmondi (Pic, 1893) = Anthicus spinosus Pic, 1912 syn. nov.; Microhoria globipennis $(\mathrm{Pic}, 1897)=$ Anthicus globipennis quercicola Sahlberg, 1913 syn. nov.; Microhoria luristanica $($ Pic, 1911) $=$ Anthicus pietschmi Pic, 1938 syn. nov.; Microhoria ottomana (LaFerté-Sénectère, 1849) = Anthicus merkli Pic, 1897 syn. nov.; Microhoria pinicola (Reitter, 1889) = Microhoria feroni Bonadona, 1960 syn. nov.; Microhoria posthuma (Krekich-Strassoldo, 1931) = Anthicus fumeoalatus Krekich-Strassoldo, 1931 syn. nov.; Microhoria truncatipennis (Pic, 1897) = Anthicus mouzafferi Pic, 1910 syn. nov. (iii) Status changes. Anthicus tauricus var. inobscura Pic, 1908 is raised to species level as Microhoria inobscura (Pic, 1908) stat. nov.; Anthicus truncatus var. decoloratus Pic, 1897 is removed from synonymy with Anthicus truncatus Pic, 1895 and raised to species level as Microhoria decolorata (Pic, 1897) stat. restit. (iv) New combinations: Microhoria disconotata (Pic, 1907) comb. nov., M. fossicollis (LaFerté-Sénectère, 1849) comb. nov., M. gestroi (Pic, 1895) comb. nov., M. irregularis (Pic, 1932) comb. nov., M. lividipes (Desbrochers des Loges, 1875) comb. nov., M. marginicollis (Pic, 1951) comb. nov., M. nystii (LaFerté-Sénectère, 1849) comb. nov., M. schimperi (Pic, 1898) comb. nov., M. semiviridis (Pic, 1951) comb. nov., M. strandi (Krekich-Strassoldo, 1931) comb. nov., and M. yemenita (Nardi, 2004) comb. nov., all from Anthicus Paykull, 1798. Microhoria abscondita (Telnov, 2000) comb. nov., M. adusta (Krekich-Strassoldo, 1931) comb. nov., M. afghana (Telnov, 2010) comb. nov., M. almorae (Krekich-Strassoldo, 1931) comb. nov., M. ambusta (Krekich-Strassoldo, 1931) comb. nov., M. angulifer (Pic, 1893) comb. nov., M. anomala (Telnov, 1998) comb. nov., M. antinorii (Pic, 1894) comb. nov., M. apicordiger (Bonadona, 1954) comb. nov., M. aquatilis (Krekich-Strassoldo, 1931) comb. nov., M. assamensis (Pic, 1907) comb. nov., M. assequens (Krekich-Strassoldo, 1931) comb. nov., M. atrata (Krekich-Strassoldo, 1931) comb. nov., M. austriaca (Pic, 1901) comb. nov., M. bicarinifrons (Pic, 1892) comb. nov., M. biguttata (Bonadona, 1964) comb. nov., M. brevipilis (Pic, 1893) comb. nov., M. bruckii (Kiesenwetter, 1870) comb. nov., M. brunneipes (Krekich-Strassoldo, 1931) comb. nov., M. caeruleicolor (Pic, 1906) comb. nov., M. callima (Baudi di Selve, 1877) comb. nov., M. comes (Krekich-Strassoldo, 1931) comb. nov., M. cordata (Krekich-Strassoldo, 1931) comb. nov., M. curticeps (Pic, 1923) comb. nov.,
\end{abstract}


M. dichrous (LaFerté-Sénectère, 1849) comb. nov., M. doderoi (Pic, 1902) comb. nov., M. erythraea (Pic, 1899) comb. nov., M. erythrodera (Marseul, 1878) comb. nov., M. feai (Pic, 1907) comb. nov., M. fugax (LaFerté-Sénectère, 1849) comb. nov., M. fugiens (Marseul, 1876) comb. nov., M. garze (Telnov, 2018) comb. nov., M. gigas (Pic, 1899) comb. nov., M. gravida (Krekich-Strassoldo, 1931) comb. nov., M. harmandi (Pic, 1899) comb. nov., M. hauseri (Pic, 1906) comb. nov., M. henoni (Pic, 1892) comb. nov., M. heydeni (Marseul, 1879) comb. nov., M. himalayana (Pic, 1909) comb. nov., M. hummeli (Pic, 1933) comb. nov., M. immaculipennis (Krekich-Strassoldo, 1931) comb. nov., M. inabsoluta (Telnov, 2003) comb. nov., M. indeprensa (Telnov, 2000) comb. nov., M. kabyliana (Pic, 1896) comb. nov., M. kejvali (Telnov, 1999) comb. nov., M. kham (Telnov, 2018) comb. nov., M. kocheri (Pic, 1951) comb. nov., M. kuluensis (Pic, 1914) comb. nov., M. lepidula (Marseul, 1876) comb. nov., M. longiceps (LaFerté-Sénectère, 1849) comb. nov., M. longicornis (Uhmann, 1983) comb. nov., M. manifesta (Pic, 1907) comb. nov., M. martinezi (Pic, 1932) comb. nov., M. muguensis (Telnov, 2000) comb. nov., M. nigrocyanella (Marseul, 1877) comb. nov., M. nigrofusca (Telnov, 2000) comb. nov., M. nigroterminata (Pic, 1909) comb. nov., M. notatipennis (Pic, 1909) comb. nov., M. olivierii (Desbrochers des Loges, 1868) comb. nov., M. optabilis LaFerté-Sénectère, 1849) comb. nov., M. paganettii (Pic, 1909) comb. nov., M. phungi (Pic, 1926) comb. nov., M. picea (LaFerté-Sénectère, 1849) comb. nov., M. plagiostola (Bonadona, 1958) comb. nov., M. plicatipennis (Pic, 1936) comb. nov., M. posthuma (Krekich-Strassoldo, 1931) comb. nov., M. postimpressa (Pic, 1938) comb. nov., M. postluteofasciata (Pic, 1938) comb. nov., M. prolatithorax (Pic, 1899) comb. nov., M. proterva (Krekich-Strassoldo, 1931) comb. nov., M. ragusae (Pic, 1898) comb. nov., M. semidepressa (Pic, 1893) comb. nov., M. separatithorax (Pic, 1914) comb. nov., M. shibatai (Nomura, 1962) comb. nov., M. schrammi Pic, 1913) comb. nov., M. sikkimensis (Pic, 1907) comb. nov., M. sinensis (Pic, 1907) comb. nov., M. spinipennis (Pic, 1898) comb. nov., M. sporadica (Krekich-Strassoldo, 1931) comb. nov., M. striaticollis (Krekich-Strassoldo, 1931) comb. nov., M. subpicea (Pic, 1914) comb. nov., M. tersa (Krekich-Strassoldo, 1931) comb. nov., M. tonkinensis (Krekich-Strassoldo, 1928) comb. nov., M. truncatella (LaFerté-Sénectère, 1849) comb. nov., M. turgida (Krekich-Strassoldo, 1928) comb. nov., M. uhagoni (Pic, 1904) comb. nov., M. uniformis (Krekich-Strassoldo, 1931) comb. nov., M. variabilis (Telnov, 2003) comb. nov., M. weigeli (Telnov, 2000) comb. nov., M. versicolor (Kiesenwetter, 1866) comb. nov., M. wuyishanensis (Nardi, 2004) comb. nov., and Nitorus niger (Uhmann, 1996) comb. nov., all from Clavicomus Pic, 1894. Microhoria agriliformis (Pic, 1893) comb. nov., M. alfierii (Pic, 1923) comb. nov., M. angelinii (Degiovanni, 2012) comb. nov., M. babaulti (Pic, 1921) comb. nov., M. barnevillei (Pic, 1892) comb. nov., M. armeniaca (Pic, 1899) comb. nov., M. bonnairii (Fairmaire, 1883) comb. nov., M. cyanipennis (Grilat, 1886) comb. nov., M. depressa (LaFertéSénectère, 1849) comb. nov., M. dolichocephala (Baudi di Selve, 1877) comb. nov., M. duplex (Nardi, 2004) comb. nov., M. edmondi (Pic, 1893) comb. nov., M. escalerai (Pic, 1904) comb. nov., M. finalis (Telnov, 2003) comb. nov., M. fuscomaculata (Pic, 1893) comb. nov., M. insignita (Pic, 1906) comb. nov., M. luristanica (Pic, 1911) comb. nov., M. meloiformis (Reitter, 1890) comb. nov., M. mesopotamica (Pic, 1912) comb. nov., M. ocreata (LaFerté-Sénectère, 1847) comb. nov., M. olivacea (LaFerté-Sénectère, 1849) comb. nov., M. ottomana (LaFertéSénectère, 1849) comb. nov., M. pallicra (Dufour, 1849) comb. nov., M. paralleliceps (Reitter, 1890) comb. nov., M. paupercula (LaFerté-Sénectère, 1847) comb. nov., M. platiai (Degiovanni, 2000) comb. nov., M. siccensis (Normand, 1950) comb. nov., M. subaerea (Reitter, 1890) comb. nov., M. subcaerulea (Pic, 1906) comb. nov., M. subsericea (Pic, 1898) comb. nov., M. tarifana (Pic, 1904) comb. nov., M. tibialis (Waltl, 1835) comb. nov., M. velox (LaFertéSénectère, 1849) comb. nov., M. viridipennis (Pic, 1899) comb. nov., and M. viturati (Pic, 1893) comb. nov., all from Tenuicomus Pic, 1894. Microhoria decolorata (Pic, 1897) comb. nov. and M. truncata (Pic, 1895) comb. nov. from Stricticomus Pic, 1894. Microhoria truncatipennis (Pic, 1897) comb. nov. from Anthelephila Hope, 1833. (v) Lectotype designations. Lectotypes are designated for the following species: Anthicus depressus LaFerté-Sénectère, 1849, A. edmondi Pic, 1893, A. luristanicus Pic, 1911, A. merkli Pic, 1897, A. mouzafferi Pic, 1910, A. pietschmi Pic, 1938, A. pinicola Reitter, 1889, A. posthumus Krekich-Strassoldo, 1931, and A. spinosus Pic, 1912.

Key words. Coleoptera, Anthicidae, Microhoriini, Aulacoderus, Clavicomus, Falsophilus, Liparoderus, Neocrohoria, Microhoria, Tenuicomus, taxonomy, faunistics, new species, new synonymy, new status, Palaearctic Region 


\section{Contents}

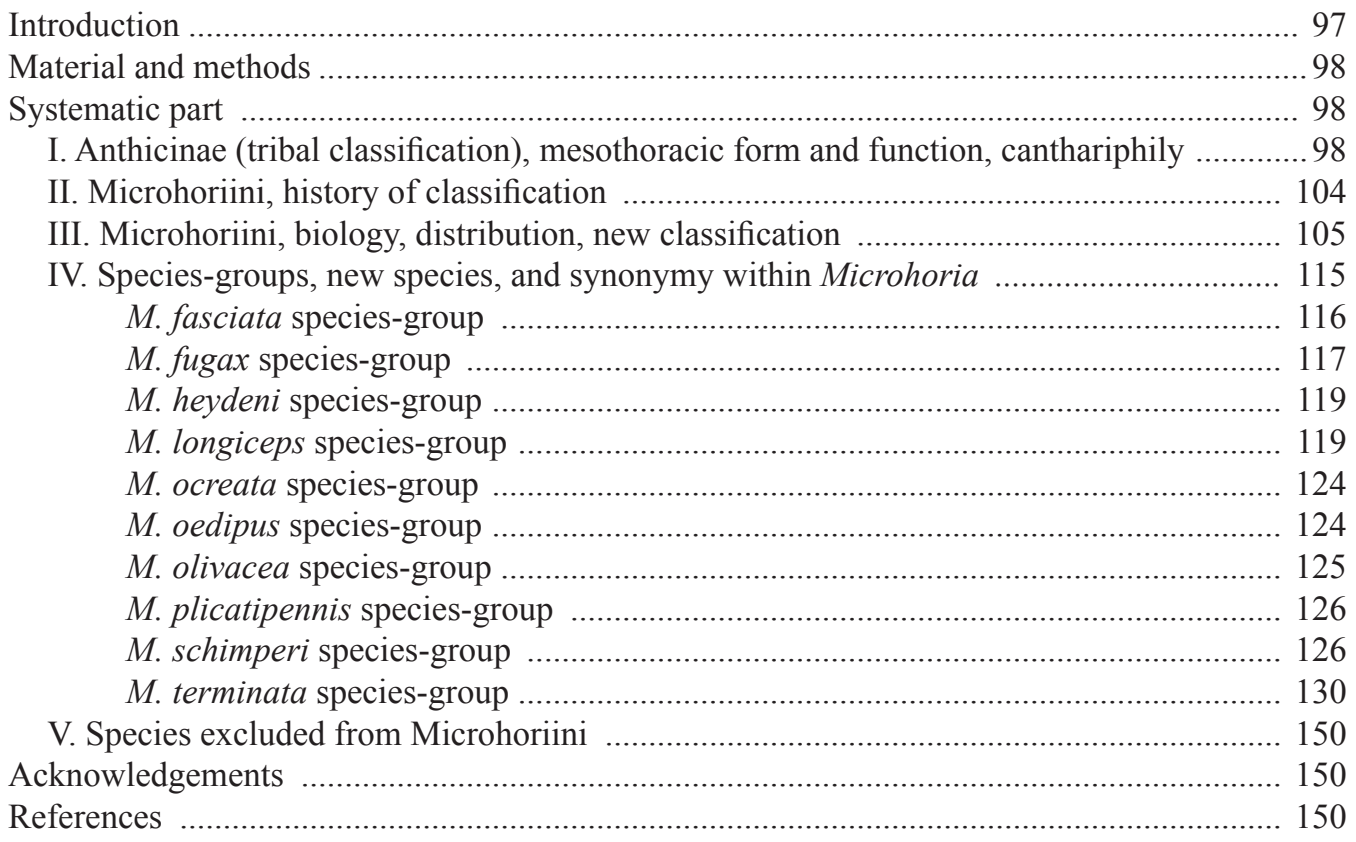

\section{Introduction}

The tribe Microhoriini Bondona, 1974 has been recognized as a natural group based on external anatomy and genitalic form (BonAdona 1974, BuCCiARELli 1980), and more recently by shared canthariphilous behavior and associated chemical adaptations of its members (HEMP 1994). However, definitions of most Microhoriini genera are still rather archaic and questionable, based mainly on shape of the pronotum in dorsal view.

In the first world classification of Anthicidae, LAFERTÉSÉNECTĖRE (1849c) dealt with only 43 species that would eventually be placed as Microhoriini, and the creation of his groups based on pronotal characters was more straightforward. As knowledge of the microhoriine fauna has grown, separation of the included genera has become increasingly problematic as the defined boundaries among genera break down due to the discovery of species that are intermediates of the body and genitalic forms. In his treatment of the Italian fauna BuCCIARELLI (1980) provided broader and much more complete characterizations of the genera and subgenera by describing the differences in distinctness and setation of the lateral antebasal foveae of the pronotum, form of the pubescence on the elytra, male features of the elytral apices, and more fully describing form and position of the male genitalia. Yet he (BuCCIARELLI 1977: 20, 1980: 185) commented that in his opinion Tenuicomus Pic, 1894 was likely a subgenus of Clavicomus Pic, 1894 due to the convergent characters of the two groups, and problems in separating these two groups had been noted by PIC (1894: 42, footnote) and NARdi (2003: 55). VAn Hille (1984: 2) commented on the issue of using pronotal form to characterize Aulacoderus LaFerté-Sénectère, 1849, and in essence concluded that pronotal form varies so much within the genus that it is useless in characterizing the genus.
The basic issue described above has led us to revise the classification of the tribe Microhoriini by reevaluating traditional characters and incorporating new data obtained by extensive comparative studies. As one of major outcomes the genera Clavicomus and Tenuicomus are synonymized here with Microhoria Chevrolat, 1877, and their species are newly placed in 10 species-groups. It has become clear that previous subdivisions are untenable with respect to variation of traditional pronotal characters (Figs 156-161). This is best demonstrated by the fact that some species-groups of Microhoria sensu novo are composites of species previously placed in 2-4 different genera, such as the $M$. schimperi species-group which includes species that had been residing in four genera.

Additional outcomes are the description of 19 new species of Microhoria from the western half of the Palaearctic Region, documentation of 10 new synonyms based on study of the types, and discussion of known nomenclatural issues dealing with species placement, authorship, and year of description, with two species being removed from Microhoria and placed in genera of the Anthicini Latreille, 1819. The new species are described in order to clarify issues with recognition of described species, as well as to further support the definitions of the species groups. Lectotypes are designated for nine species to fix their identity and newly proposed synonymies.

The Microhoriini is primarily a Palaearctic and Afrotropical group, with some diffusion by species into the Oriental Region in southeast Asia. A recently described monotypic genus, Neocrohoria Telnov, 2019, is distributed in central Chile in the southern temperate area of the Neotropical Region, and is the only New World representative of this tribe. Neocrohoria is considered to be closest to Aulacoderus, a group that is most diverse in the southern subtropical and temperate areas of the Afrotropical Region. 


\section{Material and methods}

Specimens were examined with a Leica MZ 9.5 stereomicroscope; morphological measurements were taken by using an ocular graticule. Male genitalia were examined after being cleared in a hot $10 \% \mathrm{KOH}$ solution and then placed on the same card as the specimen in water-soluble dimethyl hydantoin formaldehyde resin (DMHF). Illustrations were made using a drawing tube attached to an Olympus CH-2 compound microscope. SEM micrographs were taken using a Tescan Lyra3 GMU FIB Scanning Electron Microscope and JEOL JSM-7401F Field Emission Scanning Electron Microscope, and edited with Adobe Photoshop 9.0.2. software. Digital images were taken using a Nikon Coolpix 4500 digital camera attached to a Leica MZ 9.5 trinocular stereomicroscope; images of the same specimen at different focal planes were combined with Helicon Focus 5.2 Pro and edited with Adobe Photoshop 9.0.2. software.

Data from locality labels are cited verbatim for the type specimens only, and comments are placed in square brackets. Separate labels are indicated by double slashes ( // ). Locality data of the specimens from Iran collected by the expeditions of the National Museum in Prague are specified and/or supplemented by coordinates according to Hoberlandt $(1974,1981,1983)$.

The terminology of body setation follows WERNER \& Chandler (1995).

The acronyms of the specimen depositories are:

ADBC Augusto Degiovanni collection, Bubano, Italy; BMNH The Natural History Museum, London, United Kingdom;

DCDC Donald S. Chandler collection, Durham, New Hampshire, U.S.A.;

DFPC David Frank collection, Prague, Czech Republic;

MCSN Museo Civico di Storia Naturalle 'Giacomo Doria', Genova, Italy;

MNHN Museum National d'Histoire Naturelle, Paris, France;

MZLU Biological Museum, Lund University, Lund, Sweden;

NHMW Naturhistorisches Museum in Wien, Austria;

NMPC National Museum, Prague, Czech Republic;

SBPC Stanislav Benedikt collection, Plzeň, Czech Republic;

ZFMK Zoologisches Forschungsmuseum Alexander Koenig, Bonn, Germany;

ZKDC Zbyněk Kejval collection, Domažlice, Czech Republic;

ZSMC Zoologische Staatssammlung München, Germany.

Other abbreviations used: [h] - handwritten; [p] - printed; alt. - altitude; coll. - collection; env. - environs of; lgt. - collected by; Mts - mountains; prov. - province; spec. $-\operatorname{specimen}(\mathrm{s})$.

\section{Systematic part}

\section{Anthicinae (tribal classification), mesothoracic form and function, canthariphily}

The subfamily Anthicinae Latreille, 1819 is currently composed of three tribes: Anthicini, Formicomini Bonadona, 1974, and Microhoriini. A fourth tribe, the monotypic Endomiini Kaszab, 1956 based on Endomia Laporte, 1840, was placed as a junior synonym of Anthicini by BONADONA (1974) without comment, which was followed in a few later papers (BONADONA 1976, 1991, 2013; BuCCIARELli 1977), or not followed for reasons unexplained (BUCCIARELLI 1980). This synonymy is accepted here, as Endomia is undoubtedly close to Anthicus Paykull, 1798 (BonAdona 1976), sharing both aedeagal and important external characters (mainly structure of the mesothorax). The genus is distinct by the presence of the lateral lobes of the frons covering the antennal bases (bases not covered in other Anthicini), the lack of an antebasal sulcus of pronotum (variably distinct within the Anthicini), and reduced terminal spurs of tibia (though present); the short, scale-like setae of the body have been shown to transition to longer, aciculate setae as seen in Endomia kejvali Degiovanni, 2016. We treat this combination of features as strong support for recognizing the genus Endomia, but not for treating this genus as the sole member of a separate tribe.

Major characters for grouping into tribes reside with the genitalic characters (BONADONA 1958a, 1974, 1990a, 2013; BucCiARelli 1980; ChANDLER 2010), but some external characters can be used as sets for accurately placing genera into tribes without resorting to examination of the male genitalia.

Anthicini: (i) mesepimera almost exclusively distinctly impressed to excavate and frequently distinctly setose; (ii) tibial spurs (especially mesotibial) mostly spinulose; (iii) intercoxal process of first abdominal ventrite more or less distinctly pointed to rounded apically (very rarely subtruncate) in dorsal view, its marginal bead almost exclusively complete; (iv) elytra with sutural stria present on at least apical third; (v) tegmen always open ventrally and clearly divided into parameral plate and phallobase, phallobase flattened, its basal margin truncate (Fig. 3); (vi) penis distinct, baculi of penis more or less widely separated (fused in some Endomia), primary gonopore slight; (vii) male elytral apices simple, channel/pores for cantharidin gland absent, species rarely canthariphilous, if canthariphilous then both sexes equally [?] attracted.

Formicomini: (i) mesepimera with small, nude fovea posteriorly, at most slightly impressed (never excavate); (ii) tibial spurs smooth; (iii) intercoxal process of first abdominal ventrite always broadly rounded to subtruncate, its marginal bead interrupted apically; elytra with sutural stria present on at most apical third; (v) tegmen always entirely open ventrally and clearly divided into parameral plate and phallobase, phallobase somewhat convex, its basal margin rounded (Fig. 4); (vi) penis distinct, baculi fused into elongate apodeme (at least in basal half), base of apodeme simple, primary gonopore distinct, with small opening; elytral apices simple, channel/pores for cantharidin gland absent, species rarely canthariphilous, if so both sexes attracted.

Microhoriini: (i) mesepimera excavate (Figs 35, 36), except Falsophilus and some apterous Aulacoderus; (ii) tibial spurs smooth; (iii) intercoxal process of first abdominal ventrite variable in form but its marginal bead almost exclusively complete, except Falsophilus (Fig. 38); (iv) elytra with sutural stria lacking to slightly indicated near apex; (v) tegmen partly closed, circular (sleeve-like), encasing endophallus (Figs 5, 6), exceptionally open ventrally but then strongly convex (Neocrohoria, Fig. 47), separation of parameral plate and phallobase either weakly indicated or indistinct (mostly); (vi) penis indistinct, baculi forming 

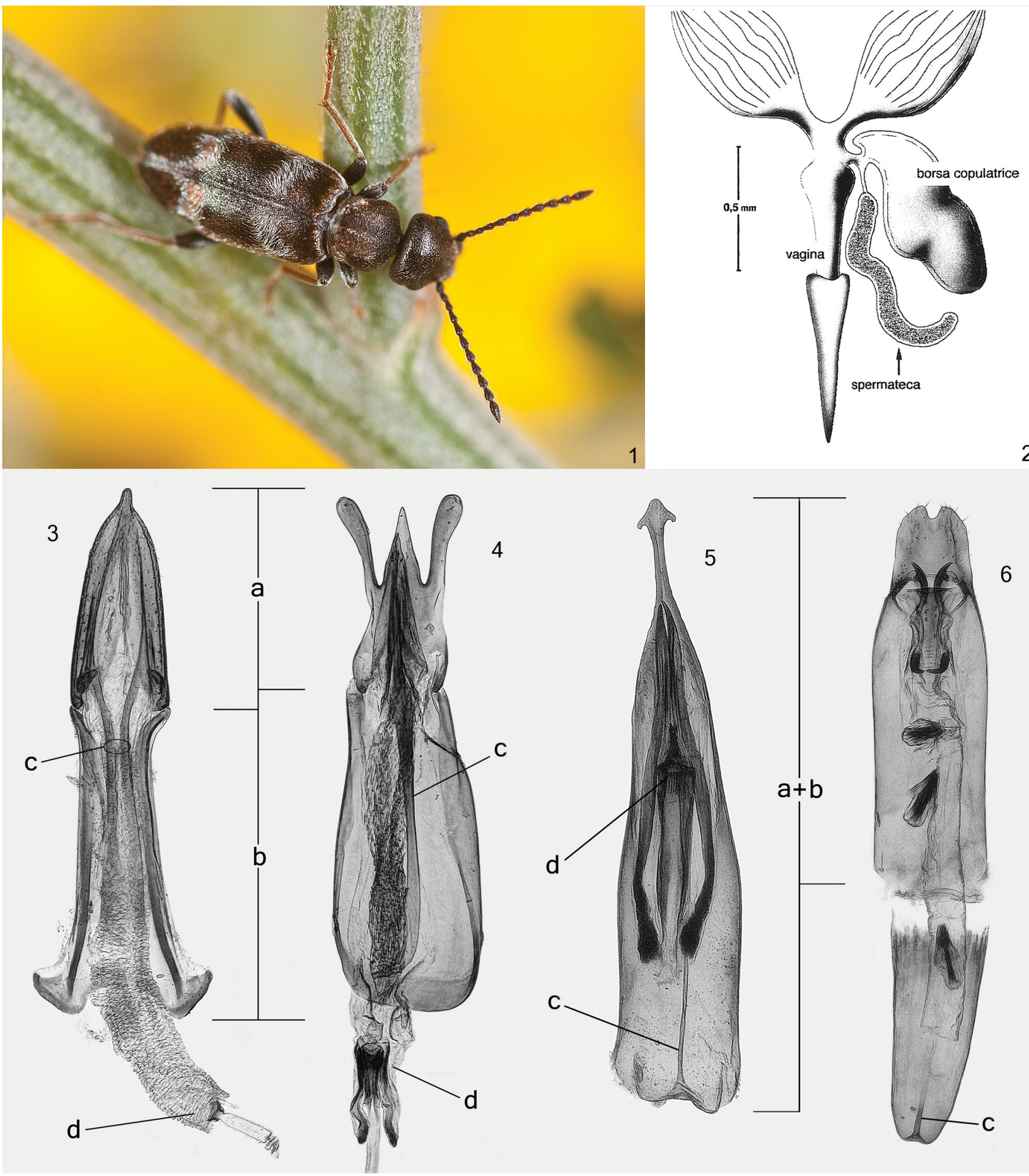

Figs 1-6. 1 - Liparoderus venator (Dufour, 1849), Spain, Zaragoza (D. Molina det., photo by B. Campo, www.biodiversidadvirtual.org.). 2 - Microhoria raveli (Pic, 1899), female internal reproductive structures, after DE MARzo (1996). 3-6 - Aedeagus in ventral view: 3 - Sapintus oceanicus (LaFertéSénectère, 1849), India, Tamil Nadu, Poovar (ZKDC); 4 - Anthelephila cyanea (Hope, 1833), South Africa, Western Cape prov., Greyton (ZKDC); 5 - Microhoria garavuti sp. nov., holotype; $6-$ M. cervi sp. nov., paratype, Al Mughsayl (a = parameral plate, $\mathrm{b}=$ phallobase, $\mathrm{c}=$ baculi of endophallus, $\mathrm{d}=$ primary gonopore). Scale not specified.

short to long thin free apodeme, base of apodeme attached to membranous apically-facing 'cup/plate' (Fig. 48), primary gonopore usually well-developed with opening large, but may be also indistinct; (vii) elytra almost exclusively with apical modifications related to presence of channel/ pores for cantharidin gland (varying in prominence, Figs 41-46), many species are canthariphilous, with only the males being attracted.
Mesothoracic form and function. BonAdONA (1958a: 7-8) was the first author to fully present characters of the ventral sclerites of the mesothorax when he systematically illustrated and discussed its structure for the genera treated in his monograph of the Madagascan Anthicidae. He continued providing these data for genera in some following papers: the African/Madagascan Tomoderini (BonADONA 1961), the genera of Notoxinae of France (BonADONA 
1971), and for several other genera that occur in France (BONADONA 1974). Mesoventral characters were later used also by WeRnER \& CHANDLER (1995) to characterize groups of the New Zealand Anthicinae. Morphology of the mesoventrite, mesepisterna, and mesepimera have been shown to be valuable in characterization of subfamilies, tribes, generic clusters, and genera of Anthicidae, with our focus being on the characteristics of the Microhoriini.

Mesoventrite. The basic form of the mesoventrite is triangular with the lateral margins straight and convergent anteriorly to an acute median point (BONADONA 1974; Bucciarelli 1980; Werner \& Chandler 1995; Chandler 2002, 2009; LAWRENCE \& ŚLIPIŃSKI 2013). The posterolateral angles are narrowly rounded and acute, and extend no further laterally than to the outer margins of the mesocoxal cavities; medially it extends posteriorly as the mesoventral process that separates the mesocoxal cavities. This shape is typical of Pyrochroidae, Ischaliidae, Meloidae (Eleticinae and members of other subfamilies), and basal subfamilies of Anthicidae (Eurygeniinae, Steropinae), with Copobaeninae and Macratriinae being differently modified from this basic form. In Anthicinae there are genera/generic clusters that have the lateral margins of the mesoventrite strongly, laterally lobed, with the posterolateral angles broadly rounded and extending laterally beyond a point even with the lateral margins of the mesocoxal cavities. One of the generic clusters with the lobed mesoventrite is found in the Microhoriini. Here the ancestral form with straight lateral margins is present for the genera Aulacoderus, Falsophilus, and Neocrohoria (Figs 7,9), with the derived lobed form characterizing the genera Liparoderus LaFerté-Sénectère, 1849 and Microhoria (Figs 11, 13).

Mesepisterna. The apical portion of the mesothorax is weakly to strongly constricted near the point of articulation with the pronotum to form a more or less broad apical 'neck.' The anterior margin of the mesothorax is formed by the apices of the mesepisterna that are medially touching or fused to different extents. The procoxal rests present in this area may be connected to or isolated from the anterior thickened rim of the mesepisterna, and the area immediately posterior to this rim can be shallowly impressed (ancestral for Anthicinae; microhoriine genera Aulacoderus, Falsophilus, Neocrohoria; Figs 8, 10) or modified to form deep, transverse, well-defined lateral grooves (derived; microhoriine genera Liparoderus and Microhoria; Figs 12, 14). There are analogous but different modifications of the mesepisterna in the other Anthicinae groups, mainly in those with lobed mesoventrites.

Mesepimera. The basal Anthicidae (e.g. Steropinae, Copobaeninae, and Eurygeniinae) and closely related heteromeran families (e.g. Meloidae, Pyrochroidae) have large mesepimera that are quite distinct, lack lines of longer setae on the posterior margin, lack any marginal foveae, and if they are tightly connected with mesepisterna, the suture is clearly defined, except for some Stereopalpus LaFerté-Sénectère, 1849 and for Mitraelabrus Solier, 1851 (Eurygeniinae).

In Anthicinae the mesepimera are always inconspicuous, being narrow and smoothly fused to the mesepisterna, with the line of fusion often seen internally as a linear flange, meaning that the apparent outer portion of the mesepisterna is in reality the mesal portion of the mesepimera. In addition they always have one or two internally projecting foveae at the sides facing the metepisterna, which is more or less deeply impressed and frequently conspicuously setose on/ along the postero-ventral margin. These mesepimeral setae may be modified in various ways that are useful in recognizing generic clusters. If well-developed, the postero-lateral impression/cavity of mesepimera can be distinctly setose, including some thicker, specialized setae (Figs 34, 36).

The function of mesepimeral foveae is unknown. They are often small, but can be conspicuously large, as in Africomus Kejval \& Chandler, 2016, numerous Sapintus Casey, 1895, and Aulacoderus. VAn Hille (1984) discussed presence and form of these foveae in defining his species-groups of Aulacoderus, with their differences being included in his keys and species descriptions.

Mesothoracic glands. The functions of the laterally lobed mesoventrite and transverse mesepisternal grooves that are characteristic of Microhoria sensu novo and Liparoderus have not been wholly determined. However, the anteromedial margin of the mesoventrite is immediately posterior to the opening of the mesothoracic glands where iridoid compounds are released and which probably repel ants and other potential predators (see below). Hemp \& DetTner (1997) theorized that the channel formed at the juncture of the mesoventrite and mesepisterna/mesepimera could serve as a conduit to disperse the iridoid compounds laterally through capillary action to the point where the channel contacts the mesepimeral setal row. Here the row of dense or spaced setae can serve as dispersing structures for the iridoids by wicking the compounds up the setae so they may volatilize quickly, with the strong curve of the mesoventrite allowing placement of a larger number of setae on the mesepimera to disperse the chemicals. Certainly many species of Acanthinus, seem to run or forage with ants without being attacked or even noticeably disturbed (D. S. Chandler, pers. observ.), which could be attributed to the chemical dispersal potential of the bowed mesoventrites and the mesepimera with their long appressed to erect setae.

The mesothoracic glands have been found in all members examined of the Anthicinae, Notoxinae, and Tomoderinae (Hemp 1994, De Marzo 2006, C. Hemp, in litt. [note: De Marzo did not find them in Aulacoderus, though other authors did, see below]). Size and morphology of these glands, chemical composition of their secretions and position of the gland orifice are variable (HEMP 1994, HEMP \& Dettner 1997, De Marzo 2006). Different compounds are produced at the level of subfamily, with these glands producing various iridoid compounds and/or their precursors by members of the Anthicinae, aromatic compounds by Notoxinae, and indols by Tomoderinae (Hemp 1994; C. Hemp, in litt.). The defensive role of the iridoids was determined by laboratory tests and field observations in species of Anthelephila Hope, 1833 (Hemp \& Dettner 1997). Glands of Microhoriini were found to be moderately large in Microhoria terminata and small in Aulacoderus species (Hemp 1994, Hemp \& DettNer 1997). In an unpublished 

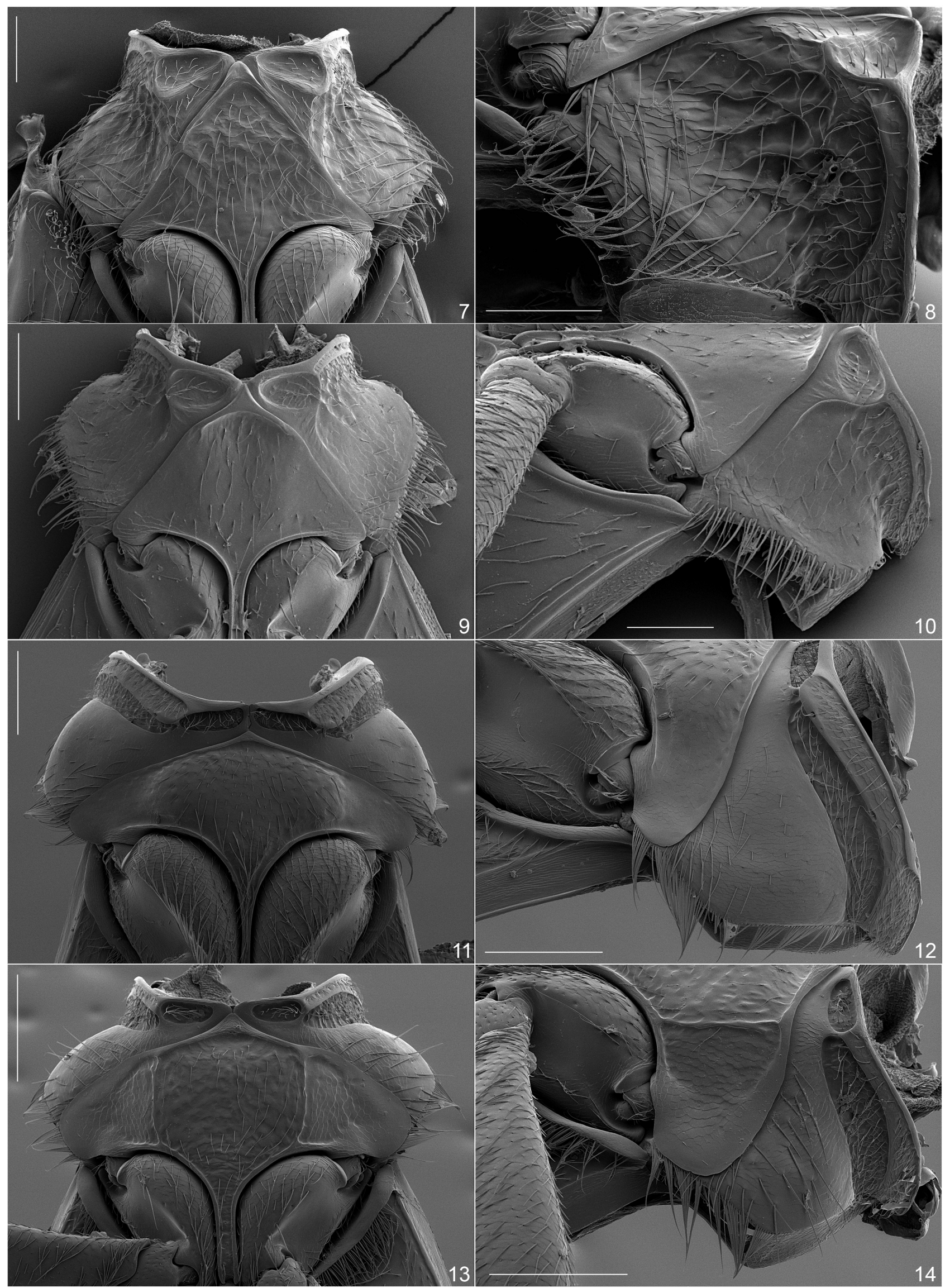

Figs 7-14. Mesothorax in ventral (left) and lateral (right) view: 7, 8 - Neocrohoria melanura (Fairmaire \& Germain, 1863), Chile, Malleco prov., 4 km W Victoria (DCDC); 9, 10 - Aulacoderus mutatus (Gemminger, 1870); 11, 12 - Liparoderus venator (Dufour, 1849); 13, 14 - Microhoria oedipus (Chevrolat, 1860). Scale bars: $100 \mu \mathrm{m}$ (Figs 7-10); $200 \mu \mathrm{m}$ (Figs 11-14). 

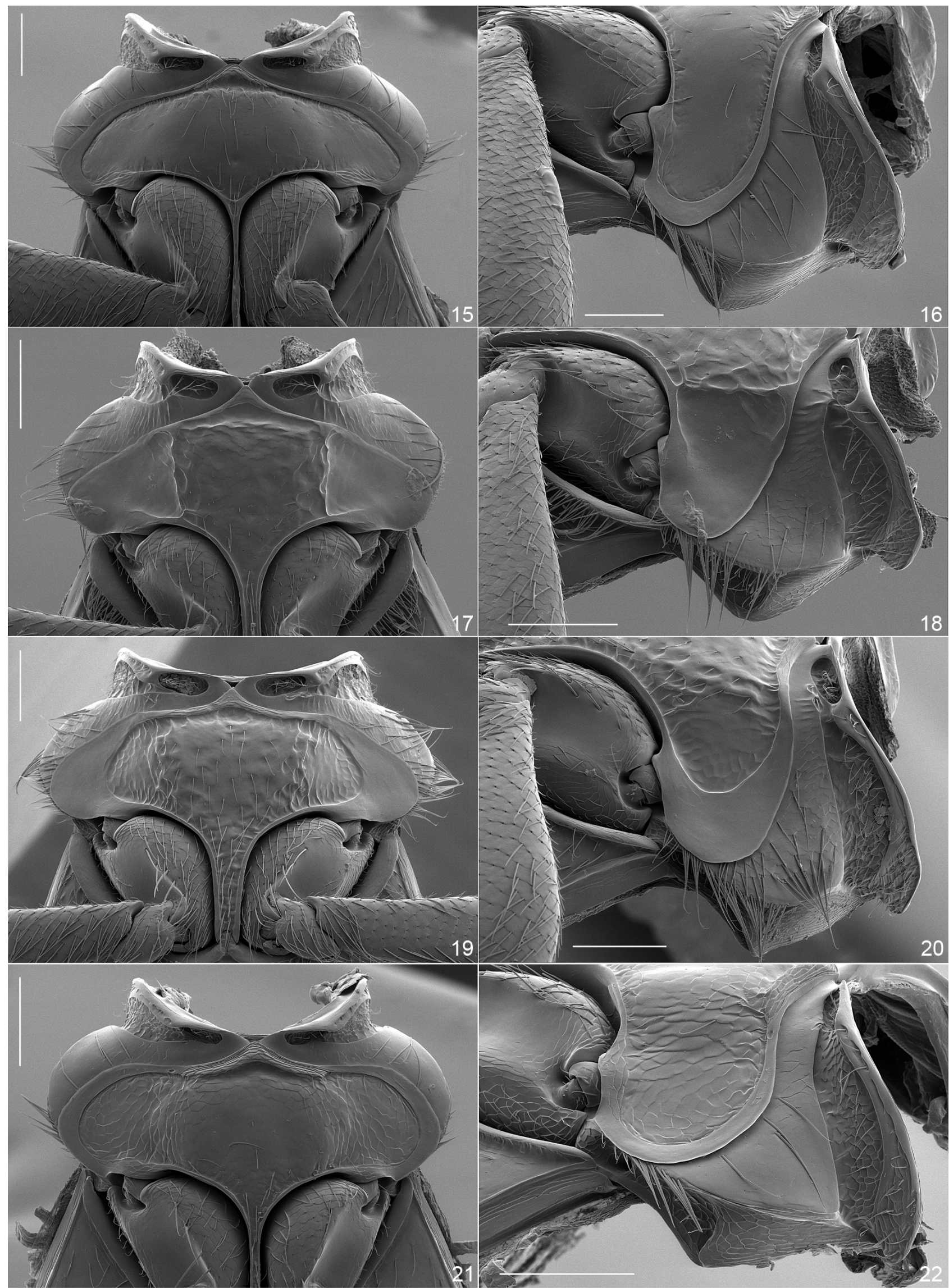

Figs 15-22. Mesothorax in ventral (left) and lateral (right) view: 15, 16 - Microhoria heydeni (Marseul, 1879) comb. nov.; 17, 18 - M. paupercula (LaFerté-Sénectère, 1849) comb. nov.; 19, 20 - M. babaulti (Pic, 1921) comb. nov.; 21, 22 - M. viturati (Pic, 1893) comb. nov. Scale bars: $100 \mu \mathrm{m}$. 


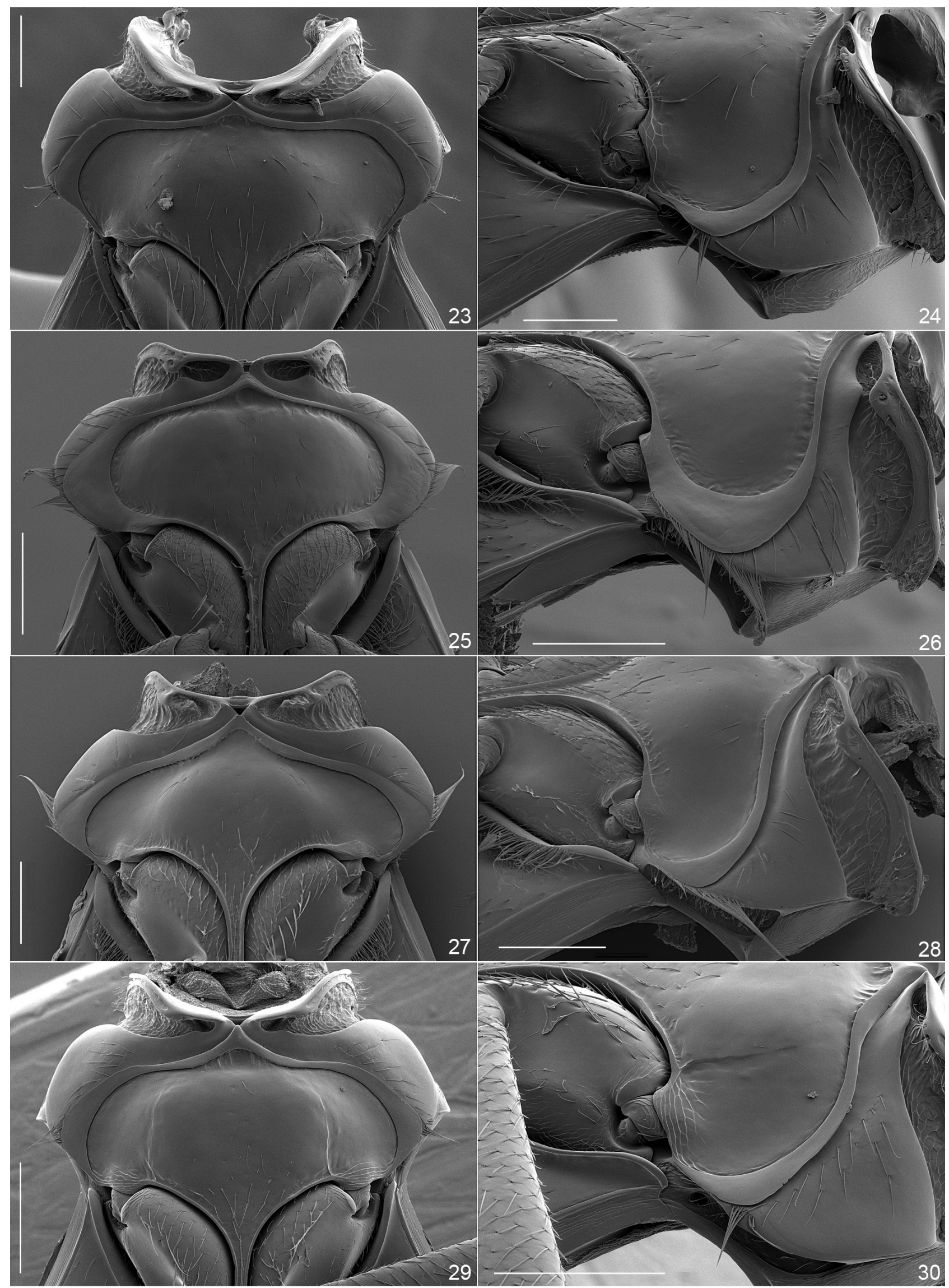

Figs 23-30. Mesothorax in ventral (left) and lateral (right) view: 23, 24 - Microhoria terminata (W. L. E. Schmidt, 1842); 25, 26 - M. longiceps (LaFerté-Sénectère, 1849) comb. nov.; 27, 28 - M. gigas (Pic, 1899) comb. nov.; 29, 30 - M. caeruleicolor (Pic, 1906) comb. nov. Scale bars: $100 \mu \mathrm{m}$ (Figs 23, 24); $200 \mu \mathrm{m}$ (Figs 25-30). 
study by Claudia Hemp (in litt.) the mesothoracic glands of 18 species of Microhoria (mesoventrite laterally lobed) and four species of Aulacoderus (mesoventrite laterally straight) were examined, with all Microhoria measured and having 'huge' glands, and all Aulacoderus having 'small to medium' glands, with the correlation of laterally lobed mesoventrites with large glands being quite strong.

It is interesting that of the families that produce or consume cantharidin only the closely related Meloidae and Anthicidae have been documented as having mesothoracic glands (Hemp \& DetTner 1997). The defensive compounds produced by the mesothoracic glands act to protect the adults; for those species that do consume cantharidin, adults will be protected by the iridoid secretions whether or not they find cantharidin, but for those with access to a cantharidin source the eggs, larvae, and pupae will be protected also.

Canthariphily. Cantharidin is a monoterpene anhydride naturally produced by the fat body of many members of the Meloidae and Oedemeridae (Holz et al. 1994, DetTNER 1997, HAsнimoto et al. 2016, JiAng et al. 2017). The compound is quite toxic to insects and vertebrates. Its presence is often coupled with strongly marked color patterns associated with aposematic coloration and serves as a potent feeding deterrent (CuÉNOT 1890, GöRNITZ 1937, vAN HiLle 1954, Carrell \& Eisner 1974, Dettner 1997). Meloid males are the primary producers of cantharidin, which is passed to the females in spermatic fluids during mating (SIERRA et al. 1976). The cantharidin is then passed by the females into their eggs (DETTNER 1997, NiKBAKHTZADEH et al. 2007) ensuring that this feeding deterrent is present not only in the female, but also serves to protect the eggs and subsequent larvae from predators and fungi (MCCORMICK \& CARREll 1987, DetTner 1997).

Though few insect groups produce cantharidin, its defensive properties have been appropriated by many groups by ingesting fluids and/or portions of living, moribund, and dead meloid and oedemerid beetles for a similar if derivative function (Young 1984a, Hemp \& DetTNER 2001). Relevant to this paper is that Anthicidae are the most abundant and diverse group of beetles attracted to cantharidin. Compilations of canthariphilous species have been produced by Abdullah (1965a), Young (1984a), and Hemp \& Dettner (2001), and indicate that members of the Microhoriini and Notoxinae are the most diverse and abundant beetles attracted to cantharidin. This is in contrast to the Anthicini and the other tribes/subfamilies of Anthicidae, where scattered positive associations have been noted, but for many of these species their abundances are low. GuYON (1848) was the first to note this phenomenon for Anthicidae when he recorded Notoxus monoceros (Linnaeus, 1760) feeding on Oedemera lurida (Marsham, 1802). TYLDEN (1865) provided the earliest record for meloids when he reported several $N$. monoceros feeding on a dead Meloe proscarabaeus Linnaeus, 1758. Among the following succession of records during the 1800 's were notes establishing the strong attraction of members of the Microhoriini to meloids: Liparoderus insignis (Lucas, 1843) (SANZ de DiEgo 1880, Bolivar y URRUTIA 1896), Microhoria fairmairei (Сноваuт 1895), Microhoria aubei, Microhoria chobauti, Microhoria cinctuta, and Microhoria pumila (PIC 1896; all as Anthicus), with many subsequent records summarized by YouNG (1974) and HEMP \& DETTNER (2001).

Members of the Microhoriini and many Notoxus Geoffroy, 1762 (Notoxinae) have apical modifications of the male elytra where small amounts of cantharidin are secreted to attract females. During mating the cantharidin-rich spermatic fluids carry this compound to the females where some is placed in the eggs, conveying protection to the eggs and larvae from predators as well as fungi (Schütz \& DETTNER 1992). In the most recent list of canthariphilous species by Hemp \& DetTner (2001), the totals for Microhoriini are: Aulacoderus, 48 species; Liparoderus, two subspecies of L. insignis; Microhoria sensu novo, 18 species (oedipus species-group, 10 species; terminata species-group, 5 species; schimperi species-group, 2 species; and ocreata species-group, 1 species). НАSHImото \& HAYASHI (2014) recently added Microhoria fugiens (as Clavicollis, presently fugax species-group) as a canthariphilous species. The male/ female sex ratio for attracted specimens of these species is usually near or at 100\% males (van Hille 1954, Schütz \& DetTner 1992, DetTner 1997, Hemp et al. 1999, Hashimoto \& HAYASH 2014). It is interesting that two phylogenetically distant groups of Anthicidae (Notoxinae and Anthicinae: Microhoriini) have either independently evolved or primitively retained these elytral glands that use cantharidin as an allomone to reduce predation pressure, with the chemical also acting as a selective agent that increases male reproductive success (VAN HILlE 1984).

Scattered members of certain genera, such as Anthelephila and some species-groups of Notoxus, may be strongly attracted to cantharidin, but lack the male elytral modifications and have both sexes attracted in roughly equal numbers (van Hille 1954, Abdullah 1965b, DetTner 1997). For these groups cantharidin appears to function as both an aggregation and sex pheromone (ABDULLAH 1965b) that brings both sexes together where they actively mate, and also obtain a defensive compound that provides protection to both sexes after they consume their cantharidin source (DE MARzo 1992, Hemp et al. 1997, Dettner 1997, Hemp et al. 1999).

\section{Microhoriini, history of classification}

The tribe Microhoriini was proposed by BonADonA (1974) to hold Clavicomus, Tenuicomus, Microhoria, and Aulacoderus, with Microhoria containing five subgenera: Liparoderus, Microhoria s. str., Immicrohoria Pic, 1894, Submicrohoria Bonadona, 1952, and Platyhoria Bonadona, 1952. Species of the genera recognized by Bonadona were perspicaciously placed by LAFERTÉ-SÉNECTĖRE (1849b) as the sole members of his Quatrième Division of Anthicus, which held the $16^{\mathrm{e}}$ Groupe (=Clavicomus), $17^{\mathrm{e}}$ Groupe (= Microhoria and Tenuicomus), and $18^{\mathrm{e}}$ Groupe (= subgenus Aulacoderus). His subgenus Liparoderus was placed as the preceding $15^{\mathrm{e}}$ Groupe of the Troisième Division of Anthicus (LAFerté-SÉneCtÈRE 1849a). The Divisions of LaFerté-Sénectère were based on differences of form as viewed dorsally, and the presence/absence of lateral 'fossettes laterales' (lateral setose impressions/foveae) on 
the pronotum. The Quatrième Division was characterized by the presence of these lateral setose impressions, while all other groups were judged to lack these impressions, including the group containing Liparoderus.

LaFerté-Sénectère's informal groups continued to be recognized as distinct groups by subsequent authors and in catalogues, with the groups usually placed together or nearby, but in slightly different arrangements that increasingly emphasized differences of pronotal form as a critical factor in placement near other genera. MARSEUL (1879) proposed a series of informal names for these groups (while apparently unaware of the description of Microhoria) ending with '-colles' (for pronotum). These were later formalized as available scientific names by PIC (1894) as subgenera within the genus Anthicus: 'Clavicolles' [= Clavicomus], 'Tenuicolles' [= Tenuicomus], and 'Bifossicolles' [= Microhoria]. PIC (1894) also added the new subgenus Immicrohoria to the generic cluster formed around the subgenus Microhoria. Preceding and following catalogues treating the Coleoptera of Europe (Heyden 1883; ReITTER 1891, 1906; WINKLER 1927) clustered Liparoderus, Microhoria, and Aulacoderus together, with Clavicomus and Tenuicomus placed closely anterior to this cluster, with all being treated as subgenera of Anthicus.

Separation of species within these subgenera was dependent solely on differences in color patterns, setal patterns, body form, and microsculpture. Hans von Krekich-Strassoldo produced the first key to the subgenera of Anthicus (KREKICH-STRASSOLdo 1911) following the original key by PIC (1894), but used the informal group names of MARSEUL (1879). KREKICH-STRASSOLDO (1914) was also the first anthicid worker to use figures of the male genitalia to support his species descriptions, when he began producing figures of the male genitalia of Anthelephila (tribe Formicomini). Genitalic figures became increasing common in his papers, and were critical components of major treatments of the Anthicus humilis group (= Cyclodinus Mulsant \& Rey, 1866, Anthicini) (KreKich-Strassoldo 1919), and relevant to this paper, the 'Bifossicolles' Group of Marseul (= Microhoria, Microhoriini) (KREKICH-STRASSOLdo 1929). This last paper was a landmark in providing modern species characterizations that incorporated figures and descriptions of the male genitalia for most of the species, while presenting other useful information such as description of the modifications of the male abdominal sternites and elytral apices.

Scattered species descriptions by Maurice Pic and other authors accumulated through the following years, with no synthetic treatments until Paul Bonadona and Johann Christoph van Hille began to publish on the Anthicidae, with the latter author contributing immensely to the knowledge of Aulacoderus. Dealing with taxonomy of the large genus Anthicus, Bonadona (1952) noted that the subgenera Microhoria and Immicrohoria share large lateral dimples (impressions/fossettes) on the pronotum, modified male elytral apices, and the male genitalia exhibited a unique structure within the Anthicidae. Therefore he raised Microhoria to the generic level and proposed its subdivision into four subgenera: Microhoria s. str.,
Immicrohoria, Submicrohoria, and Platyhoria, reflecting Krekich-Strassoldo's 'Bifossicolles' Groups 4 and 5 respectively (KREKICH-STRASSOLdo 1929: 151). Subsequently Bonadona, without discussion, began treating three other subgenera of Anthicus as genera, namely Aulacoderus (Bonadona 1956: 118), Clavicomus (Bonadona 1960: 55), and Tenuicomus (Bonadona 1974: 108). These genera were more formally characterized as such by BONADONA (1974) when he proposed the tribe Microhorini (sic!, now Microhoriini [cf. NARDI 2003, Bouchard et al. 2011]) to hold these three genera together with Microhoria, which now contained four subgenera: Liparoderus, Microhoria s. str., Immicrohoria, and Platyhoria (Bonadona 1974). BonAdona (1988: 13) later raised Liparoderus to the generic level, noting Liparoderus LaFerté-Sénectère, 1849 was an older name than Microhoria Chevrolat, 1877. He subsequently used Liparoderini in place of Microhorini (BonADONA 1990a: 20) in his key to the anthicid genera of France, without an explanation of his rationale for creating this new name. In his treatment of the Anthicidae of France Bonadona (1991) used Microhorini in the key to genera (pp. 12, 14) while using Liparoderini in the text (p. 123), which was repeated in a posthumous updated and annotated reissue of this treatment (BonAdONA 2013).

NARDI (2003) pointed out that Liparoderini was an unnecessary replacement name for the tribe, synonymized it with Microhoriini, and placed the names Immicrohoria, Platyhoria, and Submicrohoria as junior synonyms of Microhoria, leaving Aulacoderus, Clavicomus, Liparoderus, Microhoria, and Tenuicomus as the members of Microhoriini. TELNOV (1999) incorrectly included three New World genera as members of this tribe, based on unpublished portions of the Doctoral Dissertation of Claudia Hemp, and UhmanN $(2000,2007)$ incorrectly placed many Australian species in Microhoria and Aulacoderus. Recently KeJVAL (2015) added a new genus, Falsophilus Kejval, 2015, which was based on the distinctive Section 5 of Aulacoderus that had been proposed by VAN HILLE (1984), and provided a redescription of Aulacoderus in his treatment of the Palaearctic species of the genus (KEJVAL 2017).

In a case ruled on by the International Commission of Zoological Nomenclature (ICZN 2016), based on a petition by Alonso-Zarazaga (2013), use of Marseul's names that typically ended with the suffix '-colles', and which had been used by CHANDLER et al. (2004, 2008), were adjudicated to be incorrectly formed names that were to be rejected, with the correctly formed names of PIC (1894) ending with the suffix '-comus' to be retained.

\section{Microhoriini, biology, distribution, new classification}

\section{Microhoriini Bonadona, 1974}

Microhorini Bonadona, 1974: 106, 108, 110, Figs 9-15.

Microhorini: Bonadona (1991): 12, 14 (key to genera, France); BuccIARELLI (1980): 48, 175 (characters, key to genera); BocÁK (1993): 114 (checklist); Hemp (1994): 114 (characters, relationships, phylogeny, canthariphily); DETTNER (1997): 126 (canthariphily); KUBISz \& SzWAŁKo (1998): 9, 32 (checklist); NARDi (2003): 53 (note, synonymy).

Microhoriini: DE MARZo (1996): 150, 160 (internal reproductive structures); ChANDLER (2002): 550, 555 (biology, note); NARDi (2003): 53 
(note); Bouchard et al. (2011): 448 (checklist); ZAHRADNíK (2017): 319 (checklist).

Liparoderini Bonadona, 1990a: 20.

Liparoderini: Bonadona (1991): 123 (characters, key to genera and species, France); Bonadona (2013): 11, 82 (ditto); NARDI (2003) 53 (synonymy).

Diagnosis. Antennal insertion exposed and clearly visible; mandibles always with two apical teeth, distinct mola, cutting edge on right mandible, and well-developed prostheca (Figs 51, 52); maxillary galea rounded and simply densely setose apically; apical maxillary palpomere small and more or less elongate to subtriangular (never conspicuously triangular/securiform); labial palpi always trimerous; latero-basal pronotal foveae usually distinct (varying in distinctness); mesepisterna usually narrowly separate medially at anterior margin (except Liparoderus, Fig. 32); procoxal rests with extension of anterior margin laterally; intercoxal process of mesoventrite always fully developed; mesepimera usually deeply excavate and conspicuously setose in cavity and along its ventral margin (except some apterous Aulacoderus and all Falsophilus); mesepimeral foveae always present, varying in prominence (extremely developed in some Aulacoderus); metendosternite with well-developed lamina (Fig. 53, simplified in apterous species only); mesoscutellum usually rounded apically, rarely bluntly pointed (apterous species only); sutural striae of elytra absent or at most indicated subapically and thus indistinct; elytral apices in males almost always modified, with channel/pores for cantharidin gland (Figs 41-46, except Neocrohoria and some species of Microhoria); metacoxae with complete posterior carina (except Liparoderus); terminal spurs of tibiae simple; abdominal sternite VIII formed by single or paired sclerites (sometimes conspicuously modified, Figs 90-92, 99); abdominal segment IX (spiculum) Y-shaped; tegmen of aedeagus at least partly tubular (except monotypic Neocrohoria); endophallus of aedeagus with various sclerotized inner structures (spines, projections, longitudinal sclerite/-s), and slender free apodeme with basal cup/plate (both sometimes strongly reduced); ovipositor with well-developed, slender coxites and styli.

Remarks. Bonadona (1974) proposed Microhoriini to include those groups with a unique form of the aedeagus that he described as cuculliform (= like a cap or hood). His description of this form (here modified using the terminology of LAWRENCE et al. 2011) stated that the elongate, tubular phallobase formed a 'sleeve', with the fused parameres forming a triangular apical parameral plate that was angled over the phallobase like a cap, and with the endophallus typically containing some large hooks/ spines/teeth. This form of the aedeagus is indeed unique in the Anthicidae. The tegmen (the combined phallobase and parameral plate) forms a circular, ventrally closed structure, within which the endophallus moves. Slight lateral indentations usually indicate the separation point of the parameral plate and phallobase, but for numerous species this is not apparent. A distinct penis (median lobe) is absent. At the basal end of the tegmen is typically a distinct, lightly sclerotized 'cup' (van HiLle 1984: 6, Figs
7-9) that can move freely within the tubular tegmen. The 'cup' has its basal portion usually distinctly sclerotized, with the fused baculi (struts) extending apically as an apodeme that can be minute or conspicuous and may extend through the length of the endophallus. The cup can be easily pulled out and disassociated from the aedeagus. While the function of the 'cup' is unknown, its apodeme possibly serves to provide rigidity to the endophallus when everted during mating. The primary gonopore is typically found in the apical half near the apex of the endophallus, and is usually visible as a broad, lightly sclerotized ring.

De Marzo (1996) produced the only paper dealing explicitly with the internal female and male reproductive structures of Anthicidae. He covered 23 European species that were members of the Notoxinae and Anthicinae. Two species of Microhoriini were examined (Clavicomus paganettii and Microhora raveli), one species of Formicomini, 17 species of Anthicini from 8 genera including Endomia (all preceding are Anthicinae), and three species of Notoxus (Notoxinae $-N$. monoceros species-group). He found that males of Microhoriini and Notoxinae species lack an ejaculatory ampulla (present in all other groups examined), and that for the females only the Microhoriini had a large thick-walled bursa copulatrix (Fig. 2) adjacent to the spermatheca in which he found 1-6 spermatophores in the Microhoria species and one in the single Clavicomus species examined. The members of Notoxus and other genera had a flexible expandable spermathecal receptacle situated at some distance from the vagina, with that of the Notoxinae comparably quite large. These genera lacked spermatophores, and the sperm were deposited freely mixed with secretions of the male accessory glands (DE MARzo 1996). Analogous similarities of Notoxinae and Microhoriini are that both have large sperm storage receptacles and that males could potentially share a large amount of cantharidin-laden secretions with females when mating, potentially much more than would be shared with non-canthariphilous species. In consideration of the female large seminal fluid storage organs and lack of a male ejaculatory ampulla (DE MARzo 1996), the very large primary gonopore suggests the ability to move large amounts of seminal fluid under a lower pressure, one of the issues necessary to address in transfer of cantharidin-laden fluids. Members of the European Anthicini genera, including Endomia, typically have a long, narrow ejaculatory duct coupled to a muscular ejaculatory ampulla that can force the free, non-motile sperm quickly through their narrow conduit (De Marzo 1996).

The unique form of the male genitalia, with its basal cup, lack of a penis, and tubular form, along with the presence of modified male elytra associated with canthariphily provide strong support for recogniting Microhoriini as a monophyletic group, and the shared form of the mesothoracic sclerites (Figs 11-30) provides similarly strong support that Microhoria sensu novo is a monophyletic group. DE MARzo (1996) examined 17 species from eight European genera of Anthicini and two species of Microhoria placed 
in different species-groups, and provided additional, if limited, evidence for the monophyly of the Microhoriini in noting that the female internal genitalia of Microhoria are different from those of Anthicini by possession of a large bursa copulatrix, presumably enlarged to receive poten- tially large amounts of cantharidin-rich spermatic fluids. This coupled with the quite large primary gonopore can allow the freer and quicker passage of male fluids during mating (the primary gonopore being comparatively very small in the Anthicini studied).

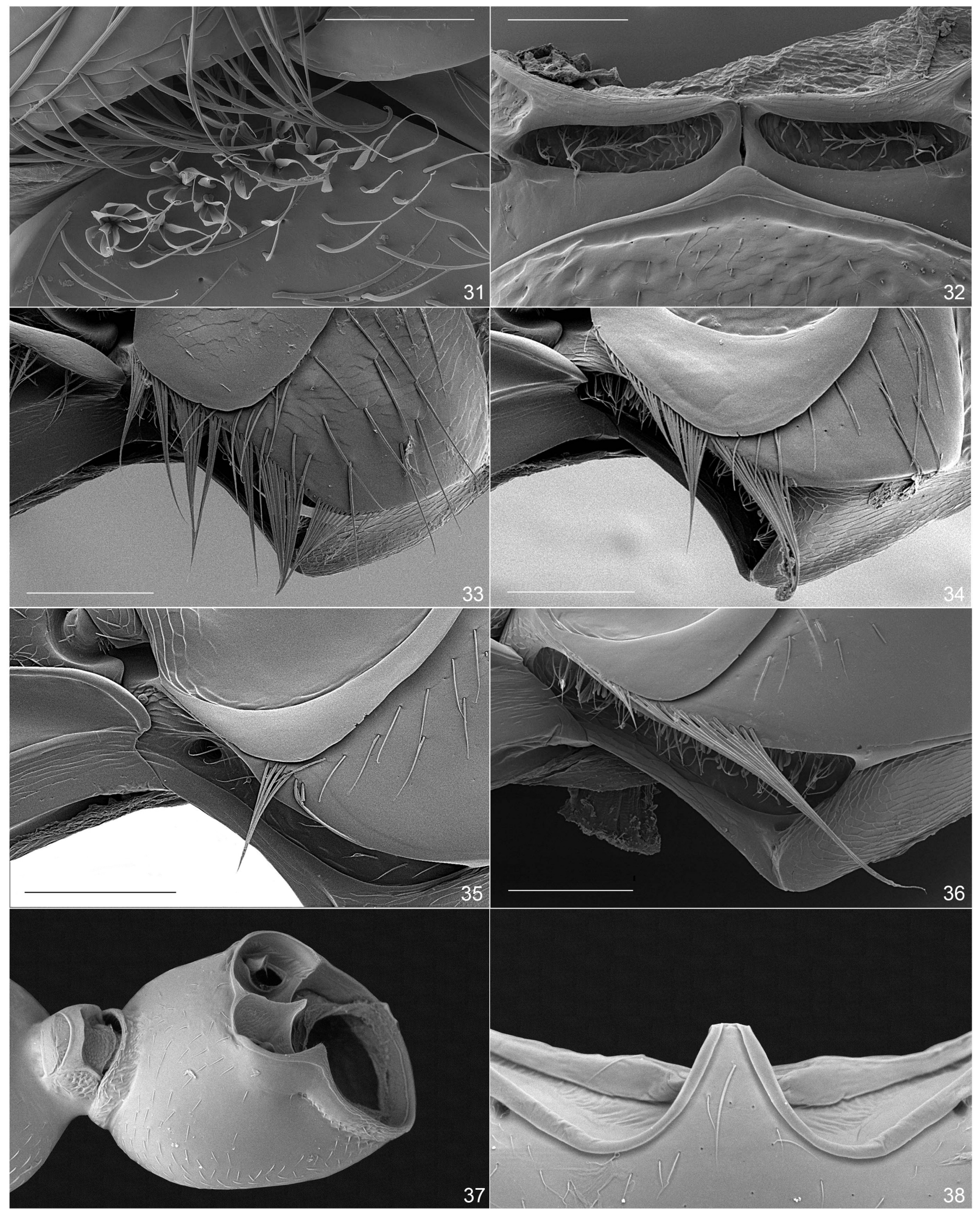

Figs 31-38. 31 - Neocrohoria melanura (Fairmaire \& Germain, 1863), Chile, Malleco prov., 4 km W Victoria (DCDC), setae of metepisterna. 32 - Liparoderus insignis (Lucas, 1843), antero-median margin of mesothorax. 33-36 - Mesothorax in lateral view (detail): 33 - Microhoria oedipus (Chevrolat, 1860); 34 - M. longiceps (LaFerté-Sénectère, 1849) comb. nov.; 35 - M. caeruleicolor (Pic, 1906) comb. nov.; 36 - M. gigas (Pic, 1899). comb. nov. 37, 38 - Falsophilus minutus (Pic, 1894), after KeJvAL (2015): 37 - prothorax in ventro-lateral view; 38 - intercoxal process of abdomen. Scale bars: $100 \mu \mathrm{m}$. 

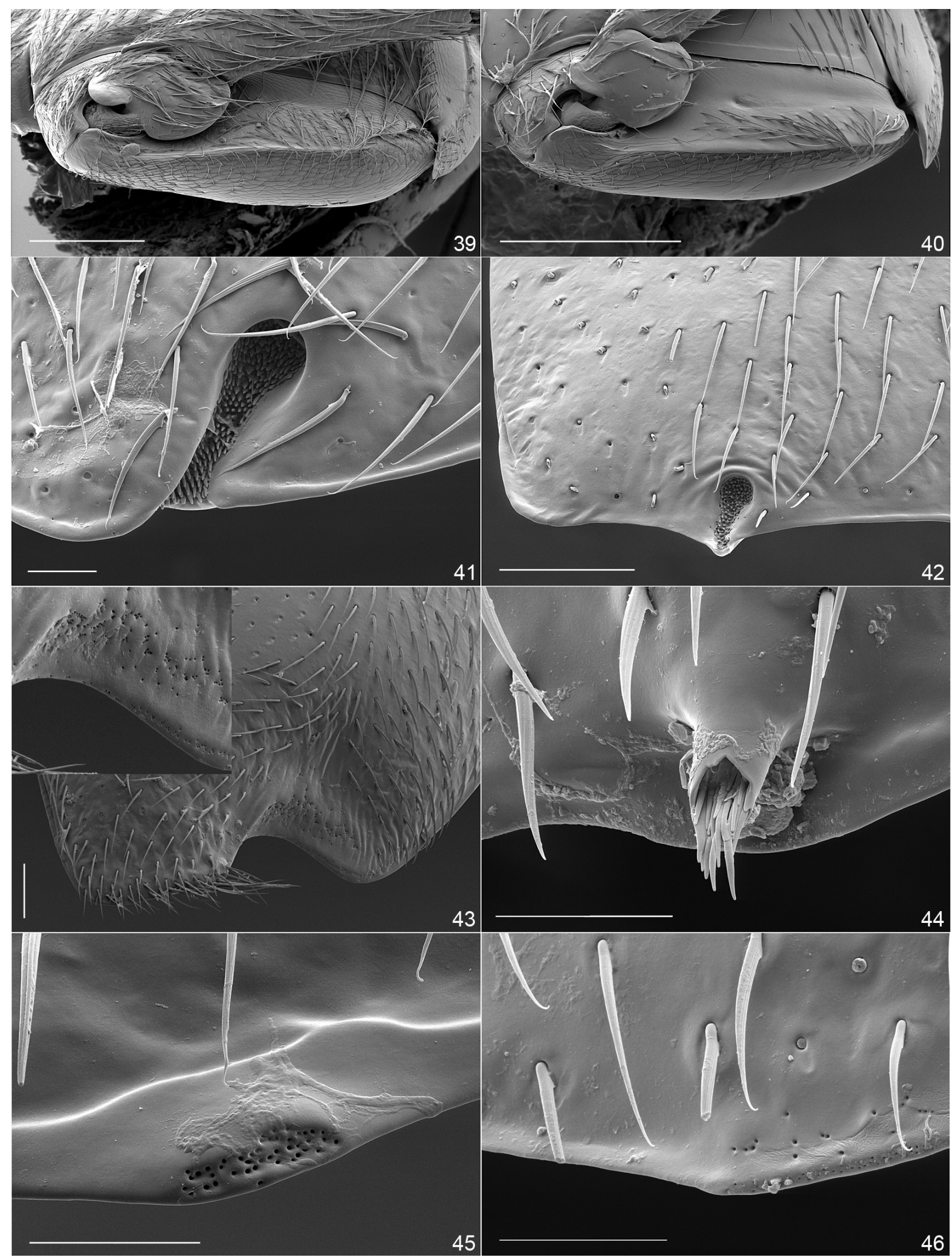

Figs 39-46. 39, 40 - Metacoxa: 39 - Liparoderus venator (Dufour, 1849); 40 - Microhoria oedipus (Chevrolat, 1860). 41-46 - Apex of male elytron: 41 - Microhoria fasciata (Chevrolat, 1834); 42 - M. paupercula (LaFerté-Sénectère, 1849) comb. nov.; 43 - M. oedipus (Chevrolat, 1860); 44 - M. terminata (W. L. E. Schmidt, 1842); 45 - M. caeruleicolor (Pic, 1906) comb. nov; 46 - M. heydeni (Marseul, 1879) comb. nov. Scale bars: $20 \mu \mathrm{m}$ (Figs 41, 44-46); $50 \mu \mathrm{m}$ (Figs 42, 43), $200 \mu \mathrm{m}$ (Figs 39, 40). 
Biology and collecting information. Larvae of Microhoriini are unknown. Limited information on biology of the adults at best generally indicates where or how they were collected. In northern India adults of Microhoria have been most commonly taken by beating the vegetation of trees and shrubs (Z. Kejval, pers. observ.). Others have stated that beating/sweeping of oak, hazel, alder, and cherry shrubs is productive, particularly when they are flowering, as well as by sweeping trees and herbaceous plants in grasslands and meadows (BuCCIARELLI 1980, TEZCAN et al. 2002, Bonadona 2013, KeJval 2017). TaKada et al. (2006) found Microhoria fugiens (as Clavicollis) to be commonly taken by sweeping the shrub layer in a Japanese forest. NARDi \& Mifsud (2003) reported the collection of Microhoria velox velox (as Tenuicomus) on Foeniculum vulgare (Apiaceae) in Malta, while this species was common on low whitish walls separating crops. Also Aulacoderus sulcithorax melitensis (Pic, 1903) was taken mainly by sweeping flowers, and in 2002 was collected primarily on mature shrubs of Lonicera implexa (Caprifoliaceae). Microhoria species have also been taken by hand-collecting from the ground where they crawl in or beneath plant debris, or very occasionally have been found beneath stones or on sand in riparian areas, though this is not a typical habitat for members of the genus.

Baits are especially effective for collecting many species of this tribe. The odor of cantharidin is quite attractive to many species of Microhoriini. The odor can be produced from the cantharidin present in living or dead meloid beetles, or may be generated by using 'cantharidin traps', Petri dishes with filter paper impregnated with a solution containing cantharidin dissolved in acetone and then dried to recrystallize the compound in the paper, or by following a similar process with cantharidin infused ethanol from vials that held meloids (van Hille 1954, Abdullah 1965a, Chander 1976, Young 1984b, KeJval 2017). Other attractants for some Microhoria species are rancid lard or fats from sausage or ham (BuCCIARELLi 1980), while meat, banana, or feces may attract many species of Aulacoderus (van Hille 1985).

Audisio \& Taglianti (2010) listed three taxa of Microhoria (as Tenuicollis) as occurring in the marine littoral zone of Italy, and Colombins et al. (1991) indicated that Microhoria dejeani was present in the littoral zone from the vegetated area of the foredunes to the area of the back dunes with its mesophytic vegetation and ground cover. Non-overlapping succession over the course of a year was documented for six species of Aulacoderus at one site in Botswana by ForCHHAMMER (1986).

Elmali (1997) reported that Microhoria unicolor was an effective predator of the aphid Diuraphis noxia (Kurdjumov, 1913) in Turkish wheat fields, though since there are numerous externally similar species occurring in Turkey and no identification keys, the accuracy of the species identification is open to question. Activity of Anthicidae as micropredators of small arthropods in crops has been noted by others (Chandler 2010, with references).

Distribution. Microhoriini is almost exclusively an Old World group, with the exception of the monotypic Neo- crohoria from Chile. Biogeographically the two genera (Aulacoderus and Neocrohoria) with straight lateral mesoventral margins have a Gondwanan distribution, while the Palaearctic lineage is essentially Laurasian, holding Liparoderus and Microhoria. The tribe is most speciose in subtropical areas. Many Aulacoderus species are present in southern Africa, but no records are known from Madagascar. In the Oriental Region, they appear to be restricted to higher elevations of the Asian mainland, with southernmost records originating from the northern provinces of Laos, Thailand, and Vietnam, and southeastern Myanmar (about same latitude as northern Thailand). Microhoriini species are known from Japan and Taiwan, but they are absent from the islands of the Philippines and Indonesia. Similarly, many species occur in the Himalaya, but no reliable records are known from the Indian subcontinent. The records of Microhoria and Aulacoderus from Australia by Uhmann (2000, 2007) actually belong to the anthicine genera Sahulanthicus Telnov, 2018 and Sapintus Casey, 1895 (KeJval 2017, Telnov 2018b).

\section{Key to genera of Microhoriini}

1(6) Mesoventrite triangular (Figs 7, 9); mesepisterna shallowly impressed (Figs 8, 10).

2(3) Anterior margin of procoxal cavity with paired incisions laterally, similarly as to Fig. 50; intercoxal process of proventrite well-developed; postcoxal bridge simple; elytral apices in males simple; distribution: Chile. Neocrohoria Telnov, 2019

3(2) Anterior margin of procoxal cavity simple (Fig. 49); intercoxal process of proventrite reduced; postcoxal bridge with median process (Fig. 37); elytral apices in males modified (cavity with pores); distribution: Afrotropical and Palaearctic Regions.

4(5) Intercoxal process of abdomen narrow and subtruncate apically (Fig. 38); all tibiae with paired terminal spurs; basal piece of tegmen open.

Falsophilus Kejval, 2015

5(4) Intercoxal process of abdomen rather short and wide, mostly rounded apically, subtriangular and pointed in some species (never narrow and subtruncate); meso- and metatibiae with single terminal spur; basal-piece of tegmen tubular.

Aulacoderus LaFerté-Sénectère, 1849

6(1) Mesoventrite conspicuously transverse, with strongly expanded and rounded lateral lobes (Figs 11, 13); mesepisterna with transverse groove (Figs 12, 14).

7(8) Mesepisterna distinctly touching medially (Fig. 11); pore of mesothoracic gland recessed into sclerite and thus well-sclerotized (Fig. 32); transverse posterior carina of metacoxae weak and reduced laterally (Fig. 39). ............... Liparoderus LaFerté-Sénectère, 1849

8(7) Mesepisterna narrowly separated medially (Fig. 13); pore of mesothoracic gland situated at margin of mesothorax; transverse posterior carina of metacoxae prominent and fully developed (Fig. 40).

Microhoria Chevrolat, 1877 
Aulacoderus LaFerté-Sénectère, 1849

(Figs 9, 10, 49, 124, 125)

Anthicus subg. Aulacoderus LaFerté-Sénectère, 1849b: 133. Type species: Anthicus transversalis LaFerté-Sénectère, 1849, by original designation; currently a junior homonym, replaced with Anthicus mutatus Gemminger, 1870.

Anthicus (Aulacoderus): LAFERTÉ-SÉNECTẺre (1849c): 266 (repeated description); Heyden (1883): 141 (catalogue); Heyden (1891): 268 (catalogue); ReITter (1906): 445 (catalogue); WinKLER (1927): 850 (catalogue); vAN HILLE (1961): 232 (characters, species-groups); vAN Hille (1971): 368 (list); van Hille (1984): 2, Figs 2-4, 7-8 (monograph); vAN Hille (1985): 56 (characters, key to species-groups).

Aulacoderus: Bonadona (1974): 108 (list); Uhmann (1976): 173 (key to genera); UhMANN (1978): 76, 79 (checklist); BuCCIARELli (1980): 175, 218 (characters, key to genera and species, Italy); ANGELINI et al. (1995): 24 (checklist, Italy); ChANDLER et al. (2004): 113, 117 (nomenclature, list); CHANDLER et al. (2008): 429 (catalogue); KeJval (2015): 178 (characters, relationships); KeJval (2017): 57 (redescription, biology, distribution, variation, key to species, Palaearctic Region)

Species/specimens examined. Aulacoderus mutatus (Gemminger, 1870), South Africa, Simons Town, J. C. van Hille det. (ZKDC). In addition, nearly all Palaearctic species (KEJVAL 2017), and members of most species-groups proposed by van HiLle (1984).

Diagnosis. (i) Mandibles with uneven cutting edge, at most with small denticle distally on right mandible; (ii) anterior margin of procoxal cavity nearly evenly concave, lacking distinct incision, Fig. 49; (iii) intercoxal process of proventrite reduced; (iv) postcoxal bridge with median projection; (v) mesoventrite subtriangular, Fig. 9; (vi) mesepisterna shallowly impressed, lacking transverse groove, Fig. 10; (vii) mesepisterna distinctly separate medially on anterior margin; (viii) pore of mesothoracic gland situated at margin of mesothorax, orifice inconspicuous; (ix) intercoxal process of abdomen rather short and wide, mostly rounded apically, subtriangular and pointed in some species; (x) posterior transverse carina of metacoxae distinct and fully developed; (xi) meso- and metatibiae with single terminal spur; (xii) basal-piece of tegmen tubular and well-developed (mostly longer or about as long as apical portion).

Distribution. Afrotropical and Palaearctic Region (about 140 species). The genus is extremely speciose in southern Africa, however no records are known from Madagascar. In the Palaearctic Region it is restricted to the western subtropical areas (27 species); its northernmost reliable records originate from Armenia, Croatia, Italy, and the easternmost records are from Afghanistan (CHANDLER et al. 2008, KeJval 2017).

Relationships. Aulacoderus is a distinctive genus, closely related to Falsophilus as indicated by the following shared features. The characters i, iii, v-viii (symplesiomorphies) and ii, iv, $\mathrm{x}$ (synapomorphies) are shared with this genus (KeJval 2017). As for differences (ix, xi, xii), the shape of the intercoxal process of the abdomen (ix) is variable, but never narrow and subtruncate (as it is in Falsophilus) or narrowed and sharply pointed apically (plesiomorphic condition). The reduced number of terminal spurs of the meso- and metatibiae (xi) is undoubtedly derived and seems to be stable, however, this character, as well as the well-developed, tubular basal-piece of the tegmen (xii), are shared with numerous Microhoria.
In addition, Aulacoderus seems to lack any metathoracic and/or abdominal foveae or setose impressions that are known in Liparoderus, many Microhoria, and numerous Falsophilus.

\section{Falsophilus Kejval, 2015}

(Figs 37, 38, 126)

Falsophilus Kejval, 2015: 176, figs 1-4. Type species: Formicomus minutus Pic, 1894, by original designation.

Diagnosis. (i) mandibles with uneven cutting edge, at most with small denticle distally on right mandible; (ii) anterior margin of procoxal cavity nearly evenly concave, lacking distinct incision; (iii) intercoxal process of proventrite reduced; (iv) postcoxal bridge with median projection, Fig. 37; (v) mesoventrite almost exclusively subtriangular; (vi) mesepisterna shallowly impressed, lacking transverse groove; (vii) mesepisterna separate or at most narrowly touching medially on anterior margin; (viii) pore of mesothoracic gland situated at margin of mesothorax, orifice inconspicuous; (ix) intercoxal process of abdomen narrow and subtruncate apically, Fig. 38; (x) posterior transverse carina of metacoxae fully developed; (xi) meso- and metatibiae with two terminal spurs; (xii) basal-piece of tegmen open and very short.

Distribution. Afrotropical Region (16 species, all apterous); known only from South Africa (Western, Northern and Eastern Cape) and Namibia.

Relationships. Falsophilus is undoubtedly very closely related to Aulacoderus, differing only in three characters (ix, xi, xii). The subtruncate intercoxal process of abdomen (locking mechanism of abdomen generally) may be related to aptery, however it was not found in apterous Aulacoderus species, and seems to represent a generic autapomorphy (KEJVAL 2015).

In addition, most species are remarkable in having small, nude, paired metaventral and abdominal foveae that are rather dissimilar to the setose impressions/slits in numerous Microhoria and Liparoderus.

\section{Liparoderus LaFerté-Sénectère, 1849}

(Figs 1, 11, 12, 32, 39, 50, 52, 127)

Anthicus subg. Liparoderus LaFerté-Sénectère, 1849a: 85. Type species: Anthicus insignis Lucas, 1843, by monotypy.

Anthicus (Liparoderus): LAFERTÉ-SÉNECTĖRE (1849c): 229 (repeated description); Heyden (1883): 141 (catalogue); Heyden (1891): 267 (catalogue); ReITter (1906): 443 (catalogue); PIC (1911b): 30 (catalogue); WinKLER (1927): 846 (catalogue); FUENTE (1932): 117 (catalogue, Iberian Peninsula).

Microhoria (Liparoderus): Bonadona (1955): 102, 104 (key to species, France); Bonadona (1958b): 296 (characters, checklist, key to species); Bonadona (1974): 108 (checklist, France); Bucciarelli (1980): 191, 194 (characters)

Liparoderus: BONADONA (1988): 13 (genus status, characters, key to species); Bonadona (1990a): 21, 23 (characters, key to genera, France); Bonadona (1991): 126 (characters); NARDI (2003): 58 (note); ChANDLER et al. (2004): 113, 119 (nomenclature, list); CHANDLER et al. (2008): 438 (catalogue); BonADONA (2013): 10, 78, 80, 107 (characters, key to genera, France); Gouvèrs \& Ponel (2014): 559 (checklist, France)

Species/specimens examined. Liparoderus insignis, Spain [no precise data], Z. Kejval det. (ZKDC); L. venator (Dufour, 1849), Spain, Alicante, Z. Kejval det. (ZKDC). 
Diagnosis. (i) mandibles on inner margin always with conspicuous, apically bluntly pointed tooth-like process, Fig. 52; (ii) anterior margin of procoxal cavity with distinct paired incisions, Fig. 50; (iii) intercoxal process of proventrite well-developed; (iv) postcoxal bridge simple; (v) mesoventrite conspicuously transverse, with strongly expanded/ lobed, apically rounded lateral arms, Fig. 11; (vi) mesepisterna with transverse groove, Fig. 12; (vii) mesepisterna distinctly touching medially; (viii) pore of mesothoracic gland situated ventrally, orifice quite distinct, sclerotized, Fig. 32; (ix) intercoxal process of abdomen conspicuously long, narrow and sharply pointed; $(\mathrm{x})$ posterior transverse
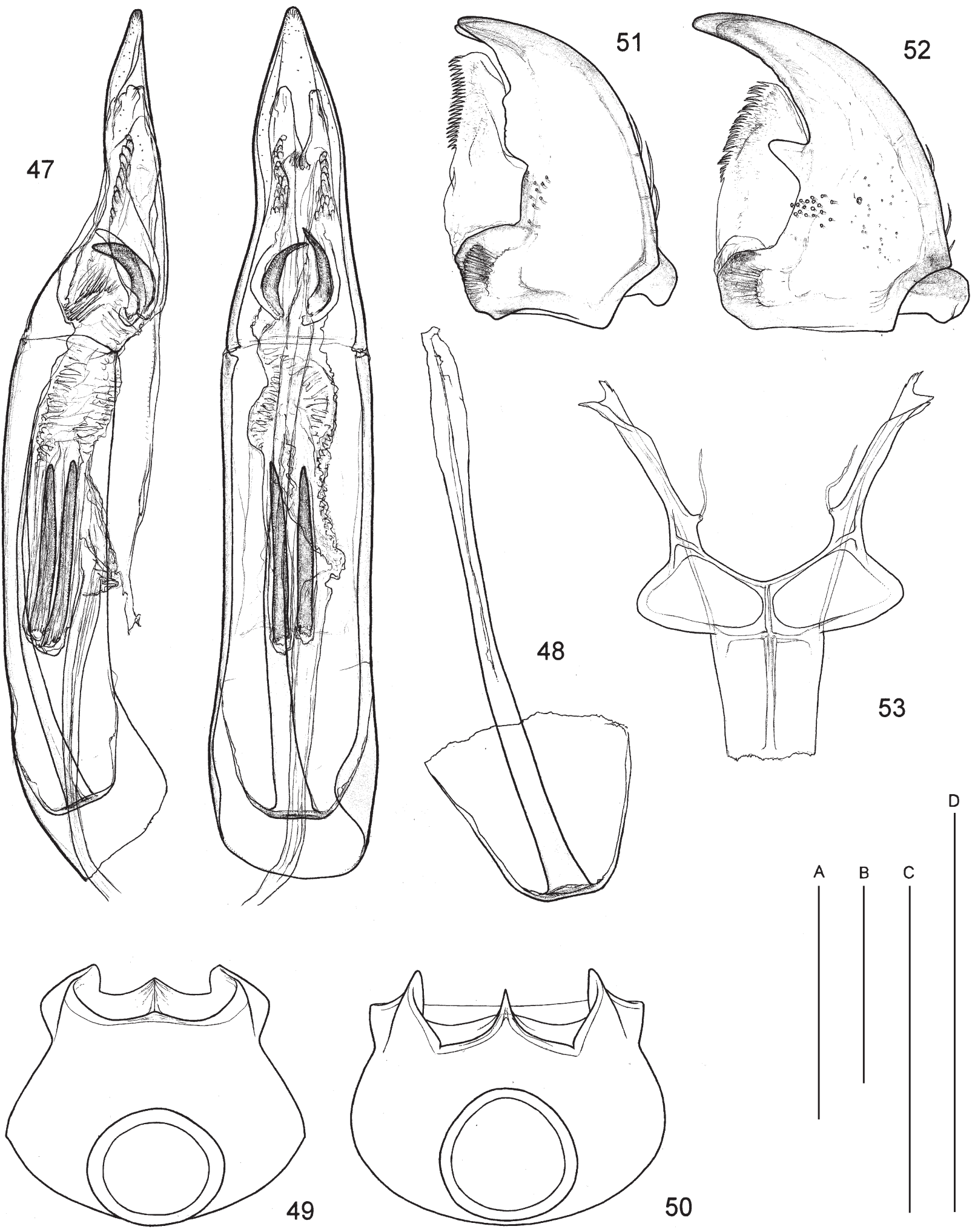

50

53

Figs 47-53. 47, 48 - Neocrohoria melanura (Fairmaire \& Germain, 1863), O'Higgins prov., Cuesta Chada (ZKDC): 47 - aedeagus in lateral (left) and ventral (right) view; 48 - fused baculi of endophallus. 49, 50 - Prothorax in ventro-cranial view: 49 - Aulacoderus mutatus (Gemminger, 1870); 50 Liparoderus venator (Dufour, 1849). 51, 52 - Right mandible: 51 - Microhoria oedipus (Chevrolat, 1860); 52 - Liparoderus insignis (Lucas, 1843). 53 - M. oedipus, metendosternite. Scale bars: $0.2 \mathrm{~mm}$ - A (Figs 51, 52); $0.5 \mathrm{~mm}$ - B (Fig. 50), C (Fig. 53), D (Figs 47, 48, 49). 
carina of metacoxae incomplete, reduced laterally, Fig. 39; (xi) meso- and metatibiae with two terminal spurs; (xii) basal piece of tegmen well-developed, tubular.

Distribution. Western Palaearctic Region (5 species); restricted to the northern, Mediterranean part of Africa and south-western Europe (Spain and southern France) (ChANDLER et al. 2008).

Relationships. Liparoderus is a rather distinctive genus, and is undoubtedy closely related to Microhoria. It was treated as its subgenus by BonADONA (1955), despite having priority (NARDI 2003). It differs from Microhoria by three major characters (vii, viii, $\mathrm{x}$ ); the medially touching mesepisterna and well-defined pore of the mesothoracic gland (vii, viii) are undoubtedly derived and unique within the Microhoriini. These states are known, however, in some genera from different Anthicinae tribes, e.g. Anthelephila, Acanthinus LaFerté-Sénectère, 1849, and Ischyropalpus LaFerté-Sénectère, 1849.

In addition, the two species examined display peculiar short, slit-like metaventral foveae, robust terminal spurs of the metatibiae that are articulated rather subapically, and a conspicuously long, narrow, and sharply pointed intercoxal process of the abdomen. The mandibular process (i), noted already by CHANDLER (2010), is also present in Microhoria, though it is less prominent, and has been found only in a single unidentified species of the $M$. fasciata speciesgroup from Spain (out of the seven species of same group examined, which holds 107 species in total).

\section{Microhoria Chevrolat, 1877}

(Figs 13-30, 33-36, 40-46, 51, 128-147, 151-155)

Anthicus subg. Microhoria Chevrolat, 1877: 168. Type species: Anthicus oedipus Chevrolat, 1860, subsequent designation by BonADONA (1952).

Anthicus (Microhoria): PIC (1911b): 30 (catalogue); WINKLER (1927): 849 (catalogue).

Microhoria: BonAdona (1952): 233 (genus status, subgenera); BonAdONA (1955): 101 (characters, key to species, France); BonAdona (1974): 108 (list, key to genera, France); UhMANN (1976): 172 (key to genera); Uhmann (1978): 76, 79 (checklist); BonAdona (1990a): 21 (key to genera, France); BonAdONA (1990b): 364 (characters, subgenera, key to species, France); BonAdONA (1991): 124, 128 (characters, key to species, France); Bonadona (2013): 11, 82, 108 (France); BuCCIARELLI (1980): 176, 191 (characters, key to genera and species, Italy); UhmanN (1992): 88, 140 (key to genera and species, Iberian Peninsula); KuBISZ \& SzWAŁKo (1998): 9, 32 (characters, checklist, key to species, Poland); CHANDLER et al. (2004): 113, 119 (nomenclature, list); Chandler et al. (2008): 438 (catalogue); Alonso-Zarazaga (2013): 172, 180 (notes); BonAdona (2013): 11, 82 (characters, key to species, France); Gouvèrs \& Ponel (2014): 559 (checklist, France); ZAHRADNík (2017): 319 (checklist)

Microharia (misspelling): HoRION (1956): 90 (note).

Bifossicollis Sahlberg, 1903a: 31. Type species: Anthicus iscariotes LaFerté-Sénectère, 1849, by monotypy.

Bifossicollis: ChANDLER et al. (2004): 113, 118 (list, nomenclature); Alonso-Zarazaga (2013): 175, 176, 180 (notes).

Anthicus subg. Immicrohoria Pic, 1894: 72. Type species: Notoxus fasciatus Chevrolat, 1834, subsequent designation by BonAdONA (1952)

Anthicus (Immicrohoria): PIC (1911b): 30 (catalogue); WinKLER (1927): 846 (catalogue).

Microhoria (Immicrohoria): BonADONA (1952): 234 (new combination); BONADONA (1974): 108 (list of subgenera); BonADONA (1990b): 364 (characters); BonAdONA (1991): 128 (characters); BuCCIARELLI (1980): 194 (characters); ANGELINI et al. (1995): 23 (checklist, Italy); NARDI
(2003): 58 (synonymy); CHANDLER et al. (2004): 120 (note); BonADONA (2013): 11, 82 (France).

Microhoria subg. Platyoria [sic!] Bonadona, 1952: 234. Type species: Anthicus terminatus W. L. E. Schmidt, 1842, by original designation. Microhoria (Platyoria): NARDI (2003): 58 (correction of original spelling). Microhoria (Platyhoria): BonAdONA (1974): 108 (list of subgenera); BoNADONA (1990b): 364 (characters); BONADONA (1991): 128 (characters); BuCCIARELLi (1980): 194 (characters); ANGELINI et al. (1995): 23 (check list, Italy); NARDI (2003): 58 (correction of spelling, synonymy); CHANDLER et al. (2004): 118 (note); BonAdONA (2013): 11, 82, 108 (France).

Microhoria subg. Submicrohoria Bonadona, 1952: 234. Type species: Anthicus plumbeus LaFerté-Sénectère, 1849, by original designation.

Microhoria (Submicrohoria): Bonadona (1974): 108 (list of subgenera); BuCCIARELLI (1980): 194 (characters); NARDI (2003): 58 (synonymy); ChANDLER et al. (2004): 118 (note).

Anthicus subg. Clavicomus Pic, 1894: 70, syn. nov. Type species: Anthicus longiceps LaFerté-Sénectère, 1849, subsequent designation by BuCCIARELLI (1980)

Anthicus (Clavicomus): Pic (1911b): 30 (catalogue); WinKLER (1927): 842 (catalogue).

Clavicomus: Bonadona (1964): 239; Bonadona (1974): 108, 110 (list, key to genera); UhMANN (1976): 173 (key to genera); UhMANN (1978): 76, 79 (checklist); BonAdONA (1990a): 21 (characters, key to genera, France); Bonadona (1991): 124 (character, key to genera, France); Bucciarell (1980): 176 (characters, key to genera and species, Italy); UHMANN (1992): 88, 131 (key to genera and species, Iberian Peninsula); ANGELINI et al. (1995): 23 (checklist, Italy); CHANDLER et al. (2004): 118 (note); Alonso-Zarazaga (2013): 174, 176, 180 (notes, synonymy); BonAdONA (2013): 11, 79, 108 (characters, key to genera, France).

Clavicollis Sahlberg, 1903b: 55. Type species: Anthicus longiceps LaFerté-Sénectère, 1849, subsequent designation by BucCiarelLi (1980).

Clavicollis: CHANDLER et al. (2004): 113, 118 (nomenclature, list, synonymy); Chandler et al. (2008): 430 (catalogue); Min et al. (2012): 276 (diagnosis, records); Alonso-ZarazAGa (2013): 175, 176, 182 (notes, synonymy); Gouvèrs \& Ponel (2014): 559 (checklist, France).

Pseudantichus Desbrochers des Loges, 1868: 80. Type species: Formicomus oliverii Desbrochers des Loges, 1868, by monotypy.

Pseudantichus: Alonso-ZarazAGA (2013): 178, 180, 182 (note, synonymy).

Pseudanthicus (misspelling): CHANDLER et al. (2004): 118 (note, synonymy); Alonso-ZarazaGa (2013): 178 (note on spelling).

Anthicus subg. Tenuicomus Pic, 1894: 69, syn. nov. Type species: Anthicus pumilus Baudi, 1877, subsequent designation by Alonso-ZARAZAGA (2013).

Anthicus (Tenuicomus): Pic (1911b): 30 (catalogue); WinKLER (1927): 844 (catalogue).

Tenuicomus: Bonadona (1974): 108, 110 (list, key to genera); UhmanN (1976): 173 (key to genera); UhmanN (1978): 76, 80 (checklist); BuCCIARELLi (1980): 176, 185 (characters, key to genera and species, Italy); Uhmann (1992): 88, 136 (key to genera and species, Iberian Peninsula); Angelini et al. (1995): 23 (checklist, Italy); CHANDLER et al. (2004): 121 (note); Alonso-Zarazaga (2013): 174, 177, 179, 181, 182 (notes, type species designation, synonymy); BonAdOna (2013): 11 (key to genera, France).

Tenuicollis Sahlberg, 1903b: 56. Type species: Anthicus pumilus Baudi, 1877, subsequent designation by Alonso-ZarazaGa (2013).

Tenuicollis: CHANDLER et al. (2004): 113, 121 (nomenclature, list); CHANDLER et al. (2008): 447 (catalogue); Alonso-ZaraZAGA (2013): 175, 177, 182 (notes, synonymy).

Species/specimens examined. Microhoria dejeani (LaFerté-Sénectère, 1849), Corse, Pinetu, Z. Kejval det. (ZKDC); M. fasciata (Chevrolat, 1834), Greece, Peloponnesos, Kalogria, Z. Kejval det. (ZKDC); M. oedipus (Chevrolat, 1860), Morocco, Ifrane, Z. Kejval det. (ZKDC); M. pallidula (Pic, 1892), Russia, Orenburg Region, Totskoye, Z. Kejval det. (ZKDC, NMPC); M. paykulli (Gyllenhal, 1808), Spain, Teruel prov., El Portillo, Z. Kejval det., tentatively identified (ZKDC); M. plumbea (W. L. E. Schmidt, 1842), France, Le Levandou, Z. Kejval det. (ZKDC, NMPC); M. schimperi 
(Pic, 1898), Ethiopia ('MUSEUM PARIS ABYSSINIE SCHIMPER 430-50'), possibly syntype (ZKDC); $M$. terminata (W. L. E. Schmidt, 1842), Greece, Corfu, Agios Georgios, Z. Kejval det. (ZKDC); M. venusta (A. Villa \& J. B. Villa, 1833), Italy, Trentino-Alto Adige Region, Folgaria, Z. Kejval det. (ZKDC); M. volxemi (Marseul, 1878), Portugal, Faro Carrapateira-Amado, Z. Kejval det., tentatively identified (ZKDC); M. vosseleri (Pic, 1894), Algeria, Aïn Sefra, Z. Kejval det. (ZKDC).

Clavicomus antinorii (Pic, 1894), Ethiopia, Scioa, Argu Agher, syntype (MCSN); C. apicordiger (Bonadona, 1954), Morocco, Khenifra, P. Bonadona det. (ZSMC); C. caeruleicolor (Pic, 1906), Thailand, Mae Hong Son Province, Soppong, Z. Kejval det. (ZKDC); C. biguttatus Bonadona, 1964, Afghanistan, Tangi-Gharuh, paratype (ZKDC); C. callimus (Baudi di Selve, 1877), Spain, Motril-Carchuna, G. Uhmann det. (ZKDC); C. fugax (LaFerté-Sénectère, 1849), Myanmar, J. V. Helfer lgt., H. Krekich-Strassoldo det. (NMPC, ZKDC); C. fugiens (Marseul, 1876), Japan, Honshu, Osakafu Iwawakiyama, Z. Kejval det. (ZKDC); C. gigas (Pic, 1899), Turkey, Marmaris, Z. Kejval det. (ZKDC); C. henoni (Pic, 1892), Algeria, Misserghin, M. Pic det. (NHMW); $C$. heydeni (Marseul, 1879), Portugal, Odiáxere, G. Uhmann det. (ZKDC); C. longiceps (LaFerté-Sénectère, 1849), Italy, Palermo, H. Krekich-Strassoldo det. (ZKDC); C. optabilis (LaFerté-Sénectère, 1849), France, Nice, P. Bonadona det. (MNHN); C. semiviridis (Pic, 1951), Ethiopia, Djem-Djem Forest, syntype (ZKDC); C. versicolor (Kiesenwetter, 1866), Spain, Valencia, Z. Kejval det. (NMPC, ZKDC).

Tenuicomus babaulti (Pic, 1921), Tanzania, Arusha District, Mto Wa Mbu env., Z. Kejval det. (ZKDC); T. barnevillei (Pic, 1892), Spain, Valencia, Burjasot, H. Krekich-Strassoldo det. (ZKDC); T. cyanipennis (Grilat, 1886), Tunisia [no precise data], Z. Kejval det. (ZKDC); T. fuscomaculatus (Pic, 1893), Algeria [no precise data], Z. Kejval det. (ZKDC); T. ocreatus (LaFerté-Sénectère, 1847), Algeria, Bouïra, Z. Kejval det. (ZKDC); T. olivaceus (LaFerté-Sénectère, 1849), Spain, Malaga Province, Puente de Salina, Z. Kejval det. (ZKDC); T. pauperculus (LaFertéSénectère, 1849), Algeria, Miliana, H. Krekich-Strassoldo det., as Anthicus pumilus (ZKDC); T. subcaeruleus (Pic, 1899), India, Himachal Pradesh, Keylong, Z. Kejval det. (ZKDC); T. viturati (Pic, 1893), Algeria, Ait Hassem, Z. Kejval det. (ZKDC).

Diagnosis. (i) mandibles almost exclusively with simple, at most uneven cutting edge, with small denticle distally on right mandible, Fig. 51 (see Remarks); (ii) anterior margin of procoxal cavity with paired lateral incisions, similarly as to Fig. 50; (iii) intercoxal process of proventrite almost exclusively well-developed (see Remarks); (iv) postcoxal bridge simple; (v) mesoventrite transverse, strongly expanded and rounded laterally, Fig. 13; (vi) mesepisterna with transverse groove, Fig. 14; (vii) mesepisterna narrowly separated medially; (viii) pore of mesothoracic gland situated at margin of mesothorax, orifice well-defined, separated from intersegmental membrane by sclerotized bridge; (ix) intercoxal process of abdomen more or less pointed or at most narrowly rounded apically; $(\mathrm{x})$ posterior transverse carina of metacoxae fully developed,
Fig. 40; (xi) mesotibiae with two, metatibiae with one or two terminal spurs; (xii) basal-piece of tegmen well-developed, tubular.

Distribution. Afrotropical, Palaearctic and Oriental region (presently about 340 species). All Oriental species are known from higher altitudes of the Asian mainland. Afrotropical species are distributed in northeastern Africa (mostly Ethiopia), and their southernmost records originate from Tanzania. Relationships. Microhoria is undoubtedly very close to Liparoderus and especially larger, robust species, having silvery setose markings of elytra (formerly classified in the subgenus Immicrohoria) can be easily confused with it. Microhoria can be distinguished from Liparoderus by three characters (vii, viii, $\mathrm{x}$ ), and at least the fully developed posterior transverse carina of the metacoxae $(\mathrm{x})$ can be regarded as a derived character state.

Remarks. The type species of Microhoria is Anthicus oedipus. Its species name refers to conspicuously modified metatibiae in this species (Fig. 139), and it seems likely that Chevrolat named his species after Oedipus, mythical Greek king of Thebes (who was named for his swollen feet). In this case the name should be treated as a noun in apposition, without change of suffix (ICZN, 31.2.1).

The intercoxal process of the proventrite is typically well-developed in Microhoria. It may be exceptionally reduced as in $M$. fasciata, but even this species has a simple postcoxal bridge that lacks a median process (small posterior protrusion of median carina is situated shortly before even posterior margin of this bridge). Similarly, the mandibles of Microhoria display rather uniform morphology (Fig. 51), but there is at least one species from Spain (unidentified, M. fasciata species-group, ZKDC) showing a small but distinct process that resembles the condition exhibited in Liparoderus (Fig. 52).

Clavicomus. Clavicomus is traditionally characterized by a somewhat elongate pronotum, which is more or less distinctly impressed laterally at the posterior half (BoNADONA 1974, BuCCIARELli 1980). Its type species, C. longiceps, shares all important characters of Microhoria (sensu stricto). The only two noteworthy differences outside of the secondary sexual characters are: mesoventrite with margins completely bordered (cf. Figs 26 versus 14), and the mesoventrite disc being evenly convex and lacking submedian carinae (cf. Figs 25 versus 13). As documented below (see also remarks under Tenuicomus), these two characters are subject to interspecific variation and/or they are shared by numerous species currently placed in Microhoria.

The submedian carinae of the mesoventrite are variably present in Microhoria (sensu lato), but may appear to be characteristic for more robust/sclerotized species treated formerly in the subgenera Microhoria (sensu stricto), Immicrohoria, and Submicrohoria. However, even these groups include aberrant species that lack or have rather slight carinae, e.g. M. paykulli and M. volxemi. Also, Clavicomus optabilis is undoubtedly much closer to Microhoria (sensu stricto), in having an incomplete submarginal sulcus of the mesoventrite (clearly absent laterally) and lacks a distinct submedian carinae. Its questionable position within Clavicomus was noted previously by BUCCIARELLI (1980). 
Most (if not all) species of the former subgenus Platyhoria of Microhoria (which is most speciose in the Middle East) and Tenuicomus distributed from Turkey eastwards have a prominent submarginal sulcus of the mesoventrite, which is only shortly interrupted posteriorly at the area where the middle legs articulate (cf. Figs 24 versus 26). They differ from Clavicomus longiceps by the reduced setose fringe of the mesepimera (cf. Figs 24 versus 26, 34 ), and have the unique, tubular outflow channel for the elytral gland of the males (Fig. 44).

Clavicomus gigas from the eastern Mediterranean Region is undoubtedly very close to $C$. longiceps, as is suggested by its larger size, similar external appearance, and a number of details, e.g. swirled elytral setation, outflow channel of elytral gland forming cavity (minute, situated near somewhat tapering elytral apices) with pores and cuticular cones, and longer paired sclerites of the endophallus. On the other hand, it has a somewhat reduced setose fringe of the mesepimera (cf. Figs $36 \mathrm{ver}$ sus 34), and differs by having an incomplete submarginal sulcus, as was discussed above for Microhoria (cf. Figs 28 versus 26 ).

Clavicomus heydeni is a very distinctive species, showing unique sexual dimorphism (modified tarsi in males) together with a peculiar morphology of the tegmen, which is quite dissimilar to that of $C$. longiceps, see Figs 62, 64. It has a nearly complete submarginal sulcus of the mesoventrite, as is similarly seen in numerous Mediterranean Tenuicomus, e.g. T. barnevillei, T. viturati, and T. olivaceus (Figs 16, 22).

Finally, all Asian species of Clavicomus have a prominent submarginal sulcus of the mesoventrite, which may be shortly interrupted posteriorly at the place of articulation with the middle legs (Fig. 30), in combination with the strongly reduced setose fringe of the mesepimera (Fig. 35). In addition, they differ from $C$. longiceps by possessing a single terminal metatibial spur plus some male characters, e.g. apical position of primary gonopore.

Tenuicomus. Tenuicomus is characterized by the comparatively short and simple pronotum, which is not impressed postero-laterally, lacking the so-called 'fossetes lateralles', and the more conspicuous setation of this latero-basal area (BonAdONA 1974). These characters are shared with a small group of externally uniform species distributed in the western part of the Mediterranean Region, including Tenuicomus ocreatus, that was listed as the type species by Bucciarelli (1980). However, Alonso-ZarazAGA (2013) found this designation invalid (the species was not originally included), and selected Anthicus pumilus as the type species.

Anthicus pumilus was described by BAudi di SElve (1877) from an unstated number of specimens collected at the locality Misserghin in Algeria (Oran Province). It is currently treated as a junior synonym of Tenuicomus pauperculus (CHANDLER et al. 2008: 49), and its type material was probably never examined (the collection of Baudi di Selve has been unavailable for some time). We have examined several specimens from northern Algeria (ZKDC, NHMW) identified as Anthicus pumilus by Hans von Krekich-Strassoldo. They agree with the descriptions of BAUdi di SELVE (1877) and LAFERTÉ-SÉnECTÈre (1847), the species remarks of PIC (1894), and their aedeagal form (Fig. 85) is very similar to the figures of T. pumilus by BuCCIARELli (1980).

Tenuicomus pauperculus clearly differs from $T$. ocreatus (Figs 141, 138), including the presence of well-developed 'fossetes lateralles', and thus does not fit the recent concept of Tenuicomus generated by BONADONA (1974) and BuCCIARELLI (1980), as already stated for T. pumilus by the latter author. On the other hand, T. pauperculus shares all major characters of Microhoria s. str., and the morphology and setation of the mesoventrite are essentially identical (cf. Figs 17,18 versus 13,14). Remarkably, this species is here classified within the Microhoria schimperi species-group in Section IV, with members of this species-group having the mesoventrite characters being somewhat variable, with a few possessing a complete submarginal sulcus (Figs 19, 20).

Based on the preceding comments, form of the submarginal sulcus and submedian carinae of mesoventrite proved to be variable characters, and are useless for separation of the discussed genera. Consequently, Clavicomus and Tenuicomus are regarded as junior synonyms of Microhoria.

\section{Neocrohoria Telnov, 2019}

(Figs 7, 8, 31, 47, 48, 123)

Type species. Anthicus melanurus Fairmaire \& Germain, 1863 , by original designation.

Diagnosis. (i) mandibles with uneven cutting edge, at most with small denticle distally on right mandible; (ii) anterior margin of procoxal cavity with paired incisions laterally; (iii) intercoxal process of proventrite well-developed; iv) postcoxal bridge simple; (v) mesoventrite triangular; (vi) mesepisterna shallowly impressed, lacking transverse groove; (vii) mesepisterna separate medially on anterior margin; (viii) pore of mesothoracic gland situated at margin of mesothorax in intersegmental membrane, orifice inconspicuous; (ix) intercoxal process of abdomen rather wide basally, pointed apically; (x) posterior transverse carina of metacoxae fully developed; (xi) meso- and metatibiae with two terminal spurs; (xii) tegmen open, basal-piece well-developed, longer than apical portion.

Relationships. Neocrohoria is a rather aberrant member of the Microhoriini, being remarkable in the males having simple elytral apices and a ventrally open tegmen. It shares most major characters (i, v-viii, x) with Aulacoderus and Falsophilus, genera that are distributed exclusively (Falsophilus) or are most speciose (Aulacoderus) in southern Africa. Neocrohoria differs from both genera by the morphology of procoxal cavities (ii-iv); from Aulacoderus additionally by the paired terminal spurs of the tibiae (xi) and the open basal-piece of the tegmen (xii); from Falsophilus additionally by the shape of the intercoxal process of the abdomen (ix), and the well-developed basal-piece of the tegmen, that is longer than its apical portion. On the other hand, the distinguishing 
characters of the procoxal cavities (ii-iv) are shared with Microhoria and Liparoderus, whose ranges are confined to the Northern Hemisphere.

Distribution. Neotropical Region: Chile. The genus contains a single species, Neocrohoria melanura (Fairmaire \& Germain, 1863), originally described from 'Forêts de Chillán' in Diguillín Province (east of Concepción). Its published records and specimens examined in this study originate from the following provinces in the Central part of the country: San Felipe de Aconcagua, Cachapoal, Cardenal Caro, Cautín, Concepción, Cordillera, Curicó, Diguillín, Linares, Malleco, Maule, and Santiago (WERnER 1974, TELNOV 2019; ZKDC, ZSMC).

\section{Species-groups, new species, and synonymy within Microhoria}

Microhoria sensu lato, as proposed herein, holds 344 known species, and represents a large and diverse genus, as does Aulacoderus. Subdivisions of such a large group are useful, and development of informal species-groups seem to be most appropriate, considering variation of the characters and the present state of knowledge. Ten speciesgroups are established below, and the following key can be used for their identification.

1(2) Metatibiae with single terminal spur (rarely absent, see species-group remarks); elytral apices in males rather slightly modified, never with conspicuous cavity or tubular process (Fig. 46); gonopore situated at apex of longitudinal sclerite (Figs 54, 57-60); distribution: Asia (from Afghanistan eastwards).

M. fugax species-group

2(1) Metatibiae with two terminal spurs; elytral apices in males mostly quite distinctly modified; gonopore free (except M. ocreata species-group); distribution: northeastern Africa and western part of Palaearctic Region (few easternmost records in Nepal, northern India, Pakistan and Tibet).

3(4) Mesoventrite with nearly completely developed submarginal sulcus (Fig. 23); setose fringe of mesepimera strongly reduced (Fig. 24); channel of elytral gland in males formed as short tubular process (Fig. 44, absent in single species).

M. terminata species-group

4(3) Mesoventrite mostly with strongly reduced submarginal sulcus (absent laterally) and setose fringe of mesepimera well-developed; elytral apices in males quite simple (M. globipennis) or showing different modifications of gland channel: pores inside sclerotized cavity, together with short cuticular cones (Figs 41,42), or simple and scattered at/near margin (Figs 43, 45).

5(14) Mesoventrite almost exclusively with largely reduced submarginal sulcus, slighty indicated to absent laterally (Figs 14, 18), its surface unevenly convex medially, frequently with distinct submedian carinae (at least indicated anteriorly); elytral apices in males almost exclusively distinctly modified, subtruncate to bilobed (Fig. 43), with subapical sclerotized cavity (Figs 41, 42) or sinuous groove (Fig. 148).

6(9) Tegmen hood-like ('cuculliform'), with comparatively well-sclerotized, pointed apex (Figs 76, 77).

7(8) Elytral apices in males somewhat unevenly rounded, channel of gland forming sclerotized cavity, cavity inside with pores and cuticular cones (Fig. 41); metatibiae of males simple.

M. fasciata species-group

8(7) Elytral apices in males conspicuously modified, subtruncate to bilobed, lacking sclerotized small cavity (pores scattered on surface as in Fig. 43); metatibiae of males frequently variously modified (Fig. 139). M. oedipus species-group

9(6) Tegmen somewhat less sclerotized and pigmented, with rounded or bilobed apex ('capsuliform'), never sharply pointed apically.

10(11) Pronotum mostly with rather uniformly short setae (Fig. 138); endophallus with elongate sclerite, bearing gonopore apically, with extremely long, slender, flexible spine, originating from its base and directed apically (Fig. 75).

M. ocreata species-group

11(10) Pronotum with mostly longer, dense setae laterally near base (Fig. 144); endophallus at most with short spinules or tooth-like sclerites, gonopore free, situated rather basally and frequently indistinct.

12(13) Elytra in males with peculiar sinuous groove at apical third (Fig. 148), lacking subapical cavity, rounded apically.

M. plicatipennis species-group

13(12) Elytra in males with subapical sclerotized cavity and pointed protrusion of apical margin (Fig. 42).

M. schimperi species-group

14(5) Mesoventrite always with complete submarginal sulcus (or nearly so), which is sometimes rather thin but developed laterally (Figs 16, 22, 26), its surface more or less evenly convex (never with distinct submedian carinae); elytral apices in males modified (distinct subapical cavity) or nearly simple.

15(16) Submarginal setose impressions of metaventrite and abdominal sternum III weakly indicated to conspicuous; elytral apices in males with sclerotized cavity (channel inside with pores and cuticular cones), rarely reduced to absent; tegmen pointed to narrowly rounded apically (Figs 64, 65, 68-72), narrowly bifurcate in single species (Fig. 67). ........

M. longiceps species-group

16(15) Submarginal setose impressions of metaventrite and abdominal sternum III always reduced to indistinct; elytral apices of males somewhat unevenly rounded, but lacking any special sclerotized structures, with pores scattered at margin (Fig. 46); tegmen rounded to shortly bilobed apically.

17(18) Tegmen with conspicuous subapical projection(s) (Figs 62, 63).

M. heydeni species-group

18(17) Tegmen simply tubular, at most with slight apical lobes (Figs 78-81). ..... M. olivacea species-group 

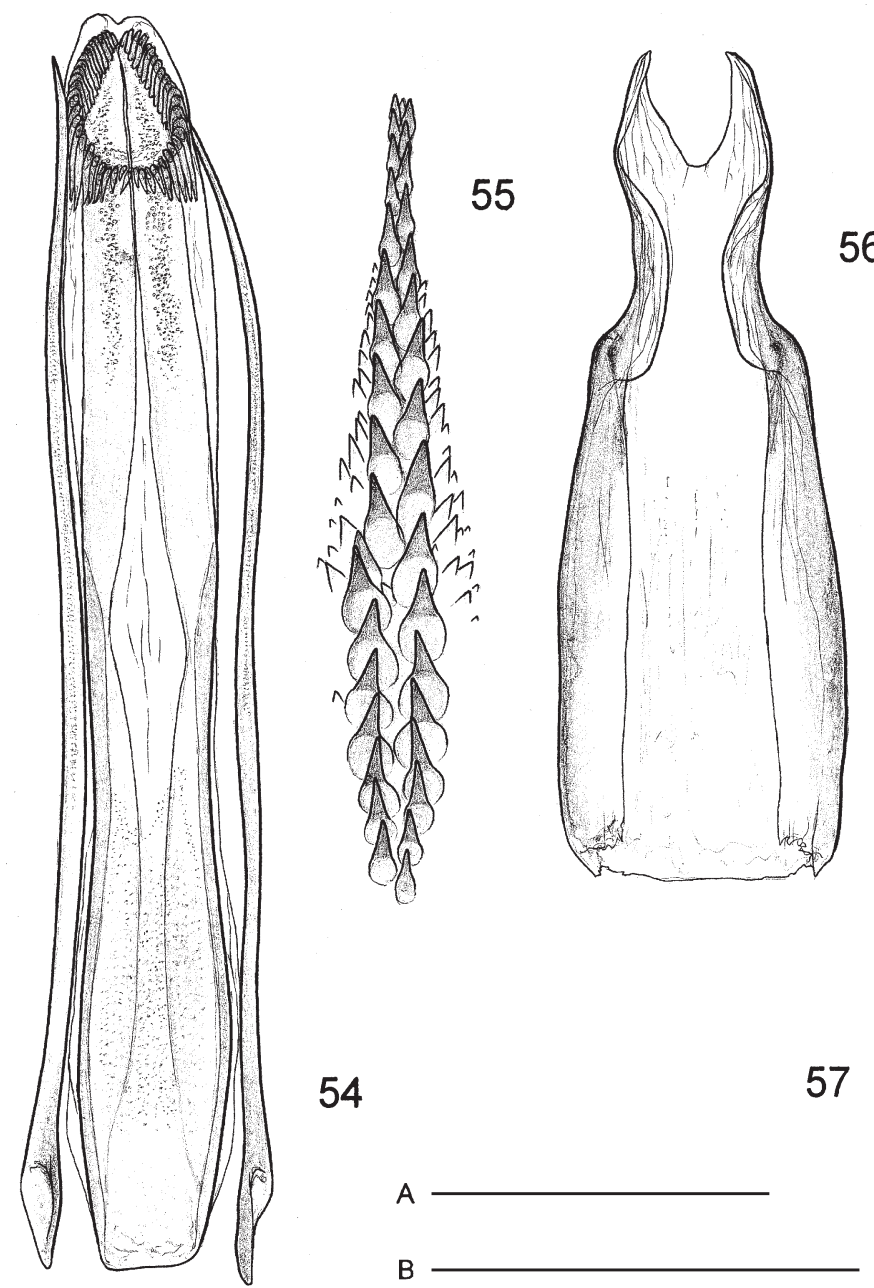

54
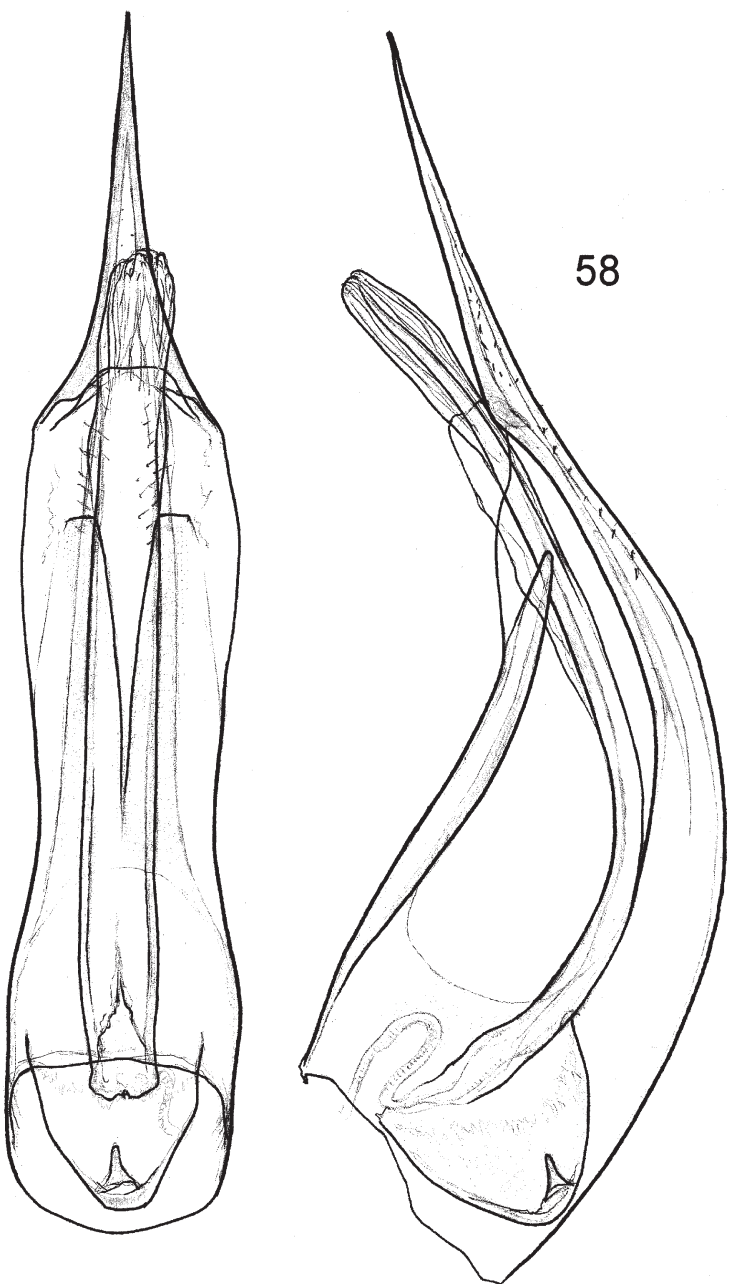

Figs 54-58. 54-56 - Microhoria caeruleicolor (Pic, 1906), inner structures of endophallus: 54 - sclerite with primary gonopore and paired spinules; 55 - spines of connecting membrane; 56 - membranous sheath. 57, 58 - M. fugiens (Marseul, 1876) comb. nov.: 57 - aedeagus in ventral view; 58 - same, lateral view. Scale bars: $0.2 \mathrm{~mm}-\mathrm{A}$ (Figs 57, 58), B (Figs 54-56).

\section{Microhoria fasciata species-group}

Diagnosis. Mostly larger, robust species, frequently with colour markings and/or modified setation of elytra (patches of swirled setae or silvery setose bands, Figs 131, 132); moderately variable in pronotal characters, latero-basal impressions mostly distinct and longer, densely setose (Figs 160, 161). Mesoventrite always with partly bordered lateral margins (simple laterally), mostly with longitudinal submedian carinae, as in Fig. 13; setose fringe of mesepimera always well-developed; submarginal setose impressions of metaventrite and abdominal sternum III conspicuous; all tibiae with paired terminal spurs; elytral apices in males modified, channel of gland forming sclerotized cavity, cavity inside with pores and cuticular cones (Fig. 41, apical elytral margin rounded, no pointed protrusion). Aedeagus similar to Figs 76, 77; tegmen hood-like, with simple pointed apex ('cuculliform'); gonopore free.

Distribution. Predominantly Western Mediterranean group, most speciose in Algeria, Morocco, Spain, and Tunisia. Few species are known from SE Europe, Caucasian region and Central Asia: M. lederi (Marseul, 1879), $M$. pallidula (Pic, 1892), M. piciceps (Desbrochers des Loges, 1875), and M. rectipennis (LaFerté-Sénectère, 1849).
Species included (107 spp.). Microhoria abdeselami (Escalera, 1914), M. abeillei (Pic, 1892), M. advecta (Krekich-Strassoldo, 1929), M. adventicia (Krekich-Strassoldo, 1929), M. agtayi Bonadona, 1986, M. albopilosa (Krekich-Strassoldo, 1929), M. amata (Bonadona, 1958), M. amicitiae (Dufour, 1849), M. andalusiaca (LaFerté-Sénectère, 1849), M. annulipes (Pic, 1894), $M$. antoinei (Chobaut, 1923), M. aspernata (Chobaut, 1923), M. atlasica (Pic, 1951), M. aubei (LaFerté-Sénectère, 1849), M. balearica (Pic, 1904), M. barrosi (Pic, 1938), M. baudii (Pic, 1893), M. baudueri (Baudi di Selve, 1877), $M$. benigna (Krekich-Strassoldo, 1929), M. biargenteofasciata (Pic, 1929), M. bicoloripes (Pic, 1932), M. binotaticollis (Pic, 1919), M. bispilifasciata (Marseul, 1978), M. bleusei (Pic, 1892), M. bremondi (Pic, 1936), M. brevipilis (Pic, 1893 ) comb. nov., M. brisouti (Desbrochers des Loges, 1875), M. cantabrica (Marseul, 1879), M. capito (LaFerté-Sénectère, 1849), M. caprai Bucciarelli, 1977, M. chardoni (Pic, 1893), M. chobauti (Pic, 1892), M. cinctuta (Marseul, 1878), M. codinai (Pic, 1919), M. constricticollis (Desbrochers des Loges, 1870), M. curticollis (Pic, 1894), M. decora (Krekich-Strassoldo, 1929), M. dejeanii (LaFerté-Sénectère, 1849), M. dentipalpis Bonadona, 1977, 
M. digitalis Marseul, 1878, M. espunana (Pic, 1930), M. fairmairei (C. Brisout de Barneville, 1863), M. fasciata (Chevrolat, 1834), M. ferianensis (Pic, 1900), M. franzi Bonadona, 1958. M. fuscipes Marseul, 1879, M. ghilianii (LaFerté-Sénectère, 1849), M. gouversi Bonadona, 1986, M. hafidi (Pic, 1923), M. hameti (Escalera, 1914), M. helenae (Koch, 1923), M. hipponensis (Pic, 1893), M. hispanica (Pic, 1899), M. imbasicornis (Pic, 1931), M. insignita (Pic, 1906) comb. nov., M. lanata (Krekich-Strassoldo, 1929), M. latecincta Chobaut, 1923), M. lavocati (Pic, 1951), M. lederi, M. leonhardi (Krekich-Strassoldo, 1913), M. lindbergi (Pic, 1923), M. ludovici (Pic, 1893), M. mactae (Pic, 1894), M. maculicollis (Pic, 1893), M. madoni (Pic, 1931), M. magnifica (Pic, 1936), M. major (Pic, 1896), M. mateui Bonadona, 1954, M. melanocephala (Bonelli, 1812), M. mogadorica (Escalera, 1914), M. moroderi (Pic, 1930), M. mylabrina (Gené, 1839), M. oberthuri (Baudi di Selve, 1877), M. opipara Bonadona, 1977, M. optabilis (LaFerté-Sénectère, 1849) comb. nov., M. pallidioritarsis (Pic, 1936), M. pallidula, M. pardoi Bonadona, 1952, M. paykullii (Gyllenhal, 1808), M. piceodiscoidalis (Pic, 1936), M. piciceps, M. planiceps (Desbrochers des Loges, 1875), M. plumbea (LaFerté-Sénectère, 1842), M. postluteomaculata (Pic, 1938), M. rectipennis, M. robustioriceps (Pic, 1938), M. roseicollis (Pic, 1892), M. rubrofasciata (Pic, 1894), M. saidi (Escalera, 1914), M. scrobicollis (LaFerté-Sénectère, 1849), M. selvei (Pic, 1895), M. separanda (Krekich-Strassoldo, 1929), M. simplicipes (Pic, 1936), M. subgracilis (Krekich-Strassoldo, 1929), M. superba (Pic, 1896), M. taeniata (Baudi di Selve, 1877), M. testaceofasciata (Pic, 1894), M. torretassoi (Pic, 1931), M. valida (Pic, 1896), M. velutina (LaFerté-Sénectère, 1849), M. venusta (A. Villa \& J. B. Villa, 1833), M. veris (Pic, 1893), M. villiersi (Bonadona, 1984), M. violaris (Marseul, 1875), M. volxemi (Marseul, 1878), M. vosseleri (Pic, 1894), and M. zonata (LaFerté-Sénectère, 1849).

Remarks. This species-group holds all species of Microhoria formerly treated in the subgenera Immicrohoria and Submicrohoria.

Microhoria insignita (Pic, 1906) comb. nov.

Anthicus insignitus Pic, 1906: 285

Anthicus insignitus: PIC (1911b): 55 (catalogue); WINKLER (1927): 845 (catalogue).

Tenuicollis insignitus: CHANDLER at al. (2008): 448 (catalogue, distribution).

Type locality. Tunisia, Oued Defaa, Foum Tatahouine.

Type material. SyNTYPES: see Remarks (at least partly MNHN).

Distribution. Tunisia.

Remarks. PIC (1906) described Anthicus insignitus from an unstated number of specimens collected by L. Vibert in southern Tunisia, which were deposited in his and the Vibert Collection. Its present placement in Microhoria is provisional, dependant on the generic synonymy proposed here. This species may belong in Liparoderus, as stated below, however this possibility must be confirmed by examination of the type specimens. Searching in Pic's collection, Z. Kejval found a single pin with the locality, identification, and type labels for this species (the specimen was lacking), together with a specimen of Liparoderus bearing the following data: 'Tunisie $[\mathrm{h}] / /$ insignitus Pic $[\mathrm{h}] / /$ Krekich vid [p].' This specimen is not quite excluded from being a member of the type series, however it lacks the type locality data and type labels. There are additional facts suggesting placement of $A$. insignitus in Liparoderus - PIC (1906) compared this new species with Anthicus barnevillei and Anthicus insignis var. insignior (the latter is presently a member of Liparoderus, see CHANDLER et al. 2008), and some characters given in the original description agree with Liparoderus, mainly the larger size (3.5-4 mm), large, posteriorly subtruncate head, robust pronotum, and two silvery, sinuous setose bands on the elytra.

\section{Microhoria fugax species-group}

Diagnosis. Small to medium-sized species, with uniform setation of elytra; rather variable in shape of head and pronotum, the latter mostly distinctly constricted in dorsal view and with uniformly short setae (Figs 128-130). Mesoventrite with nearly completely bordered margins (sulcus always rather distinct), and frequently with short submedian carinae, at least indicated posteriorly (Figs 29, 30 ); setose fringe of mesepimera strongly reduced (Figs $30,35)$; submarginal setose impressions of metaventrite and abdominal sternum III indistinct; metatibiae almost exclusively with single terminal spur (see Remarks); elytral apices in males nearly simple, secretory pores situated directly on/near margin (Fig. 45), which is usually somewhat swollen, uneven, bearing small projection. Aedeagus (Figs 54-61): tegmen with distinct, narrowed apex, mostly weakly sclerotized; endophallus always with longitudinal sclerite (gonopore situated apically, Figs 54, 60 ), in addition to various spinules, sometimes also with spines arranged in longitudinal row on connecting membrane (Fig. 55) and membranous inner sheath (Fig. 56).

Distribution. Eastern Palaearctic and Oriental Region, most speciose in the Himalaya and mountains of SW China (Yunnan). The westernmost records originate from eastern Afghanistan.

Species included (61 spp.). Microhoria abscondita (Telnov, 2000) comb. nov., M. adusta (Krekich-Strassoldo, 1931) comb. nov., M. afghana (Telnov, 2010) comb. nov., M. almorae (Krekich-Strassoldo, 1931) comb. nov., M. ambusta (Krekich-Strassoldo, 1931) comb. nov., M. anomala (Telnov, 1998) comb. nov., M. aquatilis (Krekich-Strassoldo, 1931) comb. nov., M. assamensis (Pic, 1907) comb. nov., M. assequens (Krekich-Strassoldo, 1931) comb. nov., M. atrata (Krekich-Strassoldo, 1931) comb. nov., M. biguttata (Bonadona, 1964) comb. nov., M. brunneipes (Krekich-Strassoldo, 1931) comb. nov., M. caeruleicolor (Pic, 1906) comb. nov., M. comes (Krekich-Strassoldo, 1931) comb. nov., $M$. cordata (Krekich-Strassoldo, 1931) comb. nov., $M$. curticeps (Pic, 1923) comb. nov., M. disconotata (Pic, 1907) comb. nov., M. feai (Pic, 1907) comb. nov., $M$. fossicollis (LaFerté-Sénectère, 1849) comb. nov., $M$. fugax (LaFerté-Sénectère, 1849) comb. nov., M. fugiens (Marseul, 1876) comb. nov., M. garze (Telnov, 2018) comb. nov., M. gravida (Krekich-Strassoldo, 1931) 
comb. nov., M. harmandi (Pic, 1899) comb. nov., $M$. hauseri (Pic, 1906) comb. nov., M. himalayana (Pic, 1909) comb. nov., M. hummeli (Pic, 1933) comb. nov., M. immaculipennis (Krekich-Strassoldo, 1931) comb. nov., M. inabsoluta (Telnov, 2003) comb. nov., M. indeprensa (Telnov, 2000) comb. nov., M. kejvali (Telnov, 1999) comb. nov., M. kham (Telnov, 2018) comb. nov., $M$. kuluensis (Pic, 1914) comb. nov., M. lepidula (Marseul, 1876) comb. nov., M. longicornis (Uhmann, 1983) comb. nov., M. manifesta (Pic, 1907) comb. nov., M. muguensis (Telnov, 2000) comb. nov., M. nigrocyanella (Marseul, 1877) comb. nov., M. nigrofusca (Telnov, 2000) comb. nov., M. notatipennis (Pic, 1909) comb. nov., M. nystii (LaFerté-Sénectère, 1849) comb. nov., M. phungi (Pic, 1926) comb. nov., M. picea (Laferté-Sénectère, 1849) comb. nov., M. posthuma (Krekich-Strassoldo, 1931) comb. nov., M. prolatithorax (Pic, 1899) comb. nov., M. separatithorax (Pic, 1914) comb. nov., M. shibatai (Nomura, 1962) comb. nov., M. sikkimensis (Pic, 1907) comb. nov., M. sinensis (Pic, 1907) comb. nov., M. sporadica (Krekich-Strassoldo, 1931) comb. nov., M. strandi (Krekich-Strassoldo, 1931) comb. nov., M. striaticollis (Krekich-Strassoldo, 1931) comb. nov., M. subpicea (Pic, 1914) comb. nov., M. tersa (Krekich-Strassoldo, 1931) comb. nov., M. tonkinensis (Krekich-Strassoldo, 1928) comb. nov., M. truncatella (LaFerté-Sénectère, 1849) comb. nov., M. turgida (Krekich-Strassoldo, 1928) comb. nov., M. uniformis (Krekich-Strassoldo, 1931) comb. nov., M. variabilis (Krekich-Strassoldo, 1931) comb. nov., M. weigeli (Telnov, 2000) comb. nov., and M. wuyishanensis (Nardi, 2004) comb. nov.

Remarks. This group holds nearly all Eastern Palaearctic (from Afghanistan eastwards) and Oriental species placed previously in Clavicomus (CHANDLER et al. 2008, as Clavicollis) with the exception of $C$. protervus (Krekich-Strassoldo, 1931) from northern India (Uttarakhand).

The terminal spurs of the metatibiae were found to be further reduced in males of species that exhibit modifications of the terminal portion of the tibiae; they are both absent in M. anomala and M. kejvali (based on tentatively identified specimens, ZKDC), and in two unnamed species from China and Laos (ZKDC).

\section{Microhoria posthuma (Krekich-Strassoldo, 1931) comb. nov. \\ (Figs 59-61, 130)}

Anthicus posthumus Krekich-Strassoldo, 1931: 32

Clavicomus posthumus: Telnov (2003): 296 (checklist, distribution, record Nepal).

Clavicollis posthumus: CHANDLER et al. (2008): 431 (catalogue, distribution).

Anthicus fumeoalatus Krekich-Strassoldo, 1931: 39, syn. nov.

Microhoria fumeolata [misspelling]: UhMANN (1989): 250 (record Nepal).

Microhoria fumeoalata: Telnov (2003): 297 (checklist, distribution, record Nepal); CHANDLER et al. (2008): 440 (catalogue, distribution)

Type locality. Anthicus posthumus - India, Uttarakhand, West Almora; A. fumeoalatus - India, Uttarakhand, Nainital.

Type material. Anthicus posthumus - LECTOTYPE (herewith designated): o, 'W. Almora Kumaon India H. G. Champion [p] // 98B [h] // TYPE [p; red label] // A. posthumus Kr. det. v. Krekich [p+h] // posthumus Kr. [h; ochraceous label] // coll. Heberdey [p]' (NHMW). ParalectotyPES:
3 A 1 , 'W. Almora Kumaon India H. G. Champion [p] // [male or female sex-symbol [p] // CO-TYPE [p; red label] // A. posthumus Kr. det. v. Krekich $[\mathrm{p}+\mathrm{h}] / /$ coll. Heberdey [p]'; $2 \approx 1$ \&, 'W. Almora Kumaon India H. G. Champion [p] // COTYPE [p; red label] // A. posthumus Kr. det. v. Krekich [p+h] // coll. Heberdey [p]' (all NHMW).

Anthicus fumeoalatus - HoLotype: 0 , 'Nainital, UP, 7-8600 ft. July 1923 HGC [p] // 747B [h] TYPE [p; red label] // A. fumeolatus Kr. det. v. Krekich [p+h] // fumeolatus Kr. [h; ochraceous label] // Microhoria fumeolata (Krek.) vid. D. Telnov, 1998 [p]' (NHMW).

Additional material. INDIA: Himachal Pradesh: 12 spec., Shimla District, Kufri, 2500 m, 15.-17.vii.1989, Hiermeier lgt. (ZKDC); 3 spec., same data, except: 16.vii.1989, A. Riedel lgt. (ZKDC). UTTARAKHAND: $3 \hat{\jmath} \hat{\jmath}$, 'W. Almora, Kumaon, India. H. G. C.' (ZKDC); 1 o, 30 km N of Rishikesh, NW of Chamba, 1500 m, 29.-31.vii.2003, Z. Kejval \& M. Trýzna lgt. (ZKDC); 1 ઈ, 20 km NE of Rishikesh, Kaudiyala env., Ganga River valley, ca. 500 m, 25.-17.vii.2003, Z. Kejval \& M. Trýzna lgt. (ZKDC); 2 spec., Dhanolti env., 2200-2400 m, 11.-13.vii.1989, Hiermeier lgt. (ZKDC); 5 spec., same data, except: 11.vii.1989, A. Riedel lgt. (ZKDC); 1 đ̊, Joshimath, Auli, 2800 m, 13.-17.vii.1994, M. Snížek lgt. (ZKDC); 2 spec., ca. 13 km NW of Nainital, Khairna Bridge env., 900-1000 m, 13.-17.vii.2003, Z. Kejval \& M. Trýzna lgt. (ZKDC); 16 spec., ca. $55 \mathrm{~km}$ NE of Bageshwar, W of Loharket, 1800-1900 m, 24.vi.2003, Z. Kejval \& M. Trýzna lgt. (ZKDC); 5 spec., ca. 55 km NE of Bageshwar, Munsyiari, 2200-2400 m, 6.-9.vii.2003, Z. Kejval \& M. Trýzna lgt. (ZKDC); 15 spec., Nainital, 1900 m, 18.-19.vii.2003, Z. Kejval \& M. Trýzna lgt. (ZKDC).

Diagnosis. Microhoria fugax species-group; smaller, somewhat robust species, with widely rounded head base (Fig. 130). Elytral apices in males simple, margin evenly curved (pores possibly very slight, if present at all). Male sternum VII simple; sternum VIII forming pair of delicate, simple sclerites, narrowly connected medially; tergum VII simple; tergum VIII with slightly produced (flanged) posterior margin. Female sternum VII simple; tergum VII simple. Aedeagus (Figs 59-61): tegmen with small apical notch; endophallic armature with numerous coarse spinules and flattened, longitudinal sclerite, bearing gonopore apically.

Variation. Body length ( $\jmath^{\top}+$ ) 2.1-2.6 mm. Body reddish-brown to brownish-black; elytra unicolorous, sometimes with vague indication of paler markings in dark-coloured specimens.

Distribution. India (Uttarakhand, Himachal Pradesh), Nepal.

Remarks. KREKICH-STRASSOLDo (1931) described both Anthicus posthumus and A. fumeoalatus from material collected by H. G. Champion in SE Uttarakhand; the former from a series of specimens (number unstated, deposited partly at BMNH); the latter from a single specimen, judging from singular in his statement 'Type in meiner Sammlung' (presently NHMW). In the same paper, he placed them in different groups (X and XIII, later genera Clavicomus and Tenuicomus) established by MARSEUL (1879). Having examined types of both species, we failed to find any differences in the male characters, as assumed from very similar original figures of the aedeagi by KREKICH-STRASSOLDO (1931). Consequently, Anthicus fumeoalatus is regarded as a junior synonym of the former species.

The lectotype is designated herein for a male syntype of Anthicus posthumus that was dissected and most probably used for the original description and figures by Krekich-Strassoldo; its aedeagus is present on microscope slide no. 98B (examined, NHMW). 




Figs 59-63: 59-61 - Microhoria posthuma (Krekich-Strassoldo, 1931) comb. nov., India, Nainital (ZKDC): 59 - aedagus in lateral view; 60 - apex of everted endophallus; 61 - apex of tegmen. 62, 63 - Aedeagus in lateral view: 62 - M. heydeni (Marseul, 1879); 63 - M. barnevillei (Pic, 1892). Scale bars: $0.2 \mathrm{~mm}$ - A (Figs 59-62), B (Fig. 63).

\section{Microhoria heydeni species-group}

Diagnosis. Mostly smaller species, with unicolorous elytra, and elytral setae at most weakly swirled in postbasal area (no conspicuous setose bands); pronotum moderately constricted in dorsal view, with uniformly short setae (Fig. 133). Mesoventrite with nearly completely bordered lateral margins, submarginal sulcus delicate (Figs 15, 16), sometimes inconspicuous laterally; setose fringe of mesepimera well-developed; submarginal setose impressions of metaventrite and abdominal sternum III absent; all tibiae with paired terminal spurs; elytral apices in males nearly simple, secretory pores scattered along somewhat swollen margin (Fig. 46). Aedeagus (Figs 62, 63): tegmen with rounded apex ('capsuliform'), and with robust subapical projection(s); gonopore free.

Distribution. Western Mediterranean Region (Portugal, Spain) and Canary Islands.

Species included (5 spp.). Microhoria barnevillei (Pic, 1892) comb. nov., M. heydeni (Marseul, 1879) comb. nov., M. martinezi (Pic, 1932) comb. nov., M. schrammi (Pic, 1913) comb. nov., and M. uhagoni (Pic, 1904) comb. nov.
Remarks. This species-group holds species previously placed in Clavicomus and Tenuicomus (CHANDLER et al. 2008, as Clavicollis and Tenuicollis). They can be easily confused with members of the M. olivacea species-group, differing mainly by the peculiar shape of the tegmen, which has robust subapical projection(s). Two species, $M$. martinezi and M. uhagoni, are known to the authors only from their female types, and their tentative placement here is based on external similarity.

\section{Microhoria longiceps species-group}

Diagnosis. Mostly elongate species, with oval head, constricted pronotum and somewhat modified setation of elytra (at most swirled, no distinct setose bands, Figs 134-137); latero-basal pronotal setation variable, forming small patches of dense setae around fovea, fringe longer and sparser, or quite inconspicuous (e.g. M. dichrous and $M$. proterva). Mesoventrite with rather sharply bordered margins, lacking paired submedian carinae (Figs 25-28); setose fringe of mesepimera more or less well-developed (Figs 34, 36); submarginal setose impressions of metaventrite and abdominal sternum III weakly indicated to 


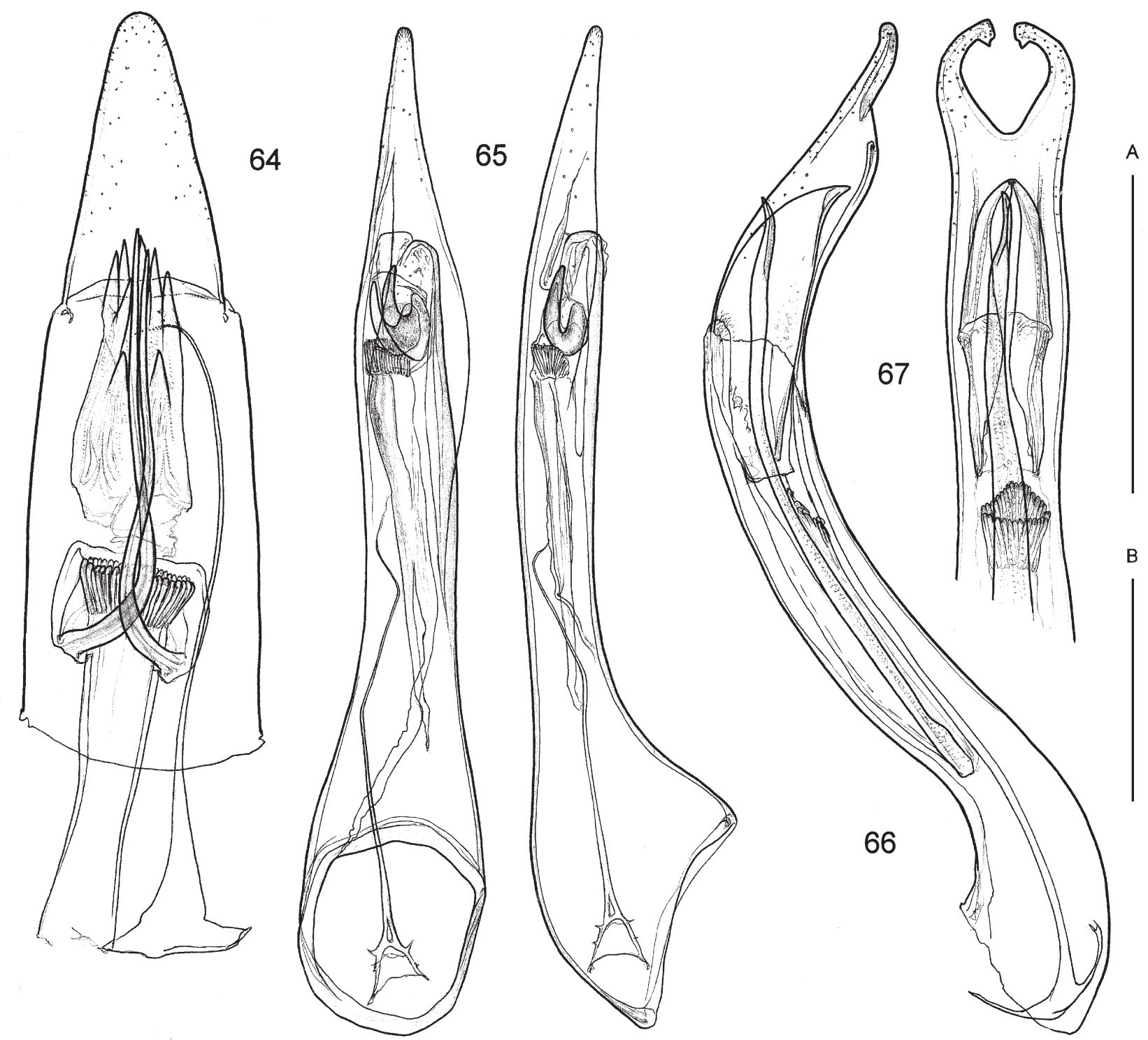

Figs 64-67. Aedeagus: 64 - Microhoria longiceps (LaFerté-Sénectère, 1849) comb. nov., ventral view; 65 - M. callima (Baudi di Selve, 1877) comb. nov., ventral (left) and lateral (right) view; 66 - M. globipennis (Pic, 1897), Turkey, Cevlik (ZKDC), lateral view; 67 - same, apical portion in ventral view. Scale bars: $0.2 \mathrm{~mm}$ - A (Fig. 65), B (Figs 64, 66, 67).

conspicuous; all tibiae with paired terminal spurs; elytral apices in males usually modified (except M. globipennis), channel forming small sclerotized cavity, varying in prominence (very slight and situated near produced apex of elytra in some species, e.g. M. antalya sp. nov., M. gigas, and $M$. truncata). Aedeagus (Figs 64-73): tegmen mostly lengthily tubular and straight, apically simply narrowed and pointed (exceptionally bifurcate as in M. globipennis); gonopore free.

Distribution. Western Palaearctic (Mediterranean Region), and 1-2 isolated species in northern India and Pakistan (see Remarks).

Species included (21 spp.). Microhoria angulifer (Pic, 1893 ) comb. nov., M. antalya sp. nov., M. austriaca (Pic, 1901) comb. nov., M. bicarinifrons (Pic, 1892) comb. nov., M. callima (Baudi di Selve, 1877) comb. nov., $M$. decolorata (Pic, 1897) stat. restit., comb. nov., M. dichrous (LaFerté-Sénectère, 1849) comb. nov., M. doderoi (Pic, 1902) comb. nov., M. erythrodera (Marseul, 1878) comb. nov., M. gigas (Pic, 1899) comb. nov., M. globipennis (Pic, 1897), M. kabyliana (Pic, 1896) comb. nov., M. longiceps (LaFerté-Sénectère, 1849) comb. nov., M. olivierii (Desbrochers des Loges, 1868) comb. nov., M. paganettii (Pic, 1909) comb. nov., M. plagiostola (Bonadona, 1958) comb. nov., M. proterva (Krekich-Strassoldo, 1931) comb. nov., M. ragusae (Pic, 1898) comb. nov., M. tibialis (Waltl, 1835) comb. nov., M. truncata (Pic, 1895) comb. nov., and M. versicolor (Kiesenwetter, 1866) comb. nov.

Remarks. This group holds mostly Mediterranean species treated previously as Clavicomus (CHANDLER et al. 2008, as Clavicollis).

Microhoria globipennis is rather aberrant in having a bifurcate apex of the tegmen and simple elytral apices in males, however it shares characters of mesothorax and externally resembles some eastern Mediterranean species of this group, see Figs 136, 137.

Microhoria proterva (Fig. 135) is another remarkable species, also with respect to its very isolated distribution. 
It was described from an unstated number of specimens originating from the Indian state of Uttarakhand and never newly recorded. There are only two male syntypes, one each deposited in BMNH and NHMW, and Z. Kejval has also examined two recently collected males from northern Pakistan (ADBC, ZKDC), which may possibly belong to another unknown, but very close species. They resemble some members of the $M$. fugax species-group (very speciose in the Himalaya) in their external appearance and some detailed characters, e.g. short setose fringe on mesepimera, absent submarginal setose impressions of metaventrite and abdominal sternum III, and comparatively short tegmen. However, important characters suggesting placement within the $M$. longiceps species-group are as follows: paired terminal spurs of metatibiae (quite distinct), channel of elytral gland forming minute cavity at elytral margin, and the free primary gonopore of the aedeagus, which is situated at the middle part of the aedeagus.

\section{Microhoria antalya Kejval, sp. nov.} (Figs 68, 70, 136)

Type locality. Turkey, Antalya Province, Manavgat env., alt. $150 \mathrm{~m}$. Type material. Holotyp: $\hat{\sigma}$, 'TR-Antalya; 150 m Umg. Manavgat; Ges 30.XII.1990 ASSING [p] // Clavicomus angulifer (Pic) det. G. Uhmann 1992 [p+h]' (ZSMC).

Additional specimen. TURKEY: 1 , Antalya prov., $22 \mathrm{~km}$ W of Alanya, Avsallar, 9.-23.v.1995, A. Pütz lgt. (ZSMC).

Description. Male (holotype). Body length $3.2 \mathrm{~mm}$. Body reddish-brown, head slightly darker, elytra with very vague paler markings (Fig. 136); legs and antennae reddish.

Head nearly 1.2 times as long as wide, widely rounded posteriorly; eyes small, moderately convex. Surface moderately glossy, distinctly punctate; punctures distinctly spaced; setation short, subdecumbent to decumbent, with several short erect setae. Antennae only moderately enlarged in apical half; antennomeres X 1.3 times, XI 2.1 times as long as wide.

Pronotum 1.1 times as long as wide, moderately narrower than head including eyes, somewhat widely rounded anteriorly, pronotal disc evenly moderately convex, outline in dorsal view with lateral margins moderately impressed posteriorly. Surface moderately glossy, distinctly punctate; punctation distinctly coarser, setation as on head, with some short erect setae.

Elytra 1.7 times as long as wide; humeri inconspicuous; apices modified, distinctly produced medially, channel of gland very slight, situated near apex. Surface moderately glossy, distinctly punctate; punctation coarser, setation somewhat longer than on head, with scattered short erect setae.

Legs slender, simple; all tibiae with paired terminal spurs.

Abdominal sternum VII moderately produced and evenly rounded apically; sternum VIII forming simple, subtriangular paired sclerites, narrowly connected medially, rounded and setose posteriorly. Aedeagus (Figs 68, 70): tegmen comparatively short and wide, straight, its apical portion somewhat flattened, straightly projecting, reinforced medially and bluntly pointed; endophallic armature with paired row of densely spaced robust spines and pair of long, slender, bluntly pointed sclerites.

Female. Identical with male for most external characters; elytral apices simple, slightly produced and narrowly rounded; sternum VII simple; tergum VII simple, subtriangular, evenly rounded apically.

Variation. Body length ( $\jmath^{\top}+$ ) 3.2-3.5 mm; body reddish to reddish-brown.

Differential diagnosis. Microhoria antalya sp. nov. belongs to the Microhoria longiceps species-group, having in general a similar armature of the endophallus as do most of the eastern Mediterranean members of this group. Considering their variation it may be difficult to recognize this species by its external characters; nevertheless, the following character set seems to be useful, at least for rough initial sorting: body reddish-brown, head base widely rounded, body punctation rather dense and distinct (especially on pronotum), setation of elytra moderately raised and uniform (setae rather evenly pointing posteriad), antennae comparatively long and slender. Major distinguishing characters of $M$. antalya sp. nov. are as follows: elytra evenly rounded postero-laterally and with prominent apical median protrusion (rather moderately angled in $M$. decolorata); tegmen comparatively short and wide, straight in lateral view, its apical part moderately produced and somewhat flattened, straightly projecting (Fig. 70), asetose and reinforced medially on ventral side (more convex and quite simple, moderately bent apically in lateral view in $M$. decolorata (Figs 69, 71); strongly convex, widened and then abruptly narrowed, with transverse carina subapically on ventral side in $M$. gigas; extremely produced, flattened and apically rounded in $M$. angulifer; for clearly different condition in $M$. truncata see Figs 72, 73).

Etymology. Named after the Turkish province Antalya where this species was discovered; noun in the nominative case, standing in apposition.

Distribution. So far known only from Antalya Province, southern Turkey.

Remarks. There is no serious doubt about the identity of the female examined. It is also from Antalya (about $30 \mathrm{~km}$ SE of Manavgat); however, it is preferable to leave the single female as a non-type specimen in this case.

\section{Microhoria decolorata (Pic, 1897) stat. restit. \& comb. nov. \\ (Figs 69, 71)}

Anthicus truncatus var. decoloratus Pic, 1897a: 120.

Anthicus truncatus var. decoloratus: PIC (1911b): 78 (catalogue); WINKLER (1927): 841 (catalogue).

Anthicus (Stricticomus) decoloratus: PIC (1901): 179 (species status). Anthicus (Stricticollis) decoloratus: SAHLBERG (1913b): 19 (record Corfu). Stricticomus truncatus var. decoloratus: UhMANN (1985): 192 (record Greece); Telnov (2010): 22 (checklist, synonymy).

Anthicus (Stricticomus) decoloratus var. subcoloratus Pic, 1901: 179. Anthicus trunncatus var. subcoloratus: WINKLER (1927): 841 (catalogue). Stricticomus truncatus var. subcoloratus: TELNOv (2010): 22 (checklist, synonymy).

Type locality. Anthicus truncatus var. decoloratus - Greece, Corfu, Gastouri; A. decoloratus var. subcoloratus - Greece, Peloponnesse, Olympia. Type material. Anthicus truncatus var. decoloratus - SynTYPE: + , 'Gasturi Apfelbeck Corfu [p+h] // type [h; yellowish label] // TYPE [p; red 

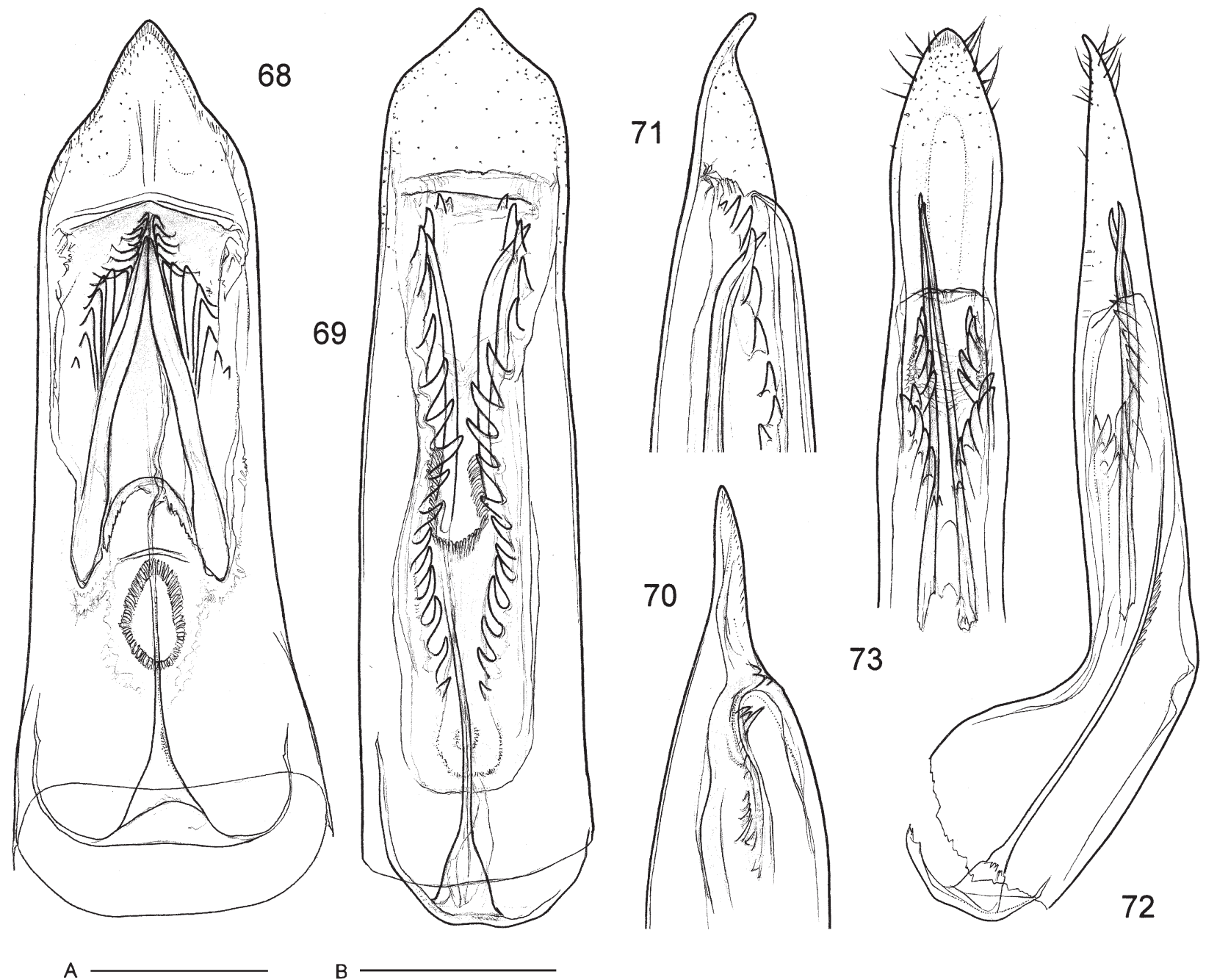

Figs 68-73. Aedeagus: 68 - Microhoria antalya sp. nov., ventral view; 69 - M. decolorata (Pic, 1897) stat. restit. \& comb. nov., ventral view; 70 - M. antalya sp. nov., apex in lateral view; $71-M$. decolorata, apex in lateral view; 72 - M. truncata (Pic, 1895) comb. nov., lateral view; 73 - same, apical half in ventral view. Scale bars: $0.2 \mathrm{~mm}$ - A (Figs 72, 73), B (Figs 68-71).

label] // A. angulifer Pic var ? tres desiré immature [h] // decoloratus Pic ? var de truncatus [h]' (coll. Pic, MNHN).

Anthicus (Stricticomus) decoloratus var. subcoloratus - SyNTYPES [common label 'v. subcoloratus Pic [h]' pinned on bottom]: 9 qq, 'Olympia [h]'; 3 +o, 'Olympia 8 Mai [h] // decoloratus Pic var [h]'; 3

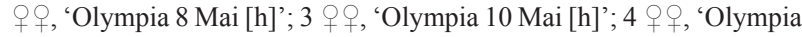
Moree [h]’; 3 우, ‘Morée Olympia [h] // decoloratus Pic var [h]’; 2 우, 'Morée Olympia [h] // decoloratus Pic [h]'; 5 spec., same plain card, no labels (all coll. Pic, MNHN).

Additional specimens. GREECE: EPIRUs: 1 , Parga, 22.-26.iv.1998, P. Poot lgt. (ZSMC). Ionian IsLands: 1 \%, Cephalonia, Rudi, 1905, O. Leonhard lgt. (NHMW); 6 \% , Corfu, Agios Mattheos [no date and collector] (NHMW, ZKDC); 1 \%, Corfu, Mount Deca [no date and collector] (NHMW); 1 o, Corfu [no date], Reitter lgt. (ZKDC). NorTH Aegean Islands: 2 웅, Samos Island, Avlakia, 37 $47^{\prime} \mathrm{N} 26^{\circ} 51^{\prime} \mathrm{E}, 100$ m, 28.iv.2003, Brachat \& Meybohm lgt. (ZSMC); 2 우, Samos Island, Manolates, $37^{\circ} 47^{\prime} \mathrm{N} 26^{\circ} 49^{\prime} \mathrm{E}, 300 \mathrm{~m}$, 29.iv.2003, Brachat \& Meybohm lgt. (ZSMC); 1 \3우, Samos Island, Platanakia, Nightingale Valley, $37^{\circ} 47^{\prime} \mathrm{N} 26^{\circ} 50^{\prime} \mathrm{E}, 50-200 \mathrm{~m}, 21 . i v .2003$, Brachat \& Meybohm lgt. (ZSMC, ZKDC).

Diagnosis. Microhoria longiceps species-group; robust, reddish-brown species. Male elytra slightly bulging subapically (flattened in female), apical margin distinctly angled, channel of gland slight (inconspicuous slit at margin). Male sternum VII produced and moderately widely rounded apically; sternum VIII forming paired, triangular sclerites, narrowly rounded and setose apically; tergum VII simple; tergum VIII simple; aedeagus (Figs 69, 71). Female sternum VII simple; tergum VII simple.

Variation. Body length $(\delta \circ)$ 2.6-3.1 mm; moderately variable in size and convexity of eyes; head base narrowly rounded to subtruncate (Epirus, Ionian Islands, Peloponnese), more or less evenly rounded (North Aegean); head and pronotal disc more or less coarsely and densely punctate. The male specimen from Samos Island has the apical part of the tegmen somewhat longer, with spines of the endophallus densely spaced, similar to Fig. 68.

Distribution. Greece.

Remarks. PIC (1897a) described Anthicus truncatus var. decoloratus from an unstated number of specimens collected on the Greek island of Corfu. It was recently treated as synonym of Stricticollis truncatus (Pic, 1895) by CHANDLER et al. (2008) and Telnov (2010), however its identity and generic placement were never accurately determined.

Based on examination of the type and additional specimens from Corfu (including males), Anthicus truncatus var. decoloratus is removed from synonymy and has proven 
to be a separate species of Microhoria, differing clearly from $M$. truncata comb. nov. by the more elongate head and elytra, the distinct humeri and postbasal impression (while ovoid, lacking humeri and evenly convex in $M$. truncata), denser punctation of the pronotal disc and elytra, and mainly by characters of the aedeagus (Figs 69, 71).

The syntypes of variety subcoloratus that were examined are essentially identical with the type of $M$. decolorata. However, this synonymy should be confirmed by examination of male specimens taken in the Peloponnese. Remarks. The specimens from Samos are tentatively identified as this species, while noting clear differences in the dense arrangement of spines of the endophallus. Nevertheless, in Microhoria species the internal sac is largely membranous and therefore position of its small sclerotized structures is not stable. Moreover, study of male material was limited to only two specimens.

\section{Microhoria globipennis (Pic, 1897) (Figs 66, 67, 137)}

Anthicus globipennis Pic, 1897a: 120.

Anthicus globipennis: PIC (1911b): 51 (catalogue).

Anthicus globipennis: WINKLER (1927): 849 (catalogue).

Microhoria globipennis globipennis: CHANDLER et al. (2008): 440 (catalogue, distribution).

Anthicus globipennis quercicola Sahlberg, 1913a: 59, syn. nov.

Anthicus globipennis var. quercicola Krekich-Strassoldo, 1913: 227 (junior homonym, see Remarks).

Anthicus globipennis var. quercicola: WINKLER (1927): 849 (catalogue).

Type locality. Anthicus globipennis - Syria, Latakia Governorate, Jabal al Akrad ('Djebel Akrab'); A. globipennis quercicola - S Turkey, Bolkar Mountains (= Bulgar Dagh).

Type material. Anthicus globipennis-SyNTYPES: 1 spec., ' $\mathrm{D}^{\mathrm{r}} \mathrm{F}$. Leuthner DjebelAkrab 85 N. SYRIEN [p; frame] // type [h; yellowish label]'; 1 spec., 'Syrie [h] type [h; yellowish label] // Krekich vidit [h] // globipennis Pic [h]'; 1 spec., 'globipennis Pic (Syrie)' (all coll. Pic, MNHN).

Anthicus globipennis quercicola - SYNTYPES: 1 \%, 'Bulghar-Dagh J. Sahlbg. [h] // TYPE [p; red label] // quercicola Krek. [h; ochraceous label]' (NHMW); 1 \&, 'BulgharDagh [p] // J. Sahlb. [p] // [female sex-symbol; p] // TYPE [p; red label]' (NMHW); 1 +, 'BulgharDagh [p] // J. Sahlb. [p] // TYPE [p; red label] // det. v. Krekich globipenis var. quercicola Krek. $[\mathrm{p}+\mathrm{h}] / /$ globipenis v. quercicola Taurus Sahlb. [h; frame]' (NHMW); 1 , 'BulgharDagh [p] // J. Sahlb. [p] // quercicola Sahlb. Spec. typ. [p+h] // [female sex-symbol; h] // A. quercicola n. sp. [h; frame]' (coll. Pic, MNHN). Additional specimens. SYRIA: 1 spec., Jabal an Nusayriah, Qual'at al Saladin, $35^{\circ} 35.509^{\prime} \mathrm{N} 36^{\circ} 03.827^{\prime} \mathrm{E}, 1334 \mathrm{~m}$, 17.iv.2008, P. Hlaváč lgt. (ZKDC); $1 \hat{\jmath}$, Qualat al Mahaliban, E of Slinfah, $40 \mathrm{~km}$ E of Latakia, 31.v.2009, M. Šárovec lgt. (ADBC). TURKEY (Hatay prov.): 3 spec., Altinozu, near Antakya, 22.iv.1992, M. Kocian lgt. (ZKDC); 1 spec., Cevlik, near Samandag, 23.-26.iv.1994, P. Průdek \& J. Kovalovský lgt. (ZKDC); 12 spec., Cevlik, 25 km W of Hatay, 22.-23.iv.1997, T. Růžička lgt. (ZKDC); 1 spec., Nur Daglari Mts, Tülek, Ulucinar env., 5.v.2005, K. Orszulik lgt. (ZKDC); 2 spec., 19 km N of Antakya, Ziyaret Daği, Şenköy, 913 m, 2.iv.2004, M. Schülke lgt. (ZKDC); 3 spec., same locality, $36^{\circ} 01^{\prime} 48^{\prime \prime} \mathrm{N} 36^{\circ} 07^{\prime} 19^{\prime \prime} \mathrm{E}$, E slope, oak and laurel shrubs, sifted, 5.iv.2004, M. Schülke lgt. (ZKDC).

Diagnosis. Largely reddish, apterous species (Fig. 137). Elytral apices in males simple, margin quite evenly shaped (not swollen, channel of gland absent). Male sternum VII rather short, with slight median emargination; sternum VIII forming paired, subtriangular, asetose, weakly sclerotized sclerites; tergum VII and VIII simple. Female sternum VII simple; tergum VII subtriangular, slightly produced apically; aedeagus (Figs 66, 67).
Variation. Body length $(\hat{\jmath}+)$ ) 2.1-2.9 mm; elytra unicolorous reddish or vaguely brownish laterally.

Distribution. Syria, Turkey.

Remarks. PIC (1897a) described Anthicus globipennis from an unstated number of specimens collected by F. J. Leuthner at the locality Jabal al Akrad, which is a mountainous region (400-1000 m) in northwestern Syria along the Coastal Mountain Range.

SAhlBerg (1913a) described Anthicus globipennis quercicola and KREKICH-STRASSOLDO (1913) described $A$. globipennis var. quercicola, based on specimens from same collection sample (Bulghar Dagh Mts, near Turunschli, from flowering Quercus ilex, 25.-28.iv.1906, J. \& U. Sahlberg lgt.). Sahlberg sent representatives of this species to Krekich-Strassoldo for his comments, and subsequently received a letter from Krekich-Strassoldo confirming that 'Anthicus quercicola Sahlberg' was a variety of A. globipennis Pic (SAhlberg 1913a: 61). Sahlberg's description was published in issue 8 of volume 55 [1912-1913] of the Öfversigt af Finska Vetenskaps-Societetens Förhandlingar which when compared with dates of publication found in the following volumes of this journal suggested that this issue was published in April or May of 1913. Krekich-Strassoldo's description of the same taxon was published in issue VII/VIII of volume 32 of the Wiener Entomologische Zeitung, dated July 15, 1913. While the date of issue cannot be precisely identified for Sahlberg's paper, it was published in the first half of the year 1913, and Sahlberg indicated later in that year (SAHLBERG 1913c: 193) [published September, 2013] that the name of Krekich-Strassoldo was a junior synonym.

\section{Microhoria truncata (Pic, 1895) comb. nov.} (Figs 72, 73)

Anthicus truncatus Pic, 1895: cclxxxiv.

Anthicus truncatus: PIC (1901): 179 (note); PIC (1911b): 78 (catalogue); WinKLER (1927): 841 (catalogue).

Stricticollis truncatus: CHANDLER et al. (2008): 447 (catalogue, distribution); Telnov (2010): 22, 29 (checklist, synonymy, record Turkey).

Type locality. Turkey, Hatay Province, Akbez.

Type material. SynTYPE: + , 'Akbés 1894 [h] // type [h; yellowish label] // sp. pres capilliger [h] // TYPE [p; red label] // truncatus Pic [h]' (coll. Pic, MNHN).

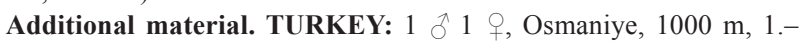
8.v.1969, F. Schubert lgt. (ZSMC, NHMW).

Diagnosis. Microhoria longiceps species-group; reddish, rather glossy, apterous species. Elytra evenly convex, lacking distinct humeri, subtruncate, median apical angle prominent, moderately produced (channel of gland forming slight cavity at apex). Male sternum VII distinctly produced and evenly rounded apically; sternum VIII forming paired simple sclerites; tergum VII and VIII simple; aedeagus (Figs 72, 73). Female sternum VII simple; tergum VII simple.

Variation. Body length ( $\jmath_{+}+2.9-3.2 \mathrm{~mm}$.

Distribution. Turkey.

Remarks. PIC (1895) described Anthicus truncatus from an unstated number of specimens collected at the locality Akbez in southern Turkey. The additional specimens examined originate from an adjacent province (Osmanyie 
is about $30 \mathrm{~km} \mathrm{NW}$ from Akbez). They were found to be identical with the single female syntype in Pic's collection, and confirm placement of $A$. truncatus in Microhoria.

\section{Microhoria ocreata species-group}

Diagnosis. Usually elongate species, with widely rounded head base and rather uniform short setae on elytra (at most weakly divergent in postbasal area, no conspicuous setose bands, Fig. 138); pronotal characters comparatively stable, with subparallel postero-lateral margins (never distinctly constricted in dorsal view) and inconspicuous setation. Mesoventrite with partly bordered margins (sulcus always thin to barely evident laterally), sometimes with indication of longitudinal submedian carinae (somewhat bulging medially); setose fringe of mesepimera well-developed; submarginal setose impressions of metaventrite and abdominal sternum III absent or indistinct; all tibiae with paired terminal spurs; elytral apices in males distinctly modified, with sclerotized cavity. Aedeagus (Figs 74, 75): tegmen capsuliform, rounded to flatly produced and somewhat tapering apically (never bilobed); endophallus with longitudinal sclerite, bearing gonopore apically and an extremely long, slender, flexible spine, originating from its base and pointing apically.

Distribution. Mediterranean Region (Algeria, Egypt, Italy, Morocco, Portugal, Spain, Tunisia). The record of Tenuicomus pallicrus from Saudi Arabia by Uhmann (1998) is probably erroneous.
Species included (7 spp.). Microhoria agriliformis (Pic, 1893 ) comb. nov., M. alfierii (Pic, 1923) comb. nov., $M$. escalerai (Pic, 1904) comb. nov., M. meloiformis (Reitter, 1890) comb. nov., M. ocreata (LaFerté-Sénectère, 1847) comb. nov., M. pallicra (Dufour, 1849), and M. tarifana (Pic, 1904) comb. nov.

Remarks. This group holds some species placed previously in Tenuicomus (CHANDLER et al. 2008, as Tenuicollis). They resemble members of the M. fasciata and M. schimperi groups based on characters of the mesoventrite and the male elytral apices, but differ by the reduced submarginal setose impressions of the metaventrite and abdominal sternum III, and by characters of the aedeagus (endophallic armature and position of the gonopore).

\section{Microhoria oedipus species-group}

Diagnosis. Robust species, showing usually more distinct sexual dimorphism (Fig. 139), mostly with modified elytral setation (swirled setae, setose bands); rather stable in pronotal characters, with distinct and longer setose latero-basal impressions. Mesoventrite with partly bordered lateral margins (sulcus absent laterally), and well-developed longitudinal submedian carinae (Figs 13, 14); setose fringe of mesepimera well-developed (Fig. 33); submarginal setose impressions of metaventrite and abdominal sternum III conspicuous; metatibiae more or less swollen and modified in males, with two terminal spurs; male metafemora with a row of coarser setae on inner side (at least in some
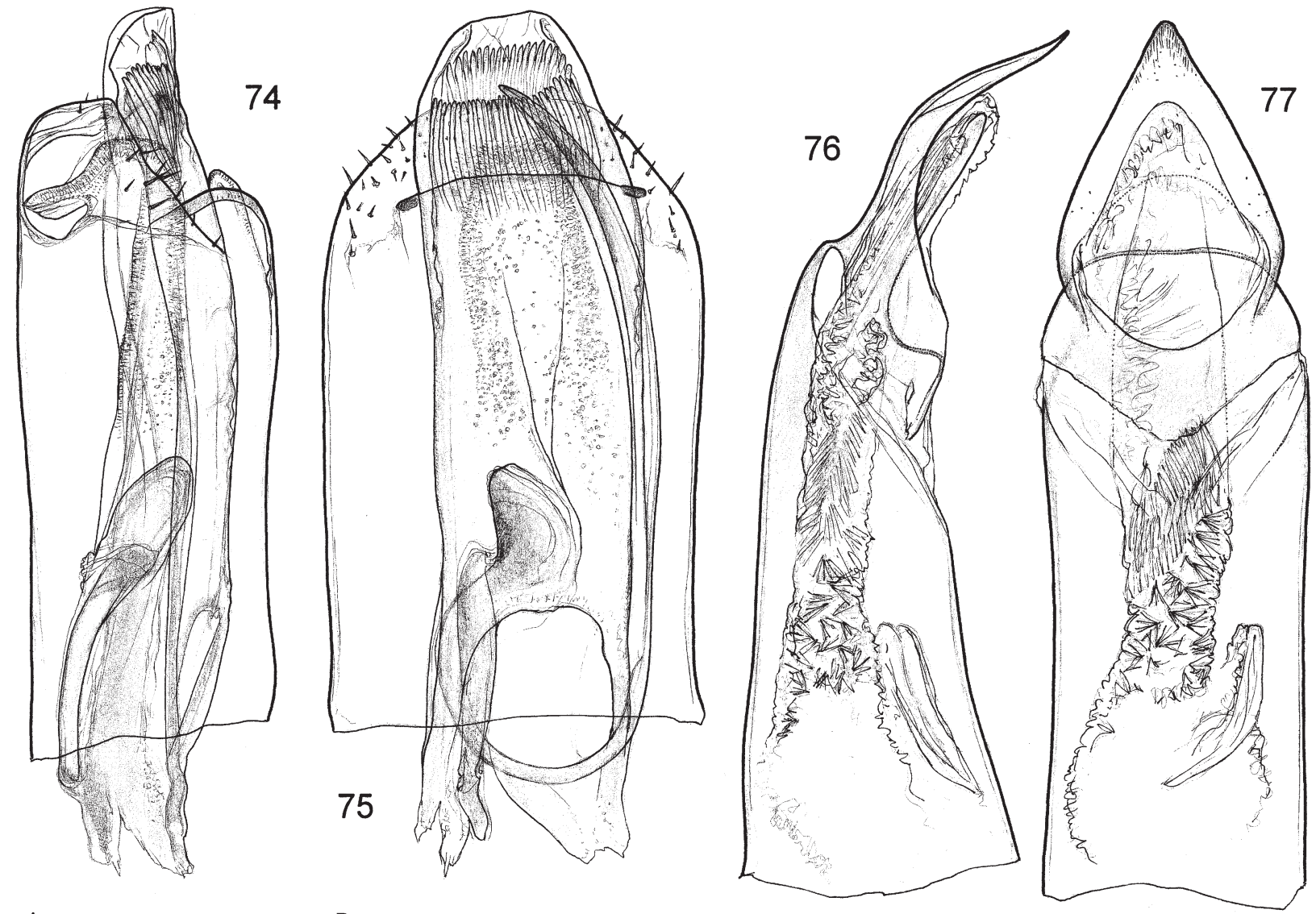

A

B

Aedeagus: 74-Microhoria ocreata (LaFerte-Senectere, 1847) comb. nov., lateral view; 75 1860), lateral view; 77 - same, ventral view. Scale bars: 0.2 mm - A (Figs 76, 77), B (Figs 74, 75). 
species); elytral apices in males conspicuously modified, subtruncate to more or less strongly excavate and lobed, with scattered secretory pores (Fig. 43). Aedeagus (Figs 76, 77): tegmen hood-like, with simple pointed apex ('cuculliform'); gonopore free.

Distribution. Northern Africa (Algeria, Morocco, Tunisia). Species included (13 spp.). Microhoria admirabilis (Pic, 1894), M. biauriculata (Pic, 1920), M. fortissima (Pic, 1894), M. leprieuri (Baudi di Selve, 1877), M. lobata (Pic, 1905), M. normandi (Pic, 1915), M. obuncata Normand, 1950, M. oedipus (Chevrolat, 1860), M. sicardi (Pic, 1893), M. subtruncata (Pic, 1920), M. succinta (Chevrolat, 1877), M. tunisica (Pic, 1893), and M. valga (Fairmaire, 1875).

Remarks. This group holds the species formerly treated as Microhoria sensu stricto. They are undoubtedly closely related to members of the $M$. fasciata species-group, but differ by the more conspicuous sexual dimorphism. However, it should be stated, that both modifications of metatibiae and elytral apices of males in this group are variably developed and most of the above listed species were only briefly examined or included on the basis of original descriptions.

\section{Microhoria olivacea species-group}

Diagnosis. Mostly smaller species, with unicolorous elytra (Fig. 140); moderately variable in pronotal characters, mostly with weak latero-basal impressions and uniformly short setation; elytral setae at most weakly divergent in postbasal area. Mesoventrite with nearly completely bordered lateral margins (Figs 21, 22), submarginal sulcus thin and sometimes inconspicuous laterally; setose fringe of mesepimera well-developed (Fig. 22); submarginal setose impressions of metaventrite and abdominal sternum III absent; all tibiae with paired terminal spurs; elytral apices in males nearly simple, pores scattered along somewhat swollen margin, similar to Fig. 46. Aedeagus (Figs 78-81): tegmen rounded to more or less distinctly bilobed apically ('capsuliform'), ventrally denticulate on outer side; gonopore free.

Distribution. Western Mediterranean Region (Algeria, Italy, Portugal, Spain, Tunisia).

Species included (8 spp.). Microhoria bruckii (Kiesenwetter, 1870) comb. nov., M. olivacea (LaFerté-Sénectère, 1849) comb. nov., M. platiai (Degiovanni, 2000) comb. nov., M. semidepressa (Pic, 1893) comb. nov.,
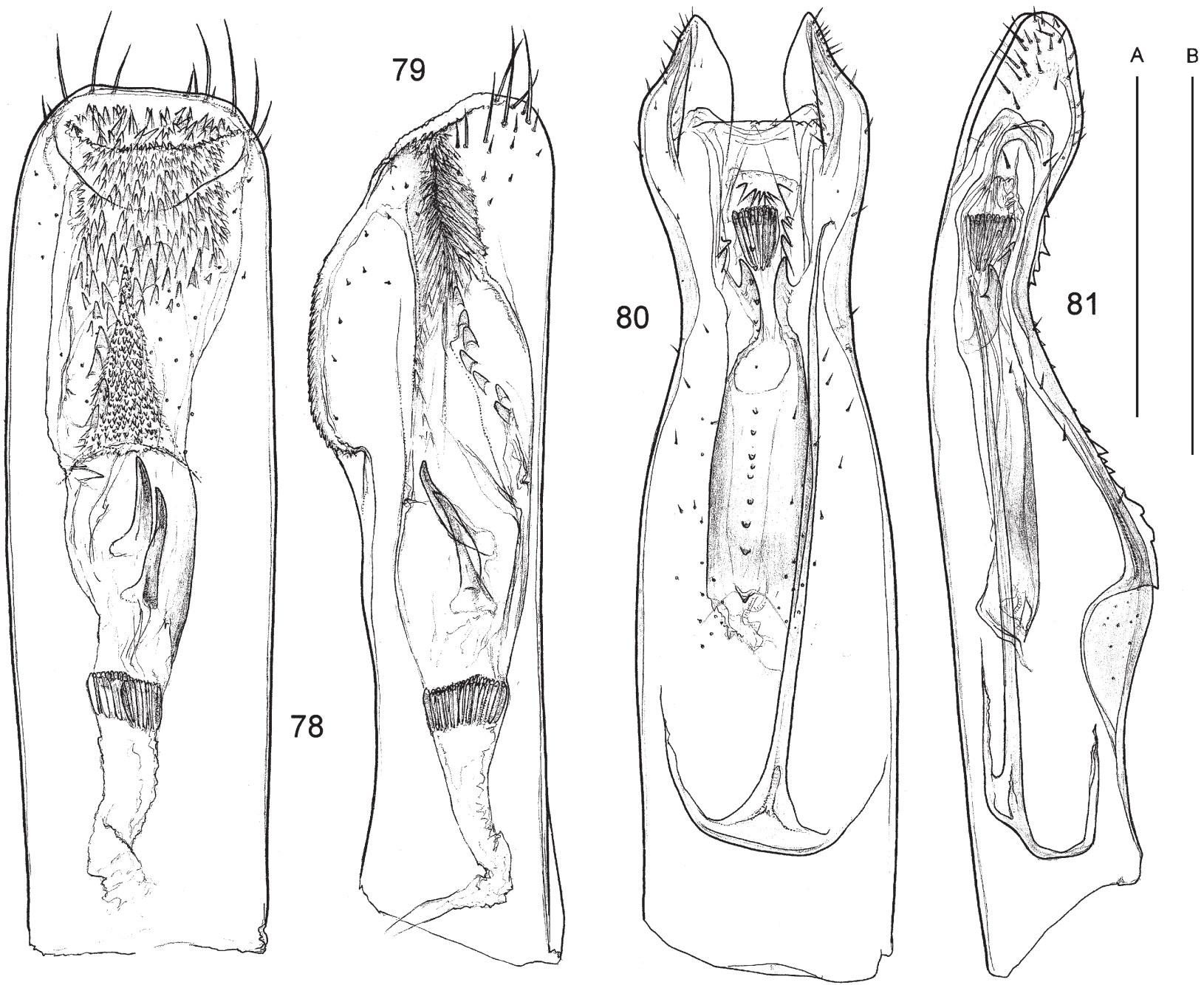

Figs 78-81. Aedeagus: 78 - Microhoria viturati (Pic, 1893) comb. nov., ventral view; 79 - same, lateral view; 80 - M. olivacea (LaFerté-Sénectère, 1849) comb. nov., ventral view; 81 - same, lateral view. Scale bars: $0.2 \mathrm{~mm}$ - A (Figs 80, 81), B (Figs $(78,79)$. 
M. subaerea (Reitter, 1890) comb. nov., M. subsericea (Pic, 1898) comb. nov., M. velox (LaFerté-Sénectère, 1849) comb. nov., and M. viturati (Pic, 1893) comb. nov.

Remarks. This species-group holds some species placed previously in Tenuicomus and Clavicomus (CHANDLER et al. 2008, as Tenuicollis and Clavicollis). They share nearly all characters of the $M$. heydeni species-group, but differ by the simple tegmen that is at most shortly bilobed at the apex.

\section{Microhoria plicatipennis species-group}

Diagnosis. Elongate species, with oval head, conspicuously setose latero-basal impressions of pronotum distinct, and elytral setation somewhat modified. Mesoventrite with partly bordered lateral margins (sulcus reduced laterally), with indication of longitudinal submedian carinae; setose fringe of mesepimera well-developed; submarginal setose impressions of metaventrite and abdominal sternum III conspicuous; all tibiae with paired terminal spurs; elytral apices in males distinctly modified, with peculiar sinuate longitudinal sulcus near middle (Fig. 148). Aedeagus (Fig. 82): tegmen capsuliform, bilobed apically; gonopore free. Distribution. Northern Africa (Morocco).

Species included (4 spp.). Microhoria apicordiger (Bonadona, 1954) comb. nov., M. kocheri (Pic, 1951) comb. nov., M. plicatipennis (Pic, 1936) comb. nov., and $M$. postimpressa (Pic, 1938) comb. nov.
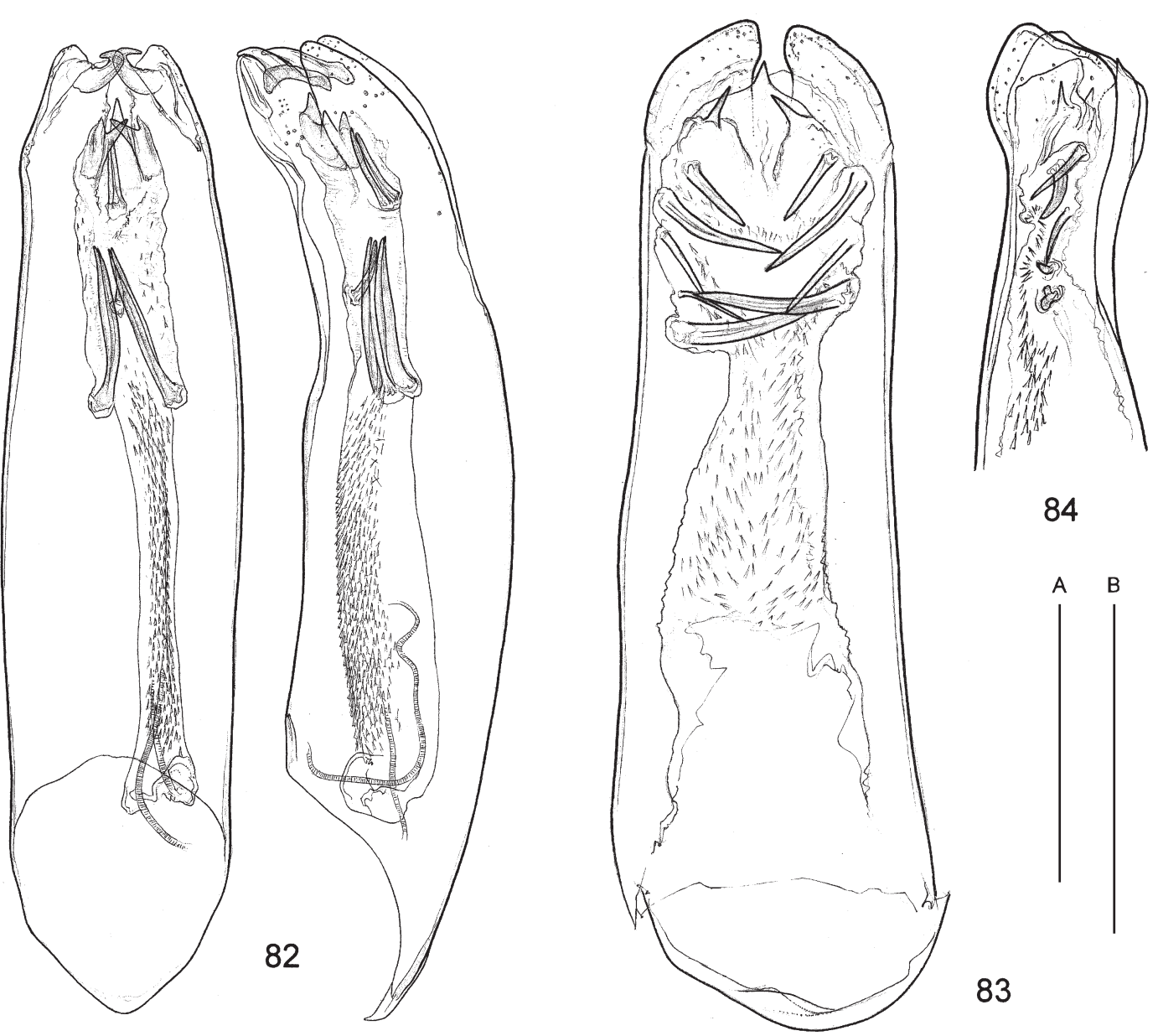

84

Diagnosis. Mostly elongate species, with distinct, conspicuously setose latero-basal impressions of pronotum, sometimes with contrasting markings on elytra (Figs 141-144). Mesoventrite with completely or partly bordered lateral margins (Figs 18, 20), mostly with distinct or at least weakly indicated longitudinal submedian carinae (Fig. 17); setose fringe of mesepimera well-developed; submarginal setose impressions of metaventrite and abdominal sternum III weakly indicated to conspicuous; all tibiae with paired terminal spurs; elytral apices in males distinctly modified, channel of gland forming sclerotized cavity (inside with pores and cuticular cones), adjacent apical margin of elytra with pointed protrusion, varying in prominence (Fig. 42). Aedeagus (Figs 83-89): tegmen capsuliform, frequently bilobed apically; gonopore free, situated basally and rather inconspicuous.

Figs 82-84. Aedeagus: 82 - Microhoria apicordiger (Bonadona, 1954) comb. nov. in ventral (left) and lateral (right) view; 83 - M. henoni (Pic, 1892) comb. nov., ventral view; 84 - same, apical part, lateral view. Scale bars: $0.2 \mathrm{~mm}$ - A (Figs 83, 84), B (Fig. 82). 
Distribution. Northern and northeastern Africa and Middle East of Asia (Iraq, Oman, SW Pakistan, Yemen).

Species included (27 spp.). Microhoria almukalla sp. nov., M. antinorii (Pic, 1894) comb. nov., M. arenaria Bonadona, 1956, M. babaulti (Pic, 1921) comb. nov., $M$. bonnairii (Fairmaire, 1883) comb. nov., M. cervi sp. nov., M. cyanipennis (Grilat, 1886) comb. nov., M. dolichocephala (Baudi di Selve, 1877) comb. nov., M. erythraea (Pic, 1899) comb. nov., M. fuscomaculata (Pic, 1893) comb. nov., M. gestroi (Pic, 1895) comb. nov., M. henoni (Pic, 1892) comb. nov., M. irregularis (Pic, 1932) comb. nov., M. lomii (Pic, 1953), M. marginicollis (Pic, 1951) comb. nov., M. mesopotamica (Pic, 1912) comb. nov., $M$. nigroterminata (Pic, 1909) comb. nov., M. paupercula (LaFerté-Sénectère, 1847) comb. nov., M. pierrei Bonadona, 1956, M. postluteofasciata (Pic, 1938) comb. nov., M. rabinovitchi (Koch, 1935), M. semiviridis (Pic, 1951) comb. nov., M. schimperi (Pic, 1898) comb. nov., M. siccensis (Normand, 1950) comb. nov., M. yemenita (Nardi, 2004) comb. nov., M. spinipennis (Pic, 1898) comb. nov., and $M$. sulaimanica sp. nov.

Remarks. The species of this group have been previously treated in various genera, mostly as Tenuicomus, but also as Clavicomus, Microhoria, and Anthicus (CHANDLER et al. 2008, the former two as Tenuicollis and Clavicollis). They are closely related to the members of $M$. fasciata species-group based on similarity, but are more elongate with more slender legs, and differ mainly by the pointed protrusion of the elytral apices in males (cf. Figs 42 versus 41) and by morphology of the tegmen, which is somewhat less sclerotized, having a bilobed or rather rounded apex.

\section{Microhoria almukalla Kejval, sp. nov.} (Fig. 86)

Type locality. Yemen, Kawr Sayban Mount, NW of Al Mukalla, $14^{\circ} 37^{\prime} \mathrm{N}$ $49^{\circ} 03^{\prime} \mathrm{E}$, alt. $575 \mathrm{~m}$.

Type material. Holotype: $\hat{\delta}$, 'S YEMEN Kawr Saybān mt. NW Al Mukāllā 575 m N14³7’ / E4903' (light) 29.III.2007 M. Rejzek [11] [p]' (NMPC).

Description. Male (holotype). Body length $2.2 \mathrm{~mm}$. Head and pronotum dark brown, elytra yellowish with vaguely outlined dark markings: brown base, transverse band at about midlength, apices, suture, and lateral margins brownish; femora brown, tibiae and tarsi yellowish-brown, antennae largely dark brown, antennomeres II-VI somewhat paler.

Head 1.1 times as long as wide, moderately widely rounded posteriorly; eyes medium-sized, convex. Surface moderately glossy, minutely and rather densely punctate; punctures distinctly spaced; setation short, subdecumbent,

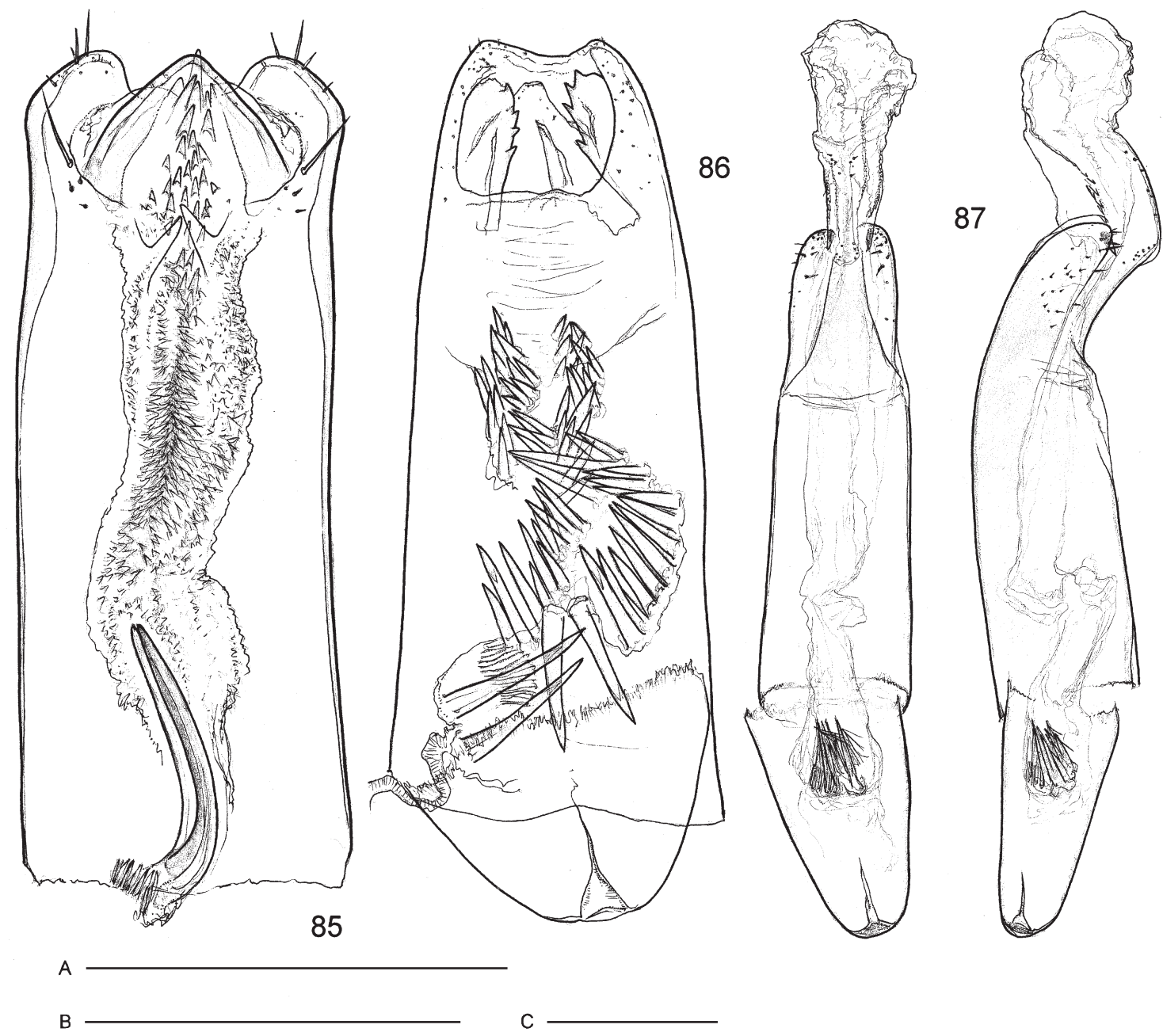

Figs 85-87. Aedeagus: 85 - Microhoria paupercula (LaFerté-Sénectère, 1849) comb. nov.; 86 - M. almukalla sp. nov., ventral view; 87 - M. schimperi (Pic, 1898) comb. nov. in ventral (left) and lateral (right) view. Scale bars: $0.2 \mathrm{~mm}$ - A (Fig. 85), B (Fig. 86), C (Fig. 87). 
with few, short erect setae. Antennae moderately enlarged in apical half; antennomeres X nearly 1.2 times, XI 2.4 times as long as wide.

Pronotum 1.1 times as long as wide, moderately narrower than head including eyes, unevenly rounded anteriorly, pronotal disc moderately convex, outline in dorsal view with lateral margins moderately impressed posteriorly. Surface moderately glossy, distinctly and densely punctate; punctation coarser, setation as on head, rather uniform, including latero-basal sides.

Elytra 1.7 times as long as wide, subparallel, slightly impressed medially in basal half; humeri distinctly protruding; apices modified, channel of gland forming minute cavity at pointed protrusion of margin. Surface at most moderately glossy, minutely and rather densely punctate; punctation and setation similar to head, with scattered short erect setae.

Legs slender, simple; all tibiae with paired terminal spurs.
Abdominal sternum VII slightly produced and rounded apically; sternum VIII forming simple, subtriangular paired sclerites, separate, moderately produced posteriorly. Aedeagus (Fig. 86): tegmen shortly tubular, with simple, rounded to moderately emarginate apex; endophallic armature with numerous robust, simple spinules.

Female. Unknown.

Differential diagnosis. Microhoria almukalla sp. nov. belongs to the $M$. schimperi species-group. It is externally very similar to $M$. cervi sp. nov. from Oman, differing by its markedly smaller eyes, more weakly defined punctation on the head, by the simple, subtriangular sclerites of male sternum VIII (strongly narrowed and elongate, sabre-like in $M$. cervi sp. nov.), and by characters of the aedeagus (cf. Figs 86 versus 88).

Etymology. Named after the type locality; noun in the nominative case, standing in apposition.

Distribution. Yemen.
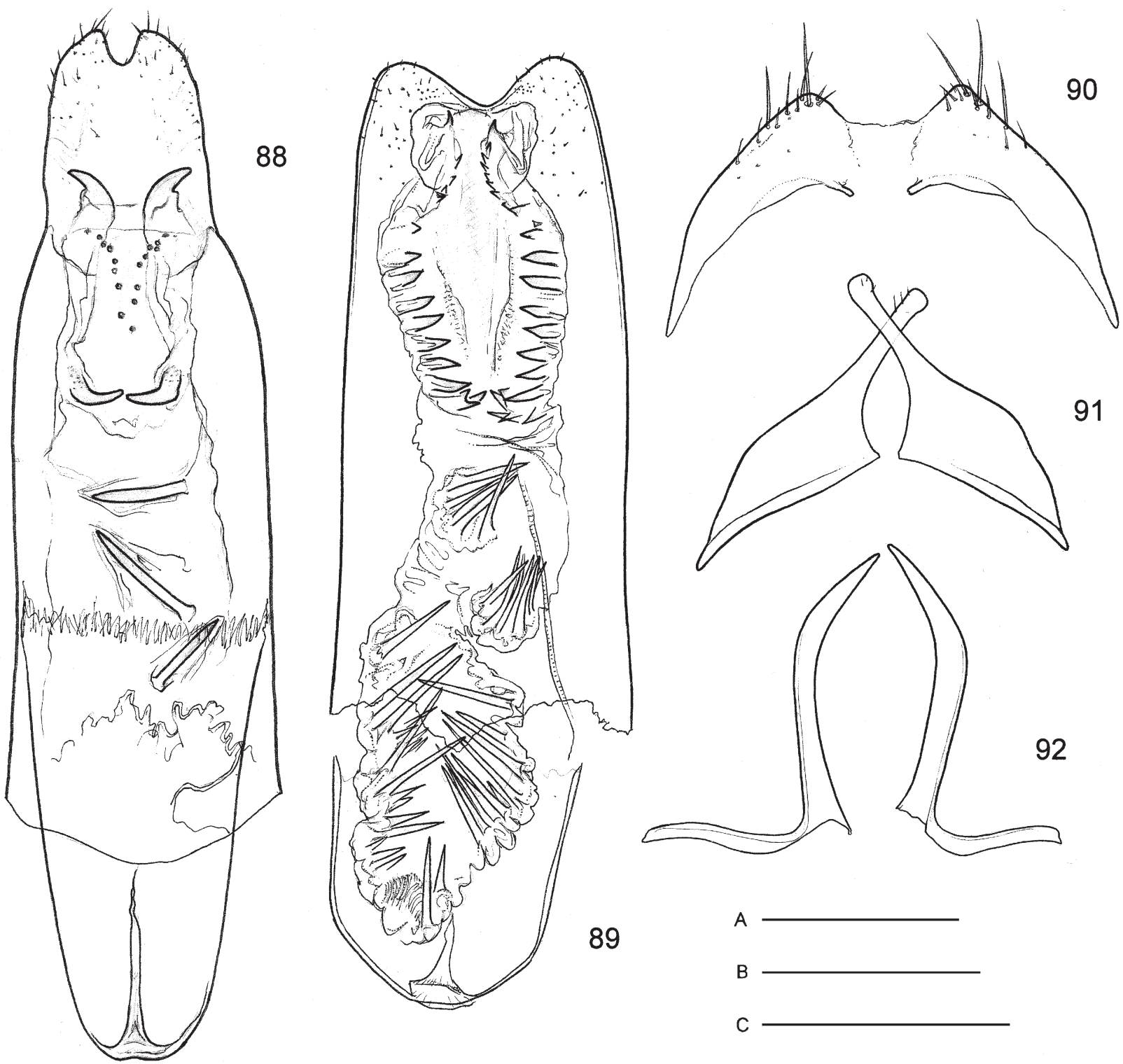

89

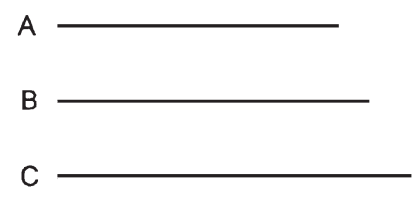

Figs 88-92. 88 - Microhoria cervi sp. nov., aedeagus in ventral view; 89 - M. sulaimanica sp. nov., aedeagus in ventral view. 90-92 - male sternum VIII: 90 - M. sawda sp. nov.; 91 - M. bacillisternum sp. nov.; 92 - M. cervi sp. nov. Scale bars: 0.2 mm - A (Fig. 92), B (Figs 89-91), C (Fig. 88). 
Microhoria cervi Kejval, sp. nov.

(Figs 6, 88, 92, 143)

Type locality. Oman, Dhofar Governorate, Taqah env., $17^{\circ} 02^{\prime} 14^{\prime \prime} \mathrm{N}$ $54^{\circ} 24^{\prime} 13^{\prime \prime} \mathrm{E}$, alt. $20-30 \mathrm{~m}$.

Type material. HoLOTYPE: $\hat{\text { of }, ~ ' O M A N ~ m e r ., ~ T A Q A H ~ e n v ., ~ c a ~ 20-30 ~ m, ~}$ 31.vii.-11.viii.1999, at light, R. Červenka leg. [p]' (NMPC). PARATYPES: $26 \hat{\partial}$, same data as holotype (ZKDC, BMNH, MZLU, NHMW, NMPC, DCDC, ZSMC); 5 วิ ${ }^{2}$, 'S - OMAN, rd. Al Mughsayl - Salalah, ca 3 km from AL MUGHSAYL, 8.-11.viii.1999, 20 m, R. Červenka lgt. [p]' (ZKDC); 2 ô, 'Oman, Dhofar Pr., Rakyut, $120 \mathrm{~km}$ E of Salalah, 9-11.IX.2007, St. Jakl leg. [p]' (ADBC); 3 ô, 'OMAN, Dhofar prov., AL MUGHSAYL, 0-20 m, viii.1999, S. Jakl lgt. [p]' (ZKDC); 39 o 'OMAN 3.9.2017 Al-Mughsayl 16 53' 00", 53 47' 42" lgt. Orszulik (KOOC, ZKDC); 10 के 20 , 'Sultanate of Oman, Dhofar prov., Wadi Al Mughsayl, 29.-31.viii.2007, J. Horák lgt. [p]' (ZKDC); 9 ô, 'Oman, Dhofar Pr, Wadi Al Mughsayi, 50 m., 29-31.VIII.2007, St. Jakl leg. [p]' (ADBC); 2 mm, 'Oman, Dhofar, 9 km WSW Al Mughsayi, 8-15. VIII.2014, S. Prepsl leg. [p]' (ADBC); 41 ô $\hat{\sigma}$, 'Sultanate of Oman, Dhofar prov., Wadi Nashib, $20 \mathrm{~km}$ E of Salalah, 16.-22.ix.2006, S. Jakl lgt. [p]' (ZKDC); 6 ô. 'Oman, Dhofar Pr, Wadi Nashib, 50m., 25-28.VIII.2007, St. Jakl leg. [p]' (ADBC); 1 , 'Oman, Dhofar Pr,Wadi Nashib, 25m., 01-02.IX.2007, St. Jakl leg. [p]'(ADBC); 37 ઈิ ô, 'Oman, Dhofar, Salalah, Wadi Darbat, 41 m., $17^{\circ} 04^{\prime} 23^{\prime \prime} \mathrm{N} 54^{\circ} 25^{\prime} 56^{\prime \prime} \mathrm{E}$, at uv light, 10.VII.2018, I. Zappi leg. [p]' (ADBC)

Description. Male (holotype). Body length $2.8 \mathrm{~mm}$. Head and pronotum dark brown, elytra yellowish to reddish, with vaguely outlined dark markings: base, transverse band at about midlength, apices and suture all brownish (Fig. 143); femora brown, tibiae and tarsi yellowish-brown, antennae reddish-brown in basal half, dark brown in apical half.

Head elongate, 1.2 times as long as wide, somewhat widely rounded posteriorly; eyes large, rather convex. Surface moderately glossy, distinctly and rather densely punctate; punctures well-spaced; setation short, subdecumbent, with scattered erect setae. Antennae slightly enlarged in apical half; antennomeres X 1.2 times, XI 2.4 times as long as wide.

Pronotum nearly as long as wide, distinctly narrower than head including eyes, evenly rounded anteriorly, pronotal disc moderately convex, outline in dorsal view with lateral margins nearly straightly narrowing posteriorly. Surface moderately glossy, minutely, densely punctate; punctation and setation as on head.

Elytra 1.8 times as long as wide; humeri distinctly protruding; omoplates slightly indicated; apices modified, channel of gland forming minute cavity at pointed protrusion of margin. Surface moderately glossy, minutely and rather densely punctate; punctation more delicate than on head, setation as on head, with scattered short erect setae.

Legs slender, simple; all tibiae with paired terminal spurs.

Abdominal sternum VII slightly produced and unevenly rounded apically; sternum VIII forming paired, slender and strongly elongate, sabre-like sclerites (Fig. 92). Aedeagus (Figs 6, 88): tegmen flatly produced and narrowly emarginate apically; endophallic armature with two pairs of robust, claw-like spines and some simple, randomly scattered spinules.

Female. Identical with male for most external characters; elytral apices simple; sternum VII simple; tergum VII simple, subtriangular, evenly rounded apically.

Variation. Body length ( $\delta \circ)$ 2.2-3.1 mm; dark markings of elytra varying in extent and prominence, some speci- mens from Wadi Al Mughsayl extremely dark, with two pairs of small yellowish spots on elytra; male abdominal sternum VII unevenly rounded to slightly emarginate apically.

Differential diagnosis. Microhoria cervi sp. nov. belongs to the M. schimperi species-group. It is externally very similar to M. almukalla sp. nov. from Yemen, differing by its markedly larger eyes, coarser punctation on the head, by the strongly narrowed and elongate sabre-like sclerites of male sternum VIII (simple, subtriangular in $M$. cervi sp. nov.), and by characters of the aedeagus (cf. Figs 88 versus 86).

Etymology. Named in honour of the late Czech entomologist Radek Červenka, nicknamed 'Červ' by friends, who collected the holotype and some of the paratypes of this species.

\section{Distribution. Oman.}

Microhoria schimperi (Pic, 1898) comb. nov. (Fig. 87)

Anthicus schimperi Pic, 1898: 70.

Anthicus schimperi: PIC (1911b): 72 (catalogue).

Anthicus (Aulacoderus) schimperi: van HiLle (1984): 60, figs 193-197 (redescription)

Type locality. Ethiopia ('Abyssinie').

Type material. Syntypes, see Remarks (MNHN).

Additional material. ETHIOPIA: $2 \hat{\jmath}$, 'MUSEUM PARIS ABYSSINIE SCHIMPER 430-50' (MNHN).

Diagnosis. Microhoria schimperi species-group; slender brownish-black species with oval head. Male sternum VII simple, slightly produced and evenly rounded apically; sternum VIII forming pair of simple, subtriangular sclerites, weakly connected medially; tergum VII simple; tergum VIII simple; aedeagus (Fig. 87).

Distribution. Ethiopia.

Remarks. PIC (1898) described Anthicus schimperi from an unstated number of specimens collected by W. Schimper in 1850 in 'Abyssinie' and deposited in MNHN. The examined specimens originate from a larger series present in a box with material collected by Schimper. These lack Pic's identification labels, but the labels bear the appropriate data and it is possible that they are syntypes, or at the least topotypes. The redescription by van HiLle (1984) was based on five 'cotypes' from MNHN, which may have originated from the same sample.

Anthicus schimperi displays all the important distinguishing characters of Microhoria, and differs from Aulacoderus in having two terminal spurs on all tibiae.

\section{Microhoria sulaimanica Kejval, sp. nov. (Figs 89, 144)}

Type locality. Pakistan, Balochistan Province, Sulaiman Mts, Zhob valley [ca. $31^{\circ} 21^{\prime} \mathrm{N} 69^{\circ} 27^{\prime} \mathrm{E}$ ], alt. $1700 \mathrm{~m}$.

Type material. Holotype: $\delta$, 'Pakistan, Sulaiman Mts, Zhob valley, $1700 \mathrm{~m}$, viii.2005 [p; no collector]' (NMPC). PARATYPes: $1 \hat{\jmath}$, same data as holotype (ZKDC); $6 \hat{\delta}$, 'UZBEKISTAN: Suzkhandaria Area, Djarkuzgen Town, 18.V.2003, leg. V. Gurko’ (ADBC, ZKDC).

Description. Male (holotype). Body length $2.8 \mathrm{~mm}$. Head largely reddish-brown, paler anteriorly, pronotum reddish, elytra yellowish with vaguely outlined dark markings: 
base, transverse band at about midlength, apices and suture brown (Fig. 144); legs reddish, antennae reddish-brown, darkened on apical third.

Head elongate, 1.3 times as long as wide, narrowed and evenly rounded posteriorly; eyes small, moderately convex. Surface glossy, minutely and rather densely punctate; punctures well-spaced; setation short, subdecumbent, with few erect setae. Antennae slightly enlarged for apical half; antennomeres X 1.4 times, XI 2.8 times as long as wide.

Pronotum 1.1 times as long as wide, as wide as head including eyes, evenly rounded anteriorly, pronotal disc moderately convex, outline in dorsal view with lateral margins narrowing and moderately impressed posteriorly. Surface glossy, densely punctate; punctation and setation of pronotal disc as on head; lateral sides along antebasal sulcus with dense fringed setation.

Elytra 1.7 times as long as wide; humeri distinctly protruding; omoplates slightly indicated; apices modified, channel of gland forming cavity at pointed protrusion of margin. Surface moderately glossy, distinctly and rather densely punctate; punctation coarser than on head, setation as on head, with scattered short erect setae.

Legs slender, simple; all tibiae with paired terminal spurs.

Abdominal sternum VII simple, evenly rounded apically; sternum VIII forming paired, subtriangular, asetose sclerites. Aedeagus (Fig. 89): tegmen shortly tubular and emarginate apically; endophallic armature with numerous spines, forming bunches and arranged in longitudinal paired rows.

Female. Unknown.

Variation. Body length (ð) 2.8-2.9 mm; the paratype with dark transverse band of elytra interrupted medially, with partly yellowish suture.

Differential diagnosis. Microhoria sulaimanica sp. nov. appears to be most similar to M. almukalla sp. nov., as suggested by similarities of the male characters, but differs as follows: body more pale coloured (largely reddish), head more produced posteriorly, pronotum minutely punctate and with conspicuous, dense, latero-basal setation (rather uniformly setose in M. almukalla sp. nov.), terminal antennomeres in males elongate, 2.8 times as long as wide (2.4 times in M. almukalla sp. nov.), endophallic armature with paired rows of robust spines (cf. Figs 89 versus 86). Etymology. Named after the Sulaiman Mountains; the name is an adjective.

Distribution. Pakistan, Uzbekistan.

Microhoria yemenita (Nardi, 2004) comb. nov.

Anthicus yemenitus Nardi, 2004: 138 (replacement name).

Anthicus (Immicrohoria) scotti Pic, 1957: 448 (junior homonym, see Remarks)

Type locality. Yemen, Jabal Jihaf, alt. $2310 \mathrm{~m}\left[13^{\circ} 45^{\prime} 38.5^{\prime \prime} \mathrm{N}\right.$ $\left.44^{\circ} 40^{\prime} 35.6^{\prime \prime} \mathrm{E}\right]$.

Type material. HolotyPE: $\bigcirc$ [lacking head], 'Type H.T. [p; round label, red circle] // W. ADEN. PROT. Jebel Jihaf, ca. 7,000 ft. 7.x.1937 [p; yellow line] // B.M.Exp. to S.W.Arabia H.Scott \& E.B.Britton B.M.1938246 [p] // AT EDGE OF CULTIVATION [p] Goudet .. [h; illegible] // Anthicus (Immicrohoria) scotti Pic: TYPE [h] // Anthicus (Immicrohoria) Scotti n sp. [h]' (BMNH).
Additional material. YEMEN: 1 'AT EDGE OF CULTIVATION [p] // W. ADEN. PROT. Jebel Jihaf, ca. 7,000 ft. 7.x.1937 [p; yellow line] // B.M.Exp. to S.W.Arabia H.Scott \& E.B.Britton B.M.1938-246 [p] // Anthicus scotti n sp [h]' (coll. Pic, MNHN).

Diagnosis. Probably Microhoria schimperi species-group; largely pale reddish species, with darker, oval head and rather convex, ovoid elytra (probably apterous or at least brachypterous). Female sternum VII simple; tergum VII simple.

\section{Distribution. Yemen.}

Remarks. PIC (1957) described Anthicus scotti from a single type specimen that lacks its head, which was confirmed by C. N. Hawkins (PIC 1957: remark on page 435). Consequently, an additional female present in MNHN does not belong to the type series, despite having identical locality data and Pic's identification label. NARDI (2004) found this name preoccupied by Anthicus tolanus var. scotti Pic, 1951, and proposed the replacement name Anthicus yemenita. He preserved its generic placement, based on examination of type material by D. Telnov (NARDi 2004).

Despite the lack of male specimens, there is no doubt about the new placement of Anthicus yemenita in Microhoria. The holotype possesses all the important characters, e.g. the arcuate lateral margins of the mesoventrite that has a distinct, nearly completely developed submarginal sulcus, submedian carinae of the mesoventrite are indicated, and the mesepimera have a distinct, longer setose fringe.

\section{Microhoria terminata species-group}

Diagnosis. Mostly smaller, weakly sclerotized species, always with uniform elytral setation (Figs 145-147, 151-155); quite variable in shape of pronotum and distinctness of its latero-basal setation (Figs 156-159). Mesoventrite with nearly completely bordered lateral margins, always lacking submedian carinae; setose fringe of mesepimera strongly reduced (Fig. 24); submarginal setose impressions of metaventrite and abdominal sternum III weakly developed (mostly indistinct); all tibiae with paired terminal spurs; elytral apices in males distinctly modified, channel of gland forming short tubular process (absent in single species, see Remarks), interior of process with long cuticular projections (Fig. 44). Aedeagus (Figs 93-122): tegmen with narrowed apex, frequently hook-like, sometimes additionally with slender conspicuous projection (Figs 94, 96, 97, and 120) that is unknown in other groups; gonopore free.

Distribution. Predominantly an eastern Mediterranean group that is most speciose in Greece and the Middle East (especially Turkey), with a few western Mediterranean species occurring in Italy, Spain, and southern France; nearly absent in North Africa except Egypt; single species known from southern part of Arabian Peninsula (M. saw$d a$ sp. nov.). Ranging as far east as Nepal and Tibet, e.g. Microhoria hingstoni (Blair, 1927).

Species included (91 spp.). Microhoria aguilari Bonadona, 1960, M. akbesiana (Pic, 1896), M. anahita sp. nov., M. angelinii (Degiovanni, 2012) comb. nov., M. angulapex Koch, 1935, M. aphaenops (Pic, 1902), M. arcuatipes (Krekich-Strassoldo, 1931), M. armeniaca (Pic, 1899) comb. 
nov., M. aspelia (Truqui, 1855), M. bacillisternum sp. nov., M. basithorax (Pic, 1941) comb. nov., M. boyadjeani (Pic, 1904), M. breviuscula (Desbrochers des Loges, 1875), M. caliginosa (LaFerté-Sénectère, 1849), M. caspia (Desbrochers des Loges, 1875), M. cerrutii Bucciarelli, 1976, M. chakouri (Pic, 1909), M. corallicollis (Reitter, 1889), M. cyrtopyga Bonadona, 1952, M. degener (Baudi di Selve, 1881), M. delagrangei (Pic, 1892), M. depressa (LaFertéSénectère, 1849) comb. nov., M. duplex (Nardi, 2004) comb. nov., M. edmondi (Pic, 1893) comb. nov., M. emaciata (Pic, 1896), M. faceta Bonadona, 1960, M. fergana sp. nov., $M$. feroni Bonadona, 1960, M. finalis (Telnov, 2003) comb. nov., M. fornicata (Krekich-Strassoldo, 1931), M. funeraria (Marseul, 1879), M. garavuti sp. nov., M. gibbipennis sp. nov., M. halophila sp. nov., M. gorgus (Truqui, 1855), $M$. hazara sp. nov., M. heracleana sp. nov., M. hindukushica Telnov, 2010, M. hingstoni, M. humerifer (Pic, 1902), M. impavida sp. nov., M. informipes (Krekich-Strassoldo, 1931), M. inobscura (Pic, 1908) stat. nov., M. ionica (Pic, 1901), M. iscariotes (LaFerté-Sénectère, 1849), M. kabulensis sp. nov., M. kaifensis (Pic, 1896), M. kermanica sp. nov., M. lafertei (Truqui, 1855), M. latipennis (Pic, 1892), M. leptostemma (Kolenati, 1846), M. leuthneri (Pic, 1897), M. lividipes (Desbrochers des Loges, 1875) comb. nov., M. loebli Uhmann, 1989, M. luristanica (Pic, 1911) comb. nov., M. miranda (Krekich-Strassoldo, 1931), M. monodi Bonadona, 1977, M. nectarina (Panzer, 1794), M. nepticula Bonadona, 1964, M. nicolasi (Pic, 1919), M. oertzeni (Pic, 1901), M. ottomana (LaFerté-Sénectère, 1849), M. ovata (Marseul, 1897), M. pahlavi sp. nov., M. palicari (Laporte, 1840), M. paralleliceps (Reitter, 1890) comb. nov., M. persica sp. nov., M. petraea (Pic, 1902), M. pinicola (Reitter, 1889), M. plagifer (Krekich-Strassoldo, 1931), M. quadraticeps (Desbrochers des Loges, 1875), M. raveli (Pic, 1899), M. rosti (Pic, 1906), M. rubriceps (Pic, 1896), M. rufescens (Pic, 1893), M. sawda sp. nov., M. schmiedeknechti (Pic, 1899), M. sidonia (Truqui, 1855), M. stettini (Pic, 1892), M. strejceki sp. nov., M. subcaerulea (Pic, 1906) comb. nov., M. sydowi (Pic, 1936), M. syrensis (Pic, 1902), M. taurica (Pic, 1904), M. tenebricosa (Pic, 1896), M. terminata (W. L. E. Schmidt, 1842), M. truncatipennis (Pic, 1897) comb. nov., M. unicolor (W. L. E. Schmidt, 1842), M. vespertina (Rosenhaur, 1856), M. viridipennis (Pic, 1899) comb. nov. and $M$. winkleri Telnov, 2004.

Remarks. This group holds all Microhoria species formerly placed in the subgenus Platyhoria and nearly all Asian Tenuicomus (CHANDLER et al. 2008, the latter as Tenuicollis). One species, $M$. cyrtopyga, lacks the tubular process of the male elytral apices, but displays a different modification - rounded subapical gibbosities. Similar gibbosities are developed in M. gibbipennis sp. nov. and are coupled with tubular projections.

PIC (1941) described Anthicus magnini var. basithorax from Crete. It was treated as Anthicus basithorax by ChandLer et al. (2004, 2008). Its new placement in Microhoria is based on examination of the syntypes of Anthicus magnini in Pic's collection (MNHN), whose original description is unknown, with this name being therefore regarded as a nomen nudum (CHANDLER et al. 2004).

\section{Microhoria anahita Kejval, sp. nov.}

(Figs 94, 146)

Type locality. Iran, Isfahan Province, $70 \mathrm{~km}$ NE of Nain, Anarak env. [33 $\left.18^{\prime} 40^{\prime \prime} \mathrm{N} 53^{\circ} 41^{\prime} 54^{\prime \prime} \mathrm{E}\right]$.

Type material. Holotype: $\delta$, 'Iran, Isfahan Prov., 70 km NE of Nain, Anarak env., 5.v.1999, K. Orszulik lgt. [p]' (NMPC). PaRATYPes: 19 ठठ 24 우, same data as holotype (ZKDC, DCDC, KOOC, MZLU, NMPC); 5 그 2 우, 'Persia: Kerman. H.E.J.Briggs. B.M.1933-246. [p]' (BMNH); 1 ' , same label, in addition: 'A. nectarinus v. atriceps Pic det. Dr. R. F. Heberdey [p+h]' (BMNH); 1 ', same label, in addition: 'nectarinus v. atriceps Pic [h]' (NHMW).

Description. Male (holotype). Body length $3.5 \mathrm{~mm}$. Head largely brownish-black, base and neck reddish, pronotum reddish, elytra largely yellowish to pale reddish, with vaguely outlined dark markings (Fig. 146); legs reddish, antennae largely reddish, terminal antennomeres darker, brownish.

Head elongate, 1.3 times as long as wide including eyes, nearly evenly rounded posteriorly; eyes mediumsized, only moderately convex. Surface glossy, minutely, moderately densely punctate; punctures distinctly spaced; setation short, subdecumbent. Antennae slightly enlarged in apical third; antennomeres X 1.4 times as long as wide, $\mathrm{XI}$ conspicuously elongate, 3.2 times as long as wide.

Pronotum 1.1 times as long as wide, somewhat unevenly rounded anteriorly, pronotal disc moderately convex, outline in dorsal view with lateral margins nearly straightly narrowing posteriorly. Surface glossy; setation and punctation as on head; latero-basal margins with some longer, more raised setae.

Elytra 1.9 times as long as wide; humeri distinctly protruding; omoplates and postbasal impression slightly indicated; apices modified, channel of gland forming short tubular process at margin. Surface moderately glossy, rather densely punctate; punctation denser and somewhat coarser than on head; setation as on head, erect tactile setae absent.

Legs slender, simple; all tibiae with paired terminal spurs.

Abdominal sternum VII slightly produced and emarginate medially; sternum VIII inconspicuous, weakly sclerotized. Aedeagus (Fig. 94): apically narrowed portion of tegmen bearing prominent median carina; endophallic armature with pair of robust, claw-like spines and apical bunch of slender spinules.

Variation. Body length ( $\delta^{\lambda}+$ ) 2.6-3.6 mm; head sometimes partly reddish anteriorly on frons; dark marking of elytra varying moderately in extent and prominence (vaguely to rather sharply outlined).

Female. Identical with male for most external characters; elytral apices simple; sternum simply rounded apically; tergum VII with shallow apical excavation.

Differential diagnosis. Microhoria anahita sp. nov. belongs to the M. terminata species-group. Externally it can be confused with $M$. strejceki sp. nov., having nearly the same body form and markings of the elytra, but differs clearly by the reddish unicolorous legs, somewhat larger eyes, more elongate and cylindrical terminal antennomeres, the shallowly excavate apex of female tergum VII (simply rounded in the latter species), and mainly by characters of 


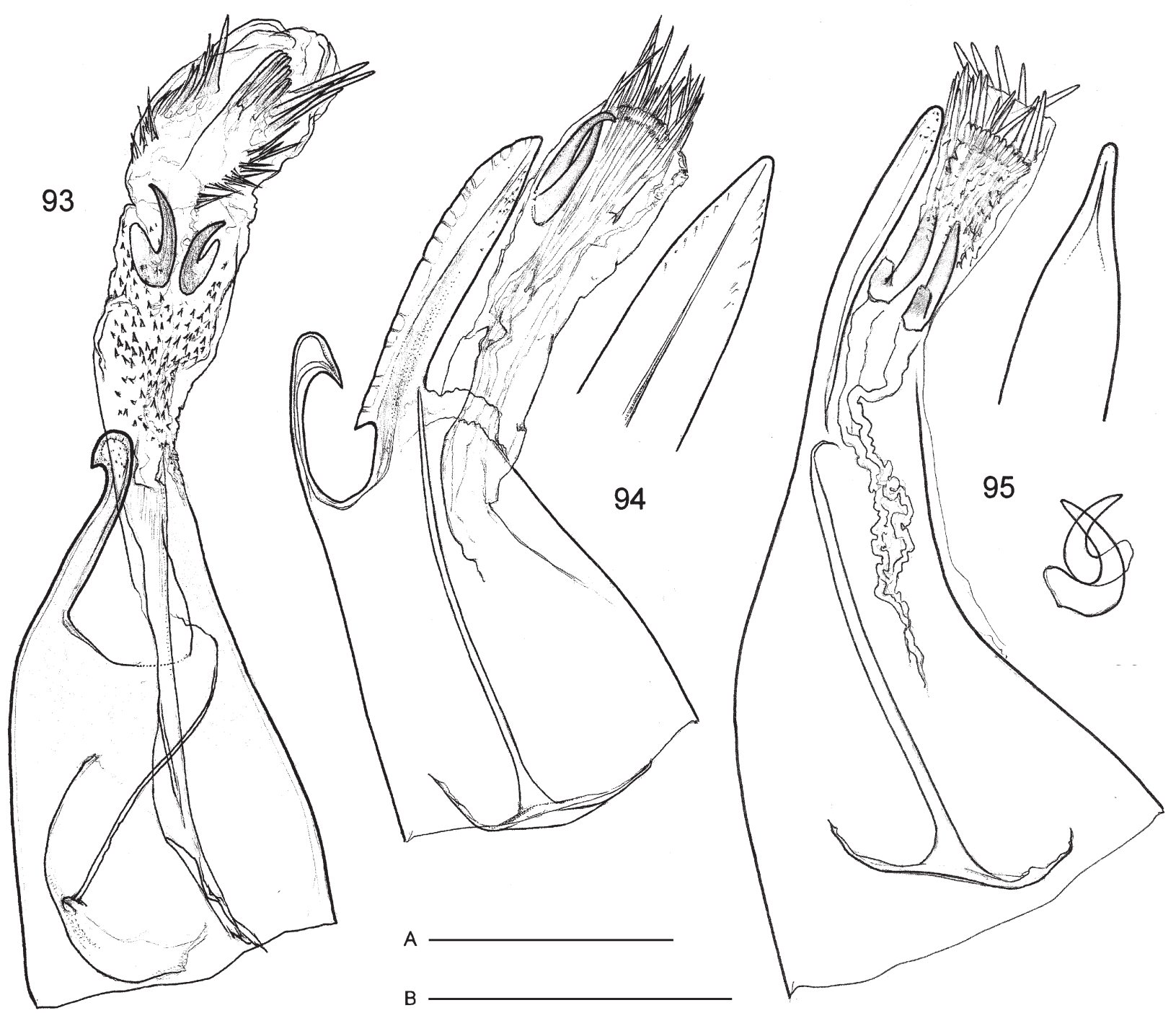

Figs 93-95. Aedeagus: 93 - Microhoria terminata (W. L. E. Schmidt, 1842), lateral view; 94 - M. anahita sp. nov., lateral view, and apex of tegmen in dorsal view; $95-$ M. bacillisternum sp. nov., lateral view, and apex of tegmen plus paired sclerites of endophallus in dorsal view. Scale bars: 0.2 mm - A (Figs 93, 94), B (Fig. 95).

the aedeagus that are quite dissimilar (cf. Figs 94 versus 121).

Etymology. Anahita is the name of the Persian goddess of fertility and water; noun in the nominative case, standing in apposition.

Distribution. Iran.

\section{Microhoria angelinii (Degiovanni, 2012) comb. nov. (Figs 147, 150, 156)}

Tenuicollis angelinii Degiovanni, 2012: 98, Figs 1-3.

Type locality. Turkey, Çankiri Province, Orta, meadows between Saçakbeli Geçidi and Ortabeli Geçidi.

Type material. HoLOTYPE: 0 , not examined (ADBC).

Additional material. TURKEY: $3 \circ \circ$, Ankara prov., Şereflikoçhisar, $25 \mathrm{~km} \mathrm{NW}$, salty shore of Tuz Gölü Lake, alt. 900 m, 1.vi.1999, S. Benedikt lgt. (ZKDC).

Remarks. This species was described from single male specimen, conspicuous in having an extremely elongate head and simple pronotum (Figs 147, 156). It is undoubtedly closely related to $M$. paralleliceps (Reitter, 1890) based on shared similarities, which is known only from its type locality (Arax River Valley) and probably occurs in northeastern Turkey. It differs from the latter species by the following major characters: head distinctly narrower, with longer, parallel tempora, and shallowly impressed mesally on dorsum (Fig. 156); male sternum VII evenly rounded (angularly produced and emarginate medially for $M$. paralleliceps); female tergum VII with deep apical notch (Fig. 150); apex of tegmen hooked (simple for $M$. paralleliceps).

\section{Microhoria bacillisternum Kejval, sp. nov.} (Figs 91, 95, 151)

Type locality. Iran, Qazvin Province, $8 \mathrm{~km}$ NE of Ziaran, $36^{\circ} 10^{\prime} \mathrm{N}$ $50^{\circ} 35^{\prime} \mathrm{E}$, alt. $2400 \mathrm{~m}$.

Type material. HоLотуPE: ^ै, 'N. Iran, $2400 \mathrm{~m} 8$ km NE Ziaran 10.16.7.1977 // Loc. no. 400 Exped. Nat. Mus. Praha // Tenuicomus luristanicus (Pic) det. G. Uhmann 1986 [p]' (NMPC). Paratypes: 1 o, same data as holotype, but lacking third label (NMPC).

Description. Male (holotype). Body length $2.6 \mathrm{~mm}$. Body dark brown, elytra unicolorous (Fig. 151; legs and antennae dark brown, tibiae and tarsi slightly paler. 
Head rather elongate, 1.4 times as long as wide, widely rounded posteriorly, tempora subparallel; eyes mediumsized, moderately convex. Surface moderately glossy, minutely but distinctly punctate and largely shagreened; punctures well-spaced; setation short, appressed to subdecumbent. Antennae moderately enlarged for apical half; antennomeres X 1.2 times, XI 2.4 times as long as wide.

Pronotum about as long as wide, slightly narrower than head including eyes, evenly rounded anteriorly, pronotal disc evenly and moderately convex, outline in dorsal view with lateral margins nearly straightly narrowing posteriorly. Surface moderately glossy, distinctly punctate and shagreened; setation and punctation as on head, with some very short erect setae.

Elytra 1.7 times as long as wide, somewhat flattened medially in basal half; humeri distinctly protruding; omoplates slightly indicated; apices modified, channel of gland forming short tubular process at margin. Surface moderately glossy, distinctly punctate; punctation and setation slightly coarser than on head, with scattered short erect setae.

Legs slender, simple; all tibiae with paired terminal spurs.

Abdominal sternum VII produced, truncate to slightly emarginate apically; sternum VIII forming paired sclerites, conspicuously, narrowly produced and rounded apically (Fig. 91). Aedeagus (Fig. 95): tegmen with simple, narrowly rounded apex; endophallic armature with pair of robust, hook-like spines and apical bunch of slender spinules.

Female. Unknown.

Variation. Head and pronotum more or less glossy, varying in distinctness of microsculpture.

Differential diagnosis. Microhoria bacillisternum sp. nov. belongs to the $M$. terminata species-group. It can be easily recognized by the combination of an elongate head and its male abdominal characters, especially by the peculiar shape of the paired sclerites of sternum VIII (Fig. 91).

Etymology. Composed from the Latin words bacillum (rod, stamen) and sternum, named in reference to the conspicuous projections of male sternum VIII. Noun in the nominative case, standing in apposition.

Distribution. Iran.

\section{Microhoria depressa (LaFerté-Sénectère, 1849) comb. nov. \\ (Figs 96, 162)}

Anthicus depressus LaFerté-Sénectère, 1849b: 156.

Anthicus depressus: LAFERTÉ-SÉnectère (1849c): 255 (repeated description); PIC (1911b): 43 (catalogue); WINKLER (1927): 845 (catalogue).

Tenuicollis depressus: CHANDLER et al. (2008): 448 (catalogue, distribution); Telnov \& GHahari (2018): 484 (note).

Anthicus mollis Desbrochers des Loges, 1875: 46, syn. nov.

Anthicus mollis: PIC (1911b): 61 (catalogue).

Anthicus (Immicrohoria) mollis: WINKLER (1927): 849 (catalogue).

Microhoria mollis: CHANDLER et al. (2008): 441 (catalogue, distribution); Telnov \& Ghahari (2018): 483 (note); Telnov (2018a): 271 (record Russia).

Type locality. Anthicus depressus - Caucasus Mountains ('Caucasus'); A. mollis - Southern Russia ('Russie mérid.').

Type material. Anthicus depressus - LECTOTYPE (herewith designated): $j$, 'Depressus mihi Caucasus. [h; pinned separately]' (MNHN).
Anthicus mollis - SyntYPES (see Remarks): 19 , 'Sarepta [h] // TYPE [p; red label]'; 1 , 'Sarepta Desbr [h] // TYPE [p; red label]' (both NHMW). Additional material. ARMENIA: 8 , 60 , Kotayk prov., $4 \mathrm{~km} \mathrm{~S}$ of Hatsavan, 23.vi.2004, Putckhov lgt. (ADBC, ZKDC); 1 , Yerevan, 17.vi.-4.vii.1988, O. Hovorka lgt. (ZKDC). AZERBAIJAN: $12 \circ \circ$, $90 \mathrm{~km} \mathrm{~N}$ of Baku, Zarat env., 15.vi.1983, V. Kubán̆ lgt. (ZKDC); 1 đ, Georgia, Tbilisi, Lisie Lake, vi.1957, Dlabola lgt. (NMPC). RUSSIA: 1 万. Volgograd ['Sarepta' no date], Becker lgt. (NHMW).

Diagnosis. Microhoria terminata species-group; small, brownish, subparallel species. Male sternum VII simple; sternum VIII forming paired subtriangular sclerites that are evenly rounded and setose apically; tergum VII and VIII simple; aedeagus (Fig. 96). Female sternum VII simple; tergum VII with deep apical notch (Fig. 162).

Variation. Body length ( $\lesssim+$ ) $2.3-2.7 \mathrm{~mm}$.

Distribution. Azerbaijan, Armenia (new record), Georgia (new record), Southern Russia, Iran.

Remarks. LAFERTÉ-SÉNECTÈRE (1849b) described Anthicus depressus from two specimens provided by M. de Chaudoir. There is a single syntype deposited in his collection (MNHN), as is indicated by the handwritten inventory on the inner side of the respective box, and is selected as the Lectotype.

Jules Desbrochers des Loges was an insect dealer whose Coleoptera collection is scattered (HoRN et al. 1990), and type specimens of his Anthicidae species are difficult to recognize. He described Anthicus mollis from an unstated number of specimens collected by Alexander Becker in southern Russia (Desbrochers Des Loges 1875). The two syntypes examined appear to be newly labelled; at least their 'TYPE' labels are not original, being identical to those used by H. von Krekich-Strassoldo. For these reasons, we refrained from designation of a lectotype. Neverthless, the specimens originate from southern Russia and agree with the original description in the following important characters: head and pronotum distinctly punctate, head widely rounded to subtruncate posteriorly, elytra flattened, their lateral margins straight and apices subtruncate, and female tergum VII deeply notched apically ('pygidium sillonné longitudinalement'). These are, moreover, distinguishing characters of $M$. mollis that are useful for separation from the externally similar M. caspia; the latter was described from material collected by A. Becker at the locality 'Sarepta' (= presently Krasnoarmeyskiy Rayon (district) of Volgograd) in the same region, and it is a well-known species, being represented by numerous topotypic specimens in MNHN (coll. Pic) and NHMW.

The examined specimens of Anthicus mollis were found to be identical with those of $A$. depressus, and consequently these species names are newly treated as synonyms.

\section{Microhoria edmondi (Pic, 1893) comb. nov. (Fig. 97)}

Anthicus Edmondi Pic, 1893: 16.

Anthicus Edmundi [sic!]: PIC (1911b): 45 (catalogue); WINKLER (1927): 844 (catalogue).

Tenuicollis edmondi: CHANDLER et al. (2008): 448 (catalogue, distribution). Anthicus spinosus Pic, 1912: 42, syn. nov.

Anthicus spinosus: WINKLER (1927): 841 (catalogue).

Omonadus spinosus: Telnov (2002): 23 (record Afghanistan); CHANDLER et al. (2008): 445 (catalogue, distribution).

Clavicollis spinosus: Telnov (2010): 9 (new combination). 
Typelocality. Anthicusedmondi-Uzbekistan, Margelan('Turkestan-Margelan'); A. spinosus - Tajikistan/Uzbekistan, GissarRange('Buchara:Hissar'). Type material. Anthicus edmondi-Lectotype (herewith designated): $\hat{\delta}$, 'Margelan Reitter [p; black frame] // type [h; yellowish label] // Edmundi Pic [h] // TYPE [p; red label]' (coll. Pic, MNHN). Paralectotypes: 3 spec., 'Margelan Reitter [p; black frame] // type [h; yellowish label]' (all coll. Pic, MNHN).

Anthicus spinosus - Lectotype (herewith designated): §, 'Hissar, Boch. Coll. Hauser. [p] // TYPE [p; red label] // spinosus Pic type [h] // coll. Heberdey [p] // spinosus Pic [h] // CLAVICOLLIS spinosus (Pic) det. D. Telnov, 2008 [p]' (NHMW).
Additional material. KIRGYZSTAN: $4 \approx 3 \propto \circ$, Osh district, 15 $\mathrm{km} \mathrm{SW}$ of Osh, $40^{\circ} 23^{\prime} \mathrm{N} 72^{\circ} 46^{\prime} \mathrm{E}$, dry steppe hill, $1150 \mathrm{~m}, 26 . \mathrm{vi} .1996$ [no collector] (ZSMC, ZKDC). TAJIKISTAN: 10 ठे 13 우, Iskanderkul Lake, 2200 m, 22.vi.2012, K. Orszulik lgt. (ZKDC); 3 ๙ 1 우, Hissar Mts, Yavroz, pr. Dushanbe, 27.vi.1983, B. Malec lgt. (ZKDC); 13 d 4 우, N of Dushanbe, Kondara-Varzob, 24.vi.1983, B. Malec lgt. (ZKDC); 2 ふ̊, Babatag Mts, 30.iv.1977, S. Bílý lgt. (NMPC). UZBEKISTAN: 1 , 'Margelan. Reitter [p]' (ZSMC); 1 , Zeravshan, Kara Tepe, 1000 m, 1.-2.vi.1959, J. Dlabola lgt. (NMPC); 5 ภे 6 우, Zeravshan Mts, $70 \mathrm{~km} \mathrm{~S}$ of Samarkand, Takhtakarach pass, $1600 \mathrm{~m}$, 30.vi.-2.vii.1983, V. Kubáň leg. (ZKDC).
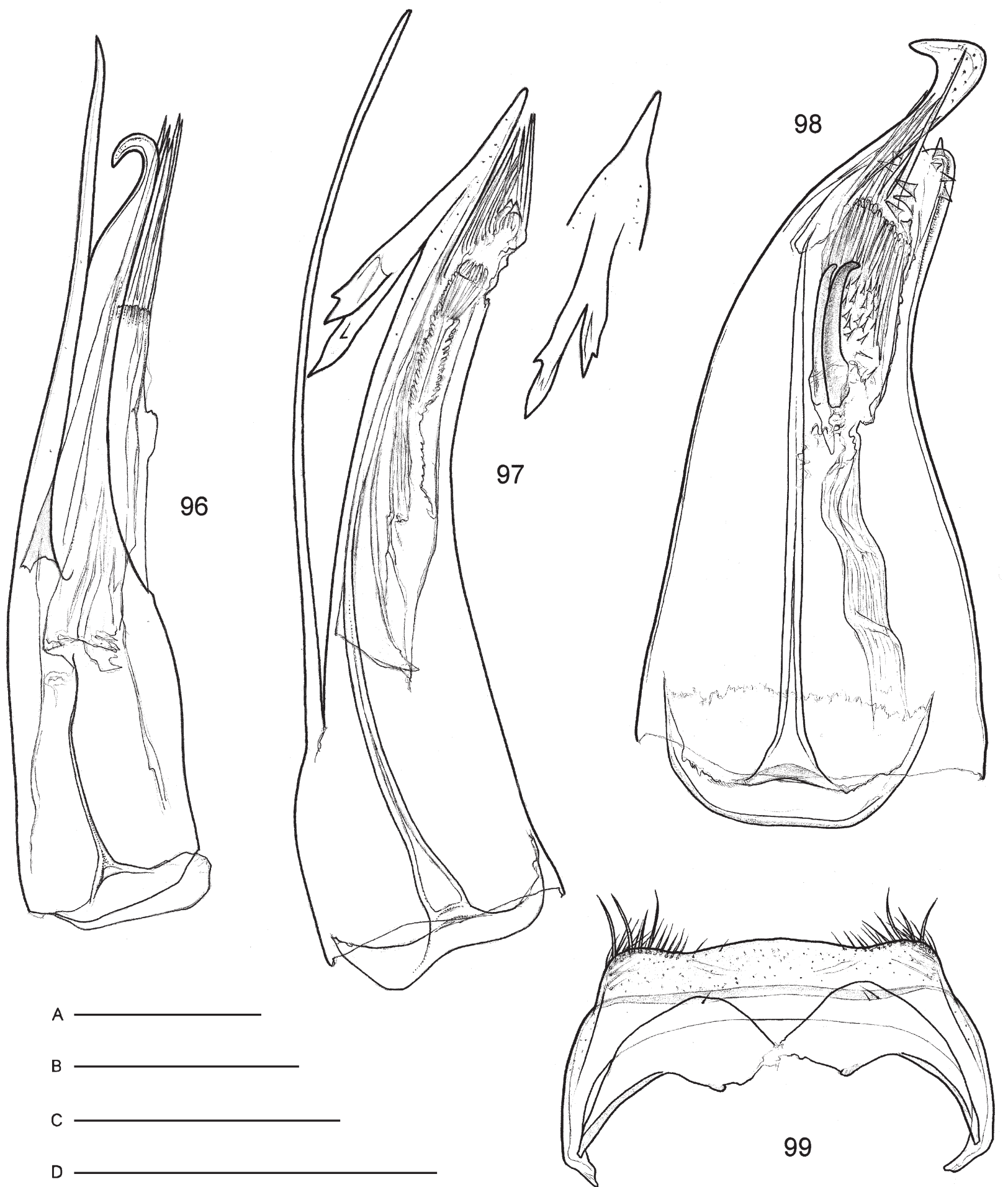

Figs 96-99. 96-98 - Aedeagus: 96 - M. depressa (LaFerté-Sénectère, 1849), Azerbaijan, Zarat (ZKDC), lateral view; 97 - M. edmondi (Pic, 1893), syntype, lateral view; 98 - M. fergana sp. nov., lateral view. 99 - M. fergana sp. nov., male abdominal segment VIII in ventral view. Scale bars: A - (Fig. 99), B (Figs 96, 97), C (Fig. 98). 
Diagnosis. Microhoria terminata species-group; small, slender species, typically brightly coloured, with paler markings on elytra. Male sternum VII moderate produced and evenly rounded apically; sternum VIII forming rounded sclerites; tergum VII and VIII simple; aedeagus (Fig. 97). Female sternum VII moderately produced and angled apically; tergum VII distinctly emarginate apically. Variation. Body length ( $\delta \circ)$ 2.2-3.1 mm. Rather variable in colouration; the specimens from Takhtakarach Pass are yellowish to reddish, with vaque brown marking on elytra; the specimens from Iskanderkul Lake and Kondara-Varzob are extremely dark, with black head, and largely brownish-black elytra (unicolorous or with subhumeral and/or subapical paler spots).

Distribution. Afghanistan, Kirgyzstan, Tajikistan, Uzbekistan.

Remarks. PIC $(1893,1912)$ described both Anthicus edmondi and $A$. spinosus from an unstated number of specimens, and gave the following depositories: $A$. edmondi - E. Reitter and M. Pic collections; A. spinosus - F. Hauser collection in NHMW. TeLnOv (2002) tentatively placed A. spinosus in Omonadus Mulsant et Rey, 1866, but after examination of the type material, he placed it in Clavicollis (Telnov 2012).

Having examined type specimens of both Anthicus edmondi and A. spinosus, plus numerous additional specimens, using male characters we found no substantial differences. Consequently, the latter species is placed as a junior synonym of $A$. edmondi, which is undoubtedly a member of the Microhoria terminata species-group since it has two terminal metatibial spurs, and shares the characteristic modification of the male elytral apices.

\section{Microhoria fergana Kejval, sp. nov. (Figs 98, 99)}

Type locality. Kyrgyzstan, Osh District, $15 \mathrm{~km} \mathrm{SW}$ of Osh, $40^{\circ} 23^{\prime} \mathrm{N}$ $72^{\circ} 46^{\prime} \mathrm{E}, 1150 \mathrm{~m}$

Type material. Hоцотуре: ô, 'Kirgisistan: Oshaskaya, Distr. Osh, trockene Steppenhügel, $15 \mathrm{~km} \mathrm{SW}$ Osh, $40^{\circ} 23^{\prime} \mathrm{N} 72^{\circ} 46^{\prime} \mathrm{E}, 1150 \mathrm{~m}$, 26.VI.1996 [p] // 96/12 [p] // Microhoria mollis (Desbrochers) det. G. Uhmann 1997 [p+h]' (ZSMC). PARATYPES: 1 \%, same data as holotype, lacking $2^{\text {nd }}$ label (ZSMC).

Description. Male (holotype). Body length $2.2 \mathrm{~mm}$. Body brown, elytra unicolorous; legs brown, tibiae moderately paler; antennae brown, slightly darker distally.

Head 1.1 times as long as wide, nearly evenly rounded posteriorly; eyes small, distinctly convex. Surface moderately glossy, minutely punctate and slightly shagreened; punctures distinctly spaced; setation short, subdecumbent, few short erect setae posteriorly. Antennae only moderately enlarged for apical third; antennomeres X 1.6 times, XI 4.0 times as long as wide.

Pronotum 1.1 times as long as wide, distinctly narrower than head including eyes, evenly rounded anteriorly, pronotal disc evenly and moderately convex, outline in dorsal view with lateral margins slightly impressed posteriorly. Surface moderately glossy, punctate, slightly shagreened; punctation and setation as on head, with some very short erect setae.
Elytra 1.6 times as long as wide, subparallel, somewhat flattened; humeri distinctly protruding; apices modified, channel of gland forming short tubular process at apical margin. Surface moderately glossy, densely punctate; punctation and setation slightly coarser than on head, with scattered short erect setae.

Legs simple; all tibiae with paired terminal spurs.

Abdominal sternum VII simple; tergum VII simple; tergum VIII with distinct, laterally angled flange posteriorly (Fig. 99); sternum VIII forming paired subtriangular sclerites that are rounded apically. Aedeagus (Fig. 98): tegmen narrowed apically, distinctly hooked in lateral view; endophallic armature with pair of short, robust, moderately curved sclerites and numerous slender spines.

Female. Identical with male for most external characters; elytral apices simple; sternum VII simple; tergum VII simple, evenly rounded apically.

Differential diagnosis. Microhoria fergana sp. nov. belongs to the $M$. terminata species-group. It may resemble M. nicolasi from Turkmenistan ('Transcaspia'), but differs by the widely flanged and somewhat sinuous posterior margin of male tergum VII, and by characters of the aedeagus (more slender and simply hooked apex of tegmen, numerous slender spinules in endophallus).

Etymology. Named after the Fergana valley in Kyrgyzstan; noun in the nominative case, standing in apposition.

Distribution. Kyrgyzstan.

\section{Microhoria garavuti Kejval, sp. nov.}

(Figs 5, 100, 152)

Type locality. Tajikistan, Aruk-Tau Mts, Garavuti.

Type material. НоLотуре: đิ, 'USSR Tadžikistan Aruk-Tau 20.4.78 / Garavuti/ Sv. Bílý lgt. [p]' (NMPC). ParatyPes: $2 \hat{\partial} \hat{\partial}$, same data as holotype (NMPC); $7 \hat{\jmath}$, 'USSR-Tadžikistan 21.4.1978 Aruk-Tau (cca 600 m) Gara-Vuti env. (pr. Šaartuz) J. Strejček lgt. [p]’ (ZKDC).

Description. Male (holotype). Body length $3.6 \mathrm{~mm}$. Body brown, with slight greenish reflection, elytra unicolorous (Fig. 152); femora brownish, tibiae and tarsi yellowish-brown, antennae reddish-brown, terminal antennomeres darker.

Head elongate, 1.3 times as long as wide, somewhat widely rounded posteriorly; eyes medium-sized, moderately convex. Surface moderately glossy, minutely but distinctly punctate and slightly shagreened; punctures distinctly spaced; setation short, subdecumbent. Antennae moderately enlarged for apical third; antennomeres X 1.2 times, XI 2.5 times as long as wide.

Pronotum 1.1 times as long as wide, slightly narrower than head including eyes, evenly rounded anteriorly, pronotal disc evenly and moderately convex, outline in dorsal view with lateral margins nearly straightly narrowing posteriorly. Surface moderately glossy, punctate, slightly shagreened; punctation and setation as on head, with some very short erect setae.

Elytra 1.8 times as long as wide, subparallel, somewhat flattened medially in basal half; humeri distinctly protruding; apices modified, somewhat bulging, channel of gland forming short tubular process. Surface moderately glossy, densely punctate; punctation and setation slightly coarser than on head, with scattered short erect setae. 
Legs simple; all tibiae with paired terminal spurs.

Abdominal sternum VII slightly produced and subtruncate apically; sternum VIII forming paired subtriangular sclerites, rounded and distinctly setose apically. Aedeagus (Figs 5, 100): tegmen strongly elongate and with widened, triangular apex; endophallus armature with a pair of long slender, apically pointed sclerites.

Female. Unknown.
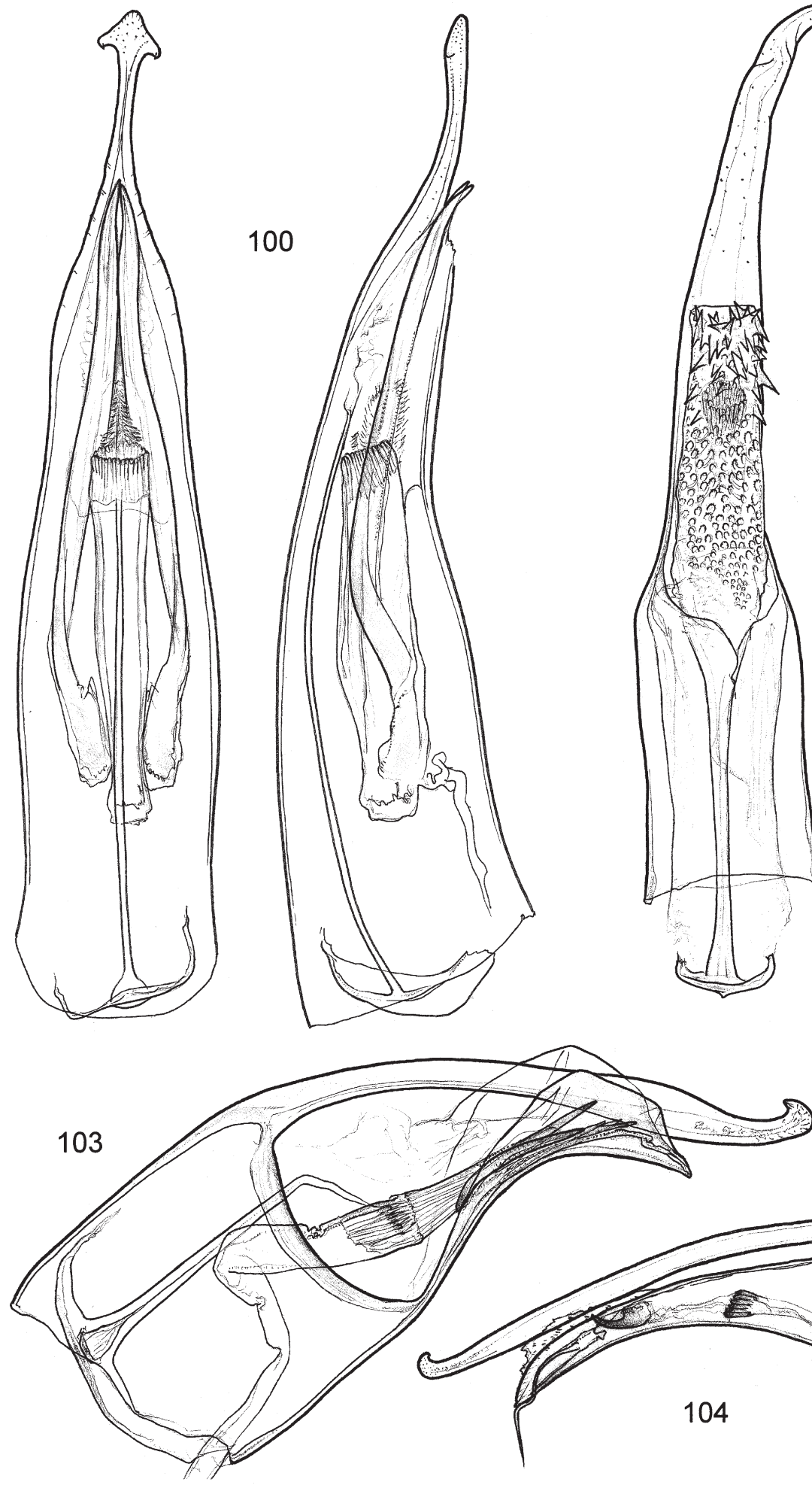

Variation. Body length ( $\left.{ }^{1}\right)$ 3.2-3.6 mm; body brown to brownish-black, antennae may be largely dark brown; surface microsculpture varying in prominence.

Differential diagnosis. Microhoria garavuti sp. nov. belongs to the $M$. terminata species-group. It displays nearly the same body shape and a similar apex of the tegmen as does the sympatric $M$. strejceki sp. nov., but differs by the generally darker colouration (unicolorous elytra), more
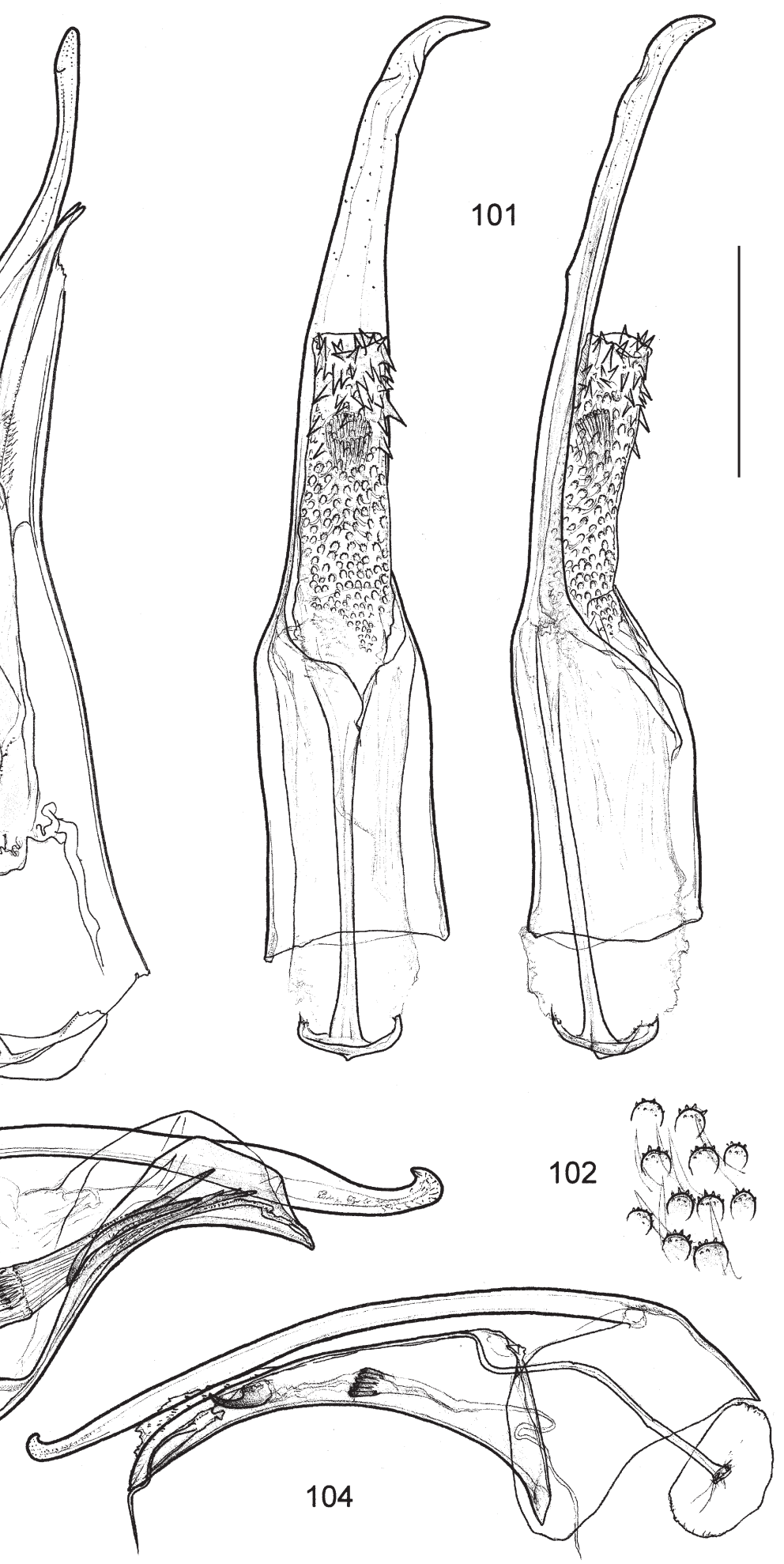

Figs 100-104. 100 - Microhoria garavuti sp. nov., aedeagus in ventral (left) and lateral (right) view; 101 - M. hazara sp. nov., aedeagus in ventral (left) and lateral (right) view; 102 - same, detail of structure of endophallus; 103 - M. halophila sp. nov. aedeagus in lateral view; 104 - M. gibbipennis sp. nov., aedeagus in lateral view. Scale bar: $0.2 \mathrm{~mm}$ (except 102). 
elongate apical part of the tegmen, and by the armature of endophallus (conspicuous paired sclerites, lack of apical bunch of spinules, cf. Figs 100 versus 121).

Etymology. Named after the type locality; noun in the nominative case, standing in apposition.

Distribution. Tajikistan.

Microhoria gibbipennis Kejval, sp. nov. (Figs 104, 149, 153, 158, 163)

Type locality. Turkey, NW of Silifke, Göksu River Canyon. Type material. Holotype: ¿̊, 'Turkey SC, NW of Silifke, Göksu Canyon, 25.iv.2015, M. Snížek lgt. [p]' (NMPC). PARATYPES: 1 + same data as holotype (ZKDC).

Description. Male (holotype). Body length $2.6 \mathrm{~mm}$. Body brownish-black, base of pronotum paler, reddish, elytra unicolorous (Fig. 153); legs dark brown; antennae reddish in basal half, gradually darkening to brownish-black in apical half.

Head 1.2 times as long as wide, evenly rounded posteriorly; eyes small, moderately convex. Surface slightly glossy, densely punctate and shagreened; punctures narrowly but distinctly spaced; setation short, subdecumbent. Antennae comparatively robust, slightly enlarged in apical third; antennomeres X about as long as wide, XI 2.3 times as long as wide.

Pronotum 1.2 times as long as wide, distinctly narrower than head including eyes, narrowly rounded anteriorly, slightly angled laterally at widest point and strongly narrowed posteriorly in dorsal view (Fig. 158), pronotal disc rather convex. Surface moderately glossy, minutely punctate and very slightly shagreened; setation as on head.

Elytra 1.4 times as long as wide, convex, widely rounded to subtruncate posteriorly; humeri absent; apices conspicuously modified, with prominent, rounded subapical gibbosity, channel of gland forming short tubular process (Fig. 149). Surface moderately glossy, densely punctate; punctation shallower than on head; setation short, subdecumbent.

Legs simple; all tibiae with paired terminal spurs.

Abdominal sternum VII with distinct apical notch; sternum VIII forming paired subtriangular sclerites that are rather rounded posteriorly. Aedeagus (Fig. 104): apical portion of tegmen slender, with moderately hooked apex; endophallic armature with pair of short, basally widened, hook-like spines and some long, delicate, sinuous spinules.

Female. Identical with male for most external characters; elytral apices simple; sternum VII simple; tergum VII subtriangular, with conspicuous apical notch/cavity, notch with serrate inner margins (Fig. 163).

Variation. Body length ( $\delta+0)$ 2.6-2.9 mm.

Differential diagnosis. Microhoria gibbipennis sp. nov. belongs to the $M$. terminata species-group. Externally it resembles $M$. taurica and $M$. inobscura, but differs by the wider, evenly rounded head base, and by the presence of subapical gibbosities of the male elytra. The male abdominal characters and the aedeagus seem to be more similar to that of $M$. inobscura in having a simply emarginate/notched sternum VII and a sinuous shape of the tegmen, but differs by the armature of endophallus, which is comprised of minute paired hook-like sclerites and rather long delicate spines.
Females can be easily distinguished by the conspicuous apical cavity of tergum VII (simple in M. inobscura).

Etymology. Composed from the Latin gibber (gibbous) and penna (wing); referring to the prominent subapical gibbosities of the elytra in males; adjective.

Distribution. Turkey.

\section{Microhoria halophila Kejval, sp. nov.} (Fig. 103)

Type locality. Turkey, NW of Tuz Gölu Lake, Kulu env.

Type material. Holotype: $\partial \hat{\sigma}$, 'TURKEY centr., Tuz Gölu, Kulu,

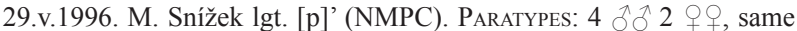
data as holotype (ZKDC); 1 đ’, 'TURKEY centr., Kulu env., 14.v.2002, J. Hlásek lgt. [p]' (ZKDC).

Description. Male (holotype). Body length $3.1 \mathrm{~mm}$. Body black, basal margin of pronotum and elytra with brownish tinge; legs dark brown, tibiae paler, reddish-brown; antennae black, unicolorous.

Head 1.2 times as long as wide, widely rounded posteriorly; eyes small, moderately convex. Surface moderately glossy, distinctly and rather densely punctate; punctures distinctly spaced; setation short, subdecumbent. Antennae slightly enlarged for apical third; antennomeres X 1.1 times, XI 2.5 times as long as wide.

Pronotum 1.1 times as long as wide, robust, slightly narrower than head including eyes, evenly rounded anteriorly, pronotal disc evenly convex, outline in dorsal view with lateral margins moderately impressed posteriorly. Surface moderately glossy, distinctly punctate; punctation and setation as on head (punctures at most slightly denser).

Elytra 1.6 times as long as wide, moderately convex, subtruncate posteriorly; humeri absent; apices modified, channel of gland forming short tubular process at apical margin. Surface moderately glossy, densely punctate; punctation shallower than on head; setation short, subdecumbent; with scattered short, suberect tactile setae.

Legs simple; all tibiae with paired terminal spurs.

Abdominal sternum VII simple or at most very slightly emarginate medially; sternum VIII forming paired subtriangular sclerites that are rather rounded posteriorly. Aedeagus (Fig. 103): narrow apical portion of tegmen moderately widened subapically and hooked apically; endophallic armature with two robust and about ten slender, simple, moderately long, straight spines.

Female. Identical with male for most external characters; elytral apices simple; sternum VII distinctly emarginate apically; tergum VII truncate apically.

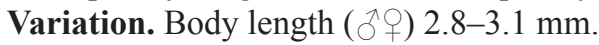

Differential diagnosis. Microhoria halophila sp. nov. belongs to the M. terminata species-group. It can be distinguished from all apterous/brachypterous species distributed in Anatolia by its robust appearance, dark colouration (entirely unicolorous black), and rather coarse punctation. Its aedeagus resembles that of M. inobscura stat. nov. (see Figs 103, 109), but the apical hook of the tegmen is more prominent and the endophallic armature is quite different.

Etymology. From the Latin halophila (halophilous); referring to its distribution near Tuz Gölu Salt Lake; adjective.

Distribution. Turkey. 
Microhoria hazara Kejval, sp. nov.

(Figs 101, 102)

Type locality. Afghanistan, $170 \mathrm{~km} \mathrm{~W}$ of Kabul, Rabodou. Type material. Holoty 2 , 'Afghanistan K. Lindberg [p] // Rabodou 170 km W Kaboul No A 1100. 23.7.1962. [p] // Microhoria nepticula Bonadona det. G. Uhmann 1984 [p+h]' (ZSMC). Paratypes: 2 q same data as holotype (MZLU); $2 \hat{\partial} \partial$, 'Afghanistan K. Lindberg [p] // Mandigak 200 km W Kaboul No A 1101. 23.7.1962. [p] // Microhoria nepticula Bonadona det. G. Uhmann 1984 [p+h]' (MZLU, ZKDC).

Description. Male (holotype). Body length $3.3 \mathrm{~mm}$. Head black, pronotum reddish; elytra yellowish, with brownish base, transverse band at midlength, with apical spot (band connected with basal spot along lateral margins); abdomen largely dark, terminal segments VII, VIII yellowish; legs brownish, tibiae paler; antennae brownish, darkened over apical third.

Head elongate, 1.1 times as long as wide, nearly evenly rounded posteriorly; eyes small, moderately convex. Surface moderately glossy, rather distinctly and densely punctate, slightly shagreened anteriorly; punctures narrowly but distinctly spaced; setation short, subdecumbent. Antennae moderately enlarged for apical third; antennomeres X 1.25 times, XI 2.4 times as long as wide.

Pronotum 1.2 times as long as wide, moderately narrower than head including eyes, evenly rounded anteriorly, pronotal disc moderately convex, outline in dorsal view with lateral margins moderately impressed posteriorly. Surface moderately glossy, distinctly punctate; punctation and setation as on head, punctures slightly shallower.

Elytra 1.7 times as long as wide, moderately widening posteriorly, somewhat flattened medially in basal half; humeri distinctly protruding; apices modified, channel of gland forming short tubular process at apical margin. Surface moderately glossy, densely punctate; punctation shallower than on head; setation short, subdecumbent, with scattered short erect setae.

Legs simple; all tibiae with paired terminal spurs.

Abdominal sternum VII moderately produced and evenly rounded apically; sternum VIII forming paired subtriangular sclerites, bearing several longer setae apically. Aedeagus (Figs 101, 102): tegmen with narrow apical portion strongly elongate, asymmetrically curved and somewhat uneven; endophallic armature with numerous tooth-like spines and peculiar spinulose scales (Fig. 102).

Female. Identical with male for most external characters; elytral apices simple; sternum VII simple; tergum VII subtruncate apically.

Variation. Body length (jo) 2.8-3.6 mm.

Differential diagnosis. Microhoria hazara sp. nov. belongs to the $M$. terminata species-group. It differs from all Central Asian species that have patterned elytra by the strongly elongate and simple apical part of the tegmen, and the minute sclerotized structures of the endophallus (lacking larger longitudinal sclerites).

Etymology. Named after the Hazara tribe, whose members inhabit central Afghanistan (westwards from Kabul); noun in the nominative case, standing in apposition.

Distribution. Afghanistan.
Microhoria heracleana Kejval, sp. nov.

(Figs 105-107, 154)

Type locality. Greece, Crete, Heraklion Prefecture, NE of Matala,

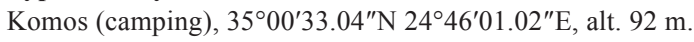

Type material. HоLотур: ${ }^{7}$ ' GREECE, Crete Iraklion Pref. Komos (camping) NE Matala, 12.v.2005; 92 m N 350033.04 E 02446 01.02; P. Chvojka leg. [p]' (NMPC). PARATYPEs: 1 , same data as holotype (NMPC); 5 के 3 우, 'CRETE m., 30.iv.2013 Kalamaki env., sandy coast, $0 \mathrm{~m}$ a.s.1., S. Benedikt lgt. [p]' (ZKDC, SBPC); 3 के 5 q 'GRECIA, Creta Sud, Kalamaki, VII.2013, leg. A. Fancello' (ADBC); $3 \lesssim 1$, 'Greece-Crete Agios Pavlos 23.5.2007 lgt. O. Konvička [p]'

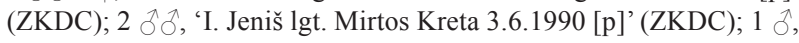
'Graecia-Creta M y r t o s 2.-4.vi.1990 ing. Kudrna lgt. [p]' (ZKDC); 1 , 'CRETE: 12.6.1992 MATALA Iraklio pref. J. Batelka lgt. [p]' (ZKDC); 2 q9, ‘Creta Biró [p] // Herakleion 1906.VI. [p/h]’ (NHMW);

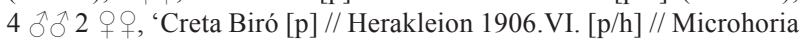
nectarina (Panz.) det. G. Uhmann 1983 [p/h]' (HNHM, DCDC); 1 , same data, except: 'Herakleion 1906. IV. [p]' (HNHM); 1 \%, 'Kreta, Iraklion, 2.8.58 Eckerlein leg. [p]' (NHMW); 1 đे, 'Kreta, Tympaki, 29.-31.7.58, Eckerlein lgt.' (NHMW); 1 †, 'Gazi, Creta Mařan et Štěp. 1934. Coll. Bartoň [p]' (NMPC); 1 đ, 'Kreta [h] // Microhoria nectarina (Panz.) det. G. Uhmann 1983 [p/h]' (HNHM); $2 \hat{\jmath}$, 'GRC, CRETE N, $4 \mathrm{~km}$ W Heraklion, Stomio, pláž $35^{\circ} 20^{\prime} 18^{\prime \prime} \mathrm{N}, 25^{\circ} 04^{\prime} 15^{\prime \prime} \mathrm{E}, 23$.VI.2016 leg. David Frank [p; pláž = beach]' (ZKDC, DFPC). $2 \lambda 1$ \% 'CRETA: Vai (spiaggia) 03.VII.2010 (su fiori di Timo) leg. M. Romano’ (ADBC).

Description. Male (holotype). Body length $4.0 \mathrm{~mm}$. Head brownish-black, mouthparts dark reddish; pronotum dark reddish, somewhat darkened antero-laterally; elytra yellowish, with extensive brownish-black markings (Fig. 154); legs and antennae reddish, distal antennomeres somewhat darker.

Head 1.3 times as long as wide including eyes, moderately widely rounded posteriorly in dorsal view; tempora slightly narrowing posteriorly, posterior temporal angles indistinct. Eyes large, moderately convex. Surface glossy, distinctly punctate; punctures distinctly separate. Setation short, appressed to subdecumbent, with few short erect setae. Antennae only moderately enlarged over distal half; antennomeres X 1.2 times, XI nearly 2.4 times as long as wide.

Pronotum 1.1 times as long as wide, slightly narrower than head including eyes, nearly evenly rounded anteriorly, narrowed and slightly impressed postero-laterally in dorsal view; pronotal disc evenly and moderately convex. Surface glossy, distinctly punctate, similar to those on head. Setation as on head, with scattered, short erect setae, and some longer setae laterally at base.

Elytra 1.7 times as long as wide; humeri well-developed, postbasal impression indistinct; apices modified, channel of gland forming short tubular process at apical margin. Surface moderately glossy, densely punctate; punctation as on head, setation similar, subdecumbent, with sparsely scattered, short erect setae.

Legs simple.

Abdominal sternum VII simple. Tergum VII simple. Sternum VIII forming paired sclerites that are simply rounded postero-medially; tergum VIII simple. Aedeagus (Figs 105-107): tegmen strongly hook-like and curved apically; endophallic armature with two pairs of robust spines (shorter curved, and longer straight).

Female. Identical with male for most external characters; elytral apices simple; sternum VII simple; tergum VII 
subtriangular, shallowly excavate apically.

Variation. Body length $(\hat{\delta}+)$ 3.8-4.5 mm; head 1.3-1.4 times as long as wide.

Differential diagnosis. Microhoria heracleana sp. nov. belongs to the M. terminata species-group. It is undoubtedly very close to $M$. nectarina, differing by its more elongate head, and mainly by the narrow and strongly hooked apical part of the tegmen. For a habitus figure and male characters of the latter species see KEJVAL (2018).

Etymology. Named after Heracles, a divine hero in Greek mythology; adjective.

Distribution. Greece (Crete).

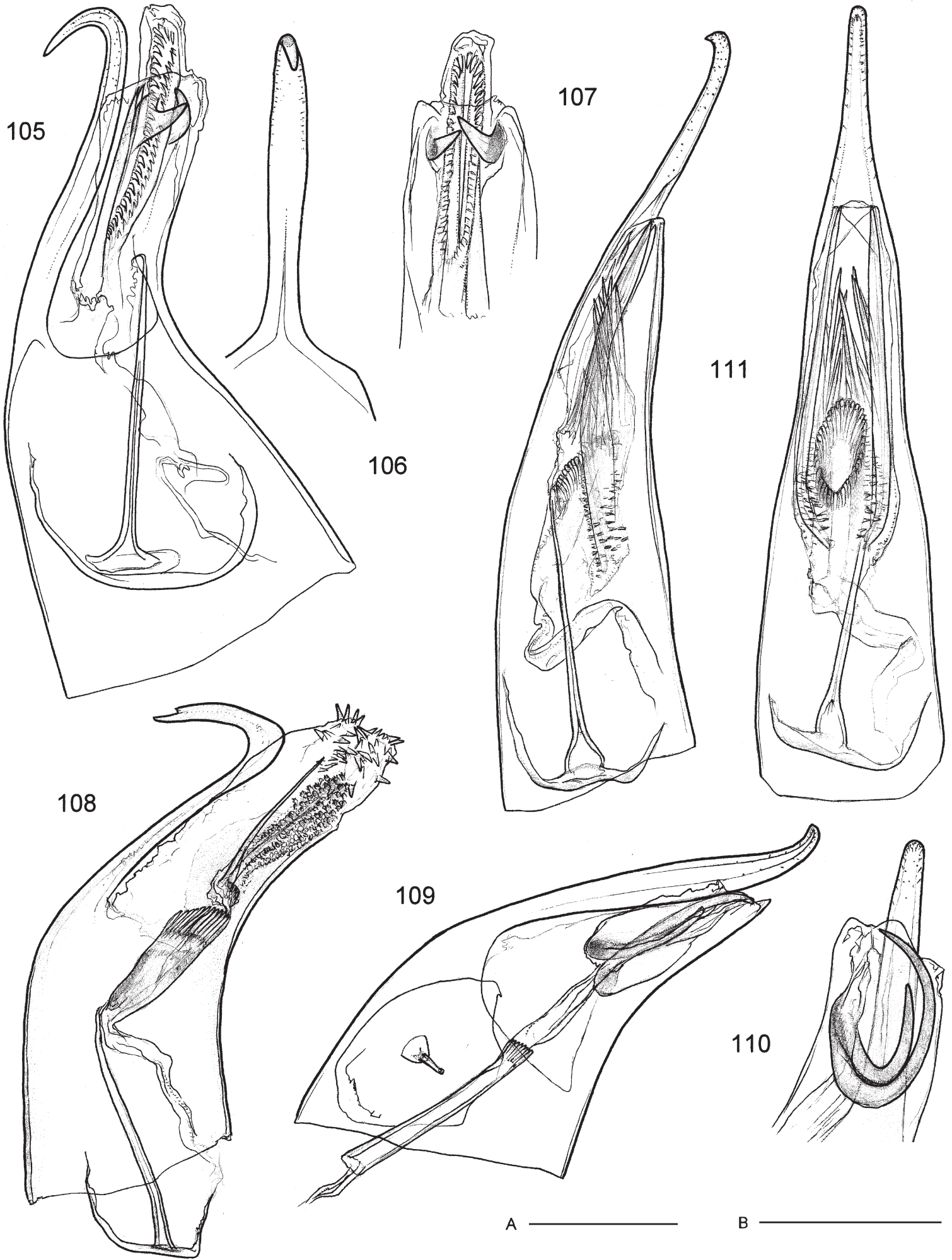

Figs 105-111. 105 - Microhoria heracleana sp. nov., aedeagus in lateral view; 106 - same, apex of tegmen in dorsal view; 107 - same, apex of everted endophallus, ventral view; 108 - M. impavida sp. nov., aedeagus in lateral view; $109-$ M. inobscura (Pic, 1908), stat nov., aedeagus in lateral view; 110 - same, apical part in ventral view; 111 - M. kabulensis sp. nov., aedeagus in lateral (left) and ventral (right) view. Scale bars: 0.2 mm - A (Fig. 111), B (Figs 105-109). 


\section{Microhoria impavida Kejval, sp. nov. (Fig. 108)}

Type locality. Turkey, Balıkesir Province, Susurluk env.

Type material. HоLотуре: đ̊, 'TURKEY occ., Susurluk env., 27.v.1996, P. Kresl lgt. [p]' (NMPC). Paratypes: $1 \delta 6 \% \circ$, same data as holotype (ZKDC).

Description. Male (holotype). Body length $2.5 \mathrm{~mm}$. Head and pronotum black, elytra brownish-black; legs brown, tibiae slightly paler; antennae brownish-black.

Head 1.2 times as long as wide, widely rounded posteriorly; eyes small, only moderately convex. Surface glossy, densely, rather coarsely punctatate; punctures distinctly spaced; setation short, subdecumbent. Antennae slightly enlarged for apical third; antennomeres X 1.1 times, XI 2.4 times as long as wide.

Pronotum 1.1 times as long as wide, narrower than head including eyes, rounded anteriorly, distinctly narrowed posteriorly in dorsal view. Surface of disc glossy, distinctly punctate, punctures similar to those on head; setation as on head, ratther evenly spaced and short.

Elytra 1.7 times as long as wide, subparallel, rounded apically; humeri well-developed; apices modified, channel of gland forming short tubular process at apical margin. Surface moderately glossy, densely punctate; punctures more delicate than those on head, distinctly spaced; setation as on head, short, subdecumbent.

Legs simple, only metatibia slightly narrowed in terminal part (impressed subapically on outer side); all tibiae with paired terminal spurs.

Abdominal sternum VII shallowly emarginate apically; sternum VIII forming paired subtriangular sclerites. Aedeagus (Fig. 108): apical portion of tegmen slender, conspicuously hooked, with slight subapical tooth; endophallic armature with pair of longer straight spinules, numerous small, tooth-like spinules, and spinulose scales (similar to those in Fig. 102).

Female. Identical with male for most external characters; elytral apices simple; sternum VII simple; tergum VII subtriangular, with shallow apical excavation.

Variation. Body length ( $\left.\delta_{+}+\right)_{\text {) }} 2.5-3.0 \mathrm{~mm}$.

Differential diagnosis. Microhoria impavida sp. nov. belongs to the $M$. terminata species-group. Externally it slightly resembles $M$. halophila sp. nov., but differs by the more slender body, prominent elytral humeri, the excavate apex of female tergum VII, and by characters of aedeagus, which is substantially different both in shape of the tegmen and structure of the endophallus (cf. Figs 108 versus 103). Etymology. From the Latin impavidus (intrepid); named in reference to the shape of the tegmen, which is armed with robust hook; adjective.

Distribution. Turkey.

Microhoria inobscura (Pic, 1908) stat. and comb. nov. (Figs 109, 110)

Anthicus tauricus var. inobscura Pic, 1908: 66.

Anthicus tauricus var. inobscurus: PIC (1911b): 76 (catalogue, distribution).

Anthicus tauricus a. inobscurus: WINKLER (1927): 849 (catalogue).

Type locality. Turkey, Taurus Mts, Saimbeyli env. (see Remarks).
Type material. SynTyPEs: $3 \curvearrowright 1 \%$, 'Hadjin Dagh taurus (1908) [h] // type $[\mathrm{h}] / /$ tauricus v. inobscura Pic [h]' (coll. Pic, MNHN).

Additional material. TURKEY: Mersin province: $13 \delta \hat{\delta} 2$ q $q$, Arslanköy, 1650-1700 m, 22.-23.v.2005, K. Orszulik lgt. (ZKDC); 25 oิ 2 우, same data, except: Z. Malinka lgt. (ZKDC); 1 , Camliyaya, 29.vi.-3.vii.1997, F. Kantner lgt. (ZKDC); 2 ổ, Erdemli, $25 \mathrm{~km} \mathrm{NW}, 900$

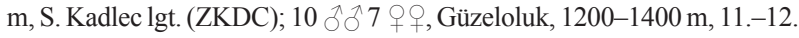
vi.1996, M. Knížek lgt. (ZKDC); 8 $\delta 7$ 9 , same data, except: P. Zahradník lgt. (ZKDC); 1 §ૈ, Namrun, 1200 m, 30.v.-10.vi.1968, C. Holzschuh lgt. (ZKDC); 1 o, same locality, 7.-13.vii.1992, D. Hauck lgt. (ZKDC).

Diagnosis. Microhoria terminata species-group; minute, apterous, at least partly reddish species. Male sternum VII moderately emarginate apically; sternum VIII forming paired subtriangular sclerites that are rounded apically, narrowly touching/connected medially; tergum VII and VIII simple. Aedeagus (Figs 109, 110): apical portion of tegmen moderately widened and curved, endophallic armature with pair of long and strongly curved, comparatively robust spines. Female sternum VII simple; tergum VII simple.

Variation. Body length $\left(j+\delta^{\prime}\right)$ 1.9-2.5 mm. Body mostly with reddish pronotum and darker, brownish to brownish-black head and elytra; sometimes largely reddish coloured. Distribution. Turkey.

Remarks. PIC (1904, 1908) described both Anthicus tauricus and A. tauricus v. nov. inobscura from the Taurus Mountains in Turkey; the former species was described from a single specimen, the latter from an unstated number of specimens ('plusieurs examplaires'). The latter taxon was treated as an aberration by WinKLER (1927), and thus placed as synonym of Microhoria taurica in the last Palaearctic catalogue (CHANDler et al. 2008). However, they are here treated as separate species. Based on photographs provided by D. Telnov, the holotype of $M$. taurica differs as follows: male sternite VII rather deeply emarginate apically, with lateral sides of emargination moderately lobed, apical portion of tegmen straight, slender; paired endophallic spines minute, shaped similarly to those in Fig. 104.

The syntypes of $M$. inobscura bear the locality data 'Hadjin Dagh', but there is no Mount Hadjin in the Taurus Mountains. The word 'Hadjin' refers most probably to the mountains around Saimbeyli village (formerly Hadjin) in Adana Province (A. Ö. Koçak, pers. comm.).

\section{Microhoria kabulensis Kejval, sp. nov. (Fig. 111)}

Type locality. Afghanistan, Kabul env., alt. 1740 m. Type material. Ноцотүре: 'ै, 'J. Klapperich Umgeb. v. Kabul 1740 m, 14.5.52 O. Afghanistan [p]' (NMPC).

Description. Male (holotype). Body length $4.2 \mathrm{~mm}$. Head black, pronotum dark reddish, elytra yellowish, with brownish-black base, apex and larger paired spots at about midlength; abdomen dark brown with distinctly paler, yellowish terminal segments VII and VIII; antennae and legs reddish.

Head rather wide, at most 1.2 times as long as wide, unevenly rounded posteriorly; eyes small, moderately convex. Surface moderately glossy, distinctly punctate; punctures distinctly spaced; setation short, subdecumbent. Antennae moderately enlarged in apical half; antennomeres X 1.1 times, XI 2.8 times as long as wide. 
Pronotum about as long as wide, as wide as head including eyes, somewhat widely rounded anteriorly, pronotal disc evenly and moderately convex, outline in dorsal view with lateral margins nearly straightly narrowing posteriorly. Surface moderately glossy; punctation and setation as on head, with few short and inconspicuous erect setae.

Elytra 1.7 times as long as wide, somewhat flattened medially in basal half; humeri distinctly protruding; apices modified, channel of gland forming short tubular process at apical margin. Surface moderately glossy; punctation somewhat weaker, setation slightly longer than on head, with scattered short erect setae.

Legs slender, simple; all tibiae with paired terminal spurs.

Abdominal sternum VII simple, at most slightly produced and rounded apically; sternum VIII forming paired, subtriangular sclerites that are narrowly connected medially, moderately angled and setose apically; tergum VII simple; tergum VIII simple. Aedeagus (Fig. 111): tegmen strongly elongate, narrowed, and distinctly hooked apically; endophallic armature with pair of long, slender sclerites and numerous shorter, more delicate spines.

Female. Unknown.

Differential diagnosis. Microhoria kabulensis sp. nov. belongs to the $M$. terminata species-group. Among the species with elytral colour patterns, it resembles especially $M$. nepticula from Afghanistan by the wider head and simple tegmen. However, the apical portion of the tegmen is markedly more elongate and slender, having a clearly hooked apex (the tegmen is wider, somewhat sinuously narrowing, and simply rounded apically in M. nepticula, see Bonadona (1964: Figs 9, 10)). Additionally, M. nepticula also exhibits a rather distinctly produced and nearly truncate apex of male sternum VII.

Etymology. Named after the type locality; adjective. Distribution. Afghanistan.

\section{Microhoria kermanica Kejval, sp. nov.} (Figs 112, 115)

Type locality. Iran, Kerman Province, Kuh-e Lalehzar, plateau in north region, vicinity of Lalehzar village, $29^{\circ} 31^{\prime} \mathrm{N} 56^{\circ} 51^{\prime} \mathrm{E}$, alt. $2800-3100 \mathrm{~m}$. Type material. HоLотуре: đo, 'C. Iran, 2800 m Lalehzar 24-30.5.1977 [p] // Loc. no. 347 Exped. Nat. Mus. Praha [p]' (NMPC). Paratypes: 2 $\delta 2$ 웅, 'IRAN prov. Kerman Sarbizhan 5.5.2010 $140 \mathrm{~km}$ S Kerman lgt. Orszulik $2700 \mathrm{~m}$ [p]’ (ZKDC).

Description. Male (holotype). Body length $2.6 \mathrm{~mm}$. Body black, elytra with slight brownish tinge posteriorly; femora brownish-black, tibiae and base of tarsi reddish-brown to yellowish, antennae black, basal five antennomeres with brownish tinge.

Head round in shape, 1.1 times as long as wide, somewhat widely rounded posteriorly (posterior angles indistinct); eyes small, moderately convex. Surface moderately glossy, minutely punctate; punctures distinctly spaced; setation short, subdecumbent. Antennae moderately enlarged in apical half; antennomeres $\mathrm{X}$ at most 1.1 times, $\mathrm{XI}$ about 2.3 times as long as wide.

Pronotum as long as wide, moderately narrower than head including eyes, evenly rounded anteriorly, pronotal disc moderately convex, outline in dorsal view with lateral margins slightly narrowing posteriorly. Surface moderately glossy, minutely punctate; punctation and setation as on head, with few very short erect setae.

Elytra 1.7 times as long as wide, subparallel, somewhat impressed medially in basal half; humeri distinctly protruding; apices modified, channel of gland forming short tubular process. Surface moderately glossy, distinctly and densely punctate; punctation somewhat denser and setation as on head, with scattered, inconspicuous, short erect setae.

Legs slender, simple; all tibiae with paired terminal spurs.

Abdominal sternum VII simple; sternum VIII forming paired, subtriangular sclerites that are rounded and setose posteriorly; tergum VII and VIII simple. Aedeagus (Figs $112,115)$; apical portion of tegmen very long and slender, slightly sinuous and with hooked apex; endophallic armature with pair of hook-like spines that are widened basally, and bunch of delicate spinules.

Female. Identical with male for most external characters; elytral apices simple; sternum and tergum VII simple. Variation. Body length $(\hat{\delta}+)$ ) 2.6-3.0 mm; paratypes with darker, brownish tibiae and tarsi.

Differential diagnosis. Microhoria kermanica sp. nov. belongs to the $M$. terminata species-group. It seem to be close to $M$. bacillisternum sp. nov., as suggested by the similar structure of the endophallus, but differs by its wider head, simple sclerites of male sternum VIII, and the hooked apex of the tegmen (cf. Figs 112 versus 95).

Etymology. Named after the Kerman Province of Iran, site of the type locality; adjective.

Distribution. Iran.

\section{Microhoria lividipes (Desbrochers des Loges, 1875) comb. nov.}

Anthicus lividipes Desbrochers des Loges, 1875: 47.

Anthicus lividipes: PIC (1911b): 58 (catalogue); BaUdi di Selve (1877): 707 (record Syria, diagnosis); WINKLER (1927): 848 (catalogue); Krekich-Strassoldo (1929): 164 (note); Uhmann et al. (2005): 37 (distribution, record Lebanon); CHANDLER et al. (2008): 427 (catalogue, distribution).

Type locality. Syria ('Syrie’).

Type material. SyNTYPE: 9 , 'Syrie [p] // 83Db [p] // type [h; yellowish label] // TYPE [p; red label] // lividipes Desb. Typiq. [h; bluish label]' (coll. Pic, MNHN).

Distribution. Lebanon, Syria.

Remarks. Desbrochers des Loges (1875) described Anthicus lividipes from an unstated number of specimens originating from Syria. It has been grouped with Microhoria species several times, especially by KREKICH-STRASSOLDO (1929), but never formally placed in this genus. Its generic identity is confirmed herein by examination of the type specimen.

Microhoria luristanica (Pic, 1911) comb. nov. (Fig. 113)

Anthicus luristanicus Pic, 1911a: 97.

Anthicus luristanicus: PIC (1911b): 59 (catalogue); WINKLER (1927): 845 (catalogue).

Tenuicomus luristanicus: UhMANN (1985): 198 (record Iran).

Tenuicollis luristanicus: CHANDlER et al. (2008): 448 (catalogue, distribution); Telnov \& GHAHARI (2018): 484 (note).

Anthicus Pietschmi Pic, 1938: 11, syn. nov. 
Tenuicollis pietschmi: CHANDLER et al. (2008): 448 (catalogue, distribution).

Type locality. Anthicus luristanicus - Iran, Luristan ('Perse: Luristan'); A. pietschmi - Iraq ('Mesopotamia').

Type material. Anthicus luristanicus - LECTOTYPE (herewith designated): $\hat{O}$, 'v. Bodemeyer Persien Luristan [p] // type [h; yellowish label] // TYPE [p; red label] // Anthicus pres ottomanus Laf. [h] // luristanicus Pic [h]' (MNHN).

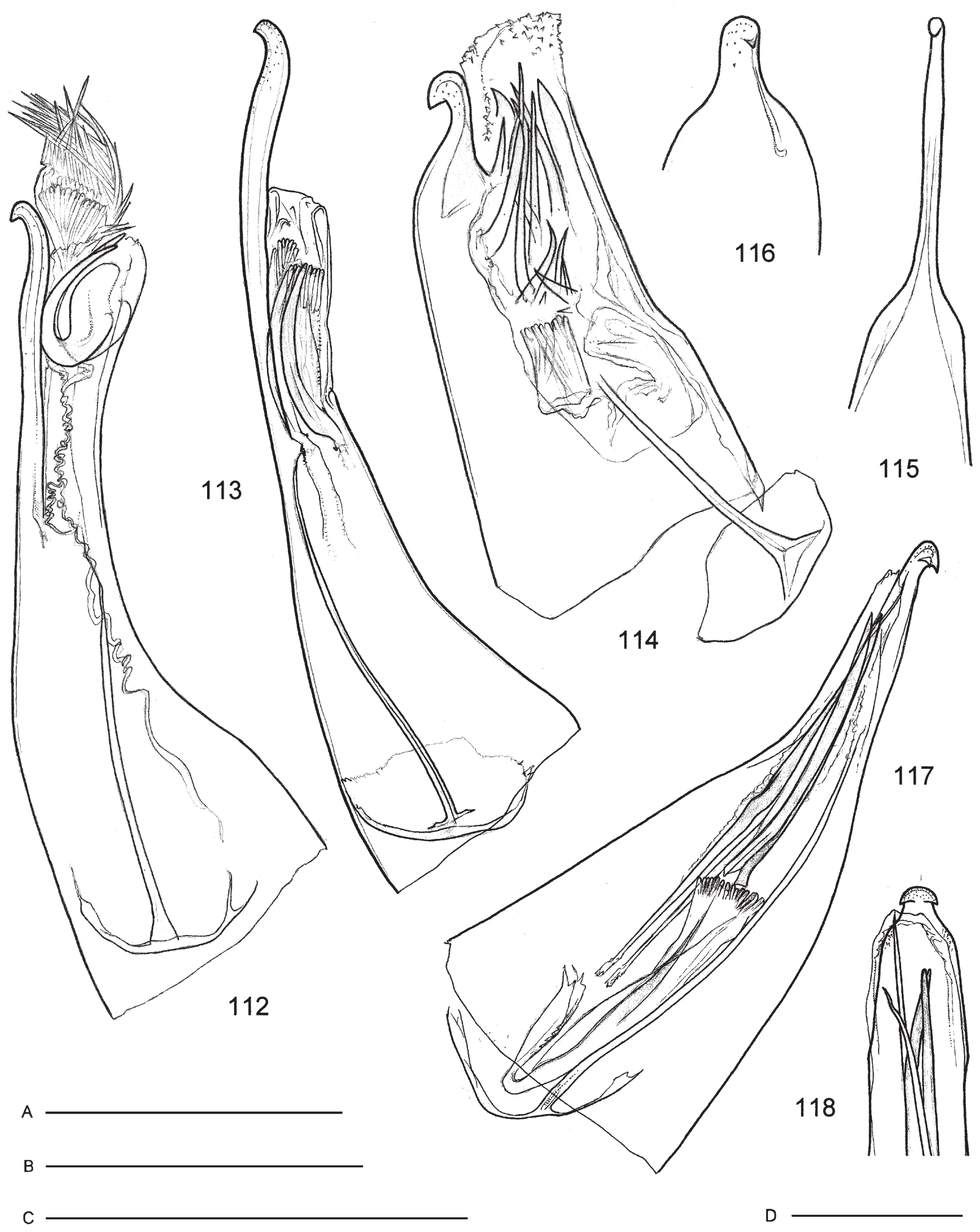

$$
\text { A }
$$

B

$$
\text { C }
$$

Figs 112-118. 112 - Microhoria kermanica sp. nov., aedeagus in lateral view; 113 - M. luristanica (Pic, 1911) comb. nov., Iran, Andimeshk, aedeagus in lateral view (ZKDC); 114 - M. ottomana (LaFerté-Sénectère, 1849) comb. nov., holotype, aedeagus in lateral view; 115 - M. kermanica sp. nov., apex of tegmen, dorsal view; 116 - M. ottomana, apex of tegmen, dorsal view; $117-M$. pahlavi sp. nov., aedeagus in lateral view; 118 - same, apical portion in ventral view. Scale bars: $0.2 \mathrm{~mm}$ - (Figs 112, 115), B (Figs 114, 116), C (Fig. 113), D (Figs 117, 118).
Anthicus pietschmi-LectotyPE (herewith designated): + , 'Mesopot ... Pietschm [partly illegible] // type [h; yellowish label] // TYPE [p; red label] // Pietschmi n sp [h]' (MNHN).

Additional material. IRAN: $12 \hat{\delta} 49+q$, Lorestan prov., $28 \mathrm{~km}$ NNW of Andimeshk, Hoseiniyeh, Bala Rud valley, 32 $41^{\prime} \mathrm{N} 48^{\circ} 16^{\prime} \mathrm{E}, 360 \mathrm{~m}$, 12.-13.iv.1977, Exped. lgt. (NMPC, ZKDC); 1 đ, Esfahan prov., Organ, $32^{\circ} 46^{\prime} \mathrm{N} 50^{\circ} 27^{\prime} \mathrm{E}$, Zayandeh-Rud river banks, $2000 \mathrm{~m}$, 1.vii.1990, Exped lgt. (NMPC); $2 \overbrace{}^{\prime}$, Khuzestan prov., Ahwaz, $31^{\circ} 19^{\prime} \mathrm{N} 48^{\circ} 41^{\prime} \mathrm{E}, 14.1 \mathrm{iv} .1977$, 
Exped. lgt. (NMPC); 1 , Khuzestan prov., Shushtar, Karun river env., $32^{\circ} 03^{\prime} \mathrm{N} 48^{\circ} 51^{\prime} \mathrm{E}$, 13.iv.1977, Exped. lgt. (NMPC); 5 ơ ${ }^{\prime}$, Khorasan prov., Kuh-e-Binalud, Mashad env. Bozgan, 17.v.2003, K. Orszulik lgt. (ZKDC); 3 o 3 , Khorasan prov., $80 \mathrm{~km}$ SW Sarakhs, Mazdavand, $800 \mathrm{~m}, 24 .-25$. iv.2006, A. Klimenko lgt. (ADBC); 1 9, Lorestan prov., Dorud env., 2.-3. vi.2005, P. Průdek lgt. (ZKDC); 3 d 1 , Golhak, near Teheran, $1400 \mathrm{~m}$, iii.-v.1961, J. Klapperich lgt. (DCDC, ZKDC). IRAQ: 95 spec., Bagdad [no date, ca. 1925-1932], V. Kálalová lgt. (NMPC, ZKDC). TURKEY: , Bitlis, Baykan, 10.v.1984, Wellschmied lgt. (ZKDC); 2 우, Urfa prov., Halfeti, 21.v.1993, V. Švihla lgt. (ZKDC); 1 , Adiyaman vill., Nemrud Dagi, Karadut env., 3.-4.v.2000, J. Mertik lgt. (ZKDC).

Diagnosis. Microhoria terminata species-group; black, elongate species, with simple pronotum. Male sternum VII slightly produced and subtruncate; sternum VIII forming paired subtriangular sclerites that are rounded apically, narrowly touching/connected medially; tergum VII and VIII simple; aedeagus (Fig. 113). Female sternum VII simple; tergum VII simple.

Variation. Body length $\left(\jmath^{\top}+\right)$ 2.2-2.8 mm.

Distribution. Iran, Iraq, and Turkey.

Remarks. Pic (1911a, 1938) described Anthicus luristanicus from Iran and A. pietschmi from Iraq; both descriptions are based on an unstated number of specimens that were provided by B. von Bodemeyer (former species) and V. Pietschmann (latter species). For A pietschmi a single female syntype was found in the Pic Collection and was thus available for study; however, its identity was resolved based on additional similar specimens collected in Iraq. The males examined are in our opinion identical, and $A$. pietschmi is thus newly placed as a junior synonym of the former species.

\section{Microhoria ottomana (LaFerté-Sénectère, 1849) comb. nov. \\ (Figs 114, 116)}

Anthicus ottomanus LaFerté-Sénectère, 1849b: 155.

Anthicus ottomanus: LAFERTÉ-SÉNECTÈre (1849c): 254 (repeated description); PIC (1911b): 65 (catalogue); WINKLER (1927): 845 (catalogue). Tenuicomus ottomanus: Uhmann (1985): 198 (record Turkey).

Tenuicollis ottomanus: CHANDLER et al. (2008): 448 (catalogue, distribution).

Anthicus Merkli Pic, 1897b: 295, syn. nov.

Anthicus Merkli: PIC (1911b): 61 (catalogue); WINKLER (1927): 845 (catalogue)

Tenuicollis merkli: CHANDLER et al. (2008): 448 (catalogue, distribution).

Type locality. Anthicus ottomanus - Turkey ('Asia-Minor'); A. merkli - Turkey.

Type material. Anthicus ottomanus - Ноцотуре: đ), 'friwal 1846 [h] // ottomanus Mihi [h]' (coll. LaFerté-Sénectère, MNHN).

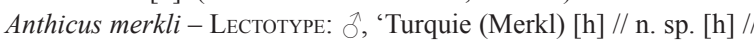
type [h; yellowish label] // A. Merkli Pic [h] // TYPE [p; red label]' (coll. Pic, MNHN). Paralectotype: 1 spec., 'Turquie (Merkl) [h] // type [h; yellowish label]' (coll. Pic, MNHN).

Additional material. TURKEY: 2 , Ankara, v.1937, Vasvári lgt. (DCDC); 1 spec., Ankara prov., Tuz Gölu Lake, $30 \mathrm{~km} \mathrm{~N}$ of Seriflikoçhisar, 1.vi.1999, S. Kadlec lgt. (ZKDC); 4 spec., Ankara prov., Tuz Gölu Lake, 25 km NW of Seriflikoçhisar, salty shore, 900 m, 1.vi.1999, S. Benedikt lgt. (ZKDC); 15 spec., Antalya prov., Elmali env., Avlanbeli Geçidi Pass, 800-1600 m, 14.-17.vi.1996, M. Knížek lgt. (ZKDC); 2 spec., $20 \mathrm{~km} \mathrm{~S}$ of Elmali, 15.-16.vi.1996, Z. Malinka lgt. (ZKDC); 1 spec., Bingöl prov., Bingöl, 1125 m, Kadlec \& Voř́ŕšek lgt. (ZKDC); 1 spec., Burdur prov., Bucak, 16.vi.1996, Z. Malinka lgt. (ZKDC); 1 spec., Burdur prov., $20 \mathrm{~km} \mathrm{SW}$ of Burdur, 37³ $37^{\prime} \mathrm{N} 30^{\circ} 09^{\prime} \mathrm{E}, 940 \mathrm{~m}$, 7.vii.2006, J. Halada lgt. (ZKDC); 1 spec., Eskişehir prov., Sakari Ilica, near Gümele, 6.-9.vii.1997, P. Průdek \& M. Ř́ha lgt. (ZKDC); 1 spec.,
İzmir prov., Bergama, 1.v.1990, F. Kantner lgt. (ZKDC); 20 spec., İzmir prov., Kabakum village env., N of Dikili, 4.-5.v.2002, T. Růžička lgt. (ZKDC); 3 spec., Konya prov., 46 km NNE Konya, 1000 m, 18.-19. vi.1996, M. Knížek lgt. (ZKDC); 4 spec., Kütahya prov., 30 km SW of Kütahya, steppe, 1200 m, S. Benedikt lgt. (ZKDC).

Diagnosis. Microhoria terminata species-group; small species, having dark, unicolorous body, mostly with slight bluish reflection on elytra and paler tibiae. Male sternum VII simple; sternum VIII forming paired, rather widely connected sclerites that are evenly rounded and setose posteriorly; tergum VII and VIII simple; aedeagus (Figs 114, 116). Female sternum VII simple; tergum VII simple. Variation. Body length ( $\left.\delta^{\lambda}\right)$ 2.2-2.9 mm.

Distribution. Turkey, Greece (Lesbos).

Remarks. LAFERTÉ-SÉNECTÈRE (1849b) described Anthicus ottomanus from a single specimen provided by Friwaldszky. PIC (1897b) described Anthicus merkli from an unstated number of specimens provided by M. E. Merkl.

The type specimens were found to be identical, including form of the inner structure of the aedeagus, and so Anthicus merkli is placed as a junior synonym of Microhoria ottomana.

\section{Microhoria pahlavi Kejval, sp. nov.} (Figs 117, 118)

Type locality. Iran, Kerman Province, $33 \mathrm{~km}$ W of Sabzevaran, on the road Sabzevaran - Esefandaqeh, $28^{\circ} 44^{\prime} \mathrm{N} 57^{\circ} 28^{\prime} \mathrm{E}$, alt. $1100 \mathrm{~m}$.

Type material. Holotype: jo, 'E. Iran, $1100 \mathrm{~m} 33 \mathrm{~km}$ W Sabzvaran 6-7.5.1973 // Loc no. 189 Exp. Nat. Mus. Praha [p]' (NMPC). PARATYPEs: 1 d, 'E Iran Env Deh Pabid 21.4.1973 // Loc no. 172 Exp. Nat. Mus. Praha [p]' (NMPC).

Description. Male (holotype). Body length $3.6 \mathrm{~mm}$. Head black, pronotum reddish, elytra largely dark brown, brownish-black at base, with large, paired, vaguely outlined, yellowish spot laterally in apical third; abdomen largely brownish-black, terminal segments VII and VIII contrastingly yellowish; femora brownish, with paler base, tibiae and tarsi reddish, antennae dark reddish, slightly paler in basal third.

Head 1.3 times as long as wide including eyes, nearly evenly rounded posteriorly; eyes comparatively small, only moderately convex. Surface moderately glossy, distinctly and rather densely punctate; punctures mostly dense, sparser medially; setation short, appressed to subdecumbent. Antennae moderately enlarged for apical third; antennomeres X 1.4 times as long as wide, XI conspicuously elongate, 4.2 times as long as wide.

Pronotum 1.1 times as long as wide, evenly rounded anteriorly, moderately narrower than head including eyes; pronotal disc moderately convex, outline in dorsal view with lateral margins nearly straightly narrowing posteriorly. Surface moderately glossy; setation and punctation as on head; latero-basal margins with some longer, more raised setae.

Elytra 1.9 times as long as wide; humeri distinctly protruding; omoplates and postbasal impression slightly indicated; apices modified, somewhat bulging, channel of gland forming short tubular process. Surface slightly glossy, rather densely punctate and somewhat shagreened; punctation more delicate, shallower than on head; setation as on head, erect setae very short, inconspicuous. 
Legs slender, simple; all tibiae with paired terminal spurs.

Abdominal sternum VII moderately emarginate apically; sternum VIII forming pair of simple sclerites that are rounded and setose posteriorly; tergum VII and VIII simple. Aedeagus (Figs 117, 118): tegmen moderately wide in apical half, abruptly narrowed in front of hooked and bidentate apex; endophallic armature with two pairs of long, robust and slender sclerites.

Female. Unknown.

Variation. Body length ( 3 ) 3.5-3.6 mm; paratype with indication of a small, yellowish posthumeral spot on the elytra. Differential diagnosis. Microhoria pahlavi sp. nov. belongs to the $M$. terminata species-group. It can be easily recognized by its larger size, bright colouration, extremely elongate terminal antennomeres, and the male characters. Etymology. Named after the Pahlavi dynasty and the last Shah of Iran, Mohammad Reza Pahlavi; noun in the nominative case, standing in apposition.

Distribution. Iran.

\section{Microhoria persica Kejval, sp. nov.} (Figs 119, 157)

Type locality. Iran, Fars Province, $29 \mathrm{~km}$ E of Yasuj, $30^{\circ} 41^{\prime} \mathrm{N} 51^{\circ} 43^{\prime} \mathrm{E}$, alt. $2300 \mathrm{~m}$.

Type material. Holotype: ' 'S Iran, 29 km E Yasuj, 2300 m, 16.-17.6. 1973 [p] // Loc. no. 245 Exp. Nat. Mus. Praha [p] // Microhoria mollis (Desbrochers) det. G. Uhmann 1985 [p]' (NMPC). ParatyPEs: 44 đa 33 우, same data as holotype (NMPC, ZKDC, DCDC); 2 우, 'S Iran, $42 \mathrm{~km}$ N Masírí, 2230 m, 12.6.1973 [p] // Loc. no. 238 Exp. Nat. Mus. Praha [p] // Microhoria mollis (Desbrochers) det. G. Uhmann 1985 [p]' (NMPC).

Description. Male (holotype). Body length $2.5 \mathrm{~mm}$. Body dark brown, elytra slightly paler; femora brown, tibiae and tarsi yellowish, antennae partly yellowish, distinctly darkened on apical third, also basal antennomere brownish.

Head elongate, 1.1 times as long as wide, widely rounded posteriorly; eyes small, moderately convex. Surface glossy, minutely but distinctly punctate; punctures distinctly spaced; setation short, subdecumbent. Antennae slightly enlarged for apical half; antennomeres $\mathrm{X}$ as long as wide, XI 2.5 times as long as wide.

Pronotum about as long as wide, narrower than head including eyes, widely rounded anteriorly; pronotal disc moderately convex, outline in dorsal view with lateral margins rather strongly, straightly narrowing posteriorly (Fig. 157). Surface glossy, minutely punctate; setation and punctation as on head, latero-basal sides with some longer, more raised setae.

Elytra 1.5 times as long as wide, somewhat flattened medially in basal half; humeri distinctly protruding; omoplates slightly indicated; apices modified, channel of gland forming short tubular process. Surface moderately glossy, distinctly punctate; punctation and setation slightly coarser than that on head, with scattered short erect setae.

Legs slender, simple; all tibiae with paired terminal spurs.

Abdominal sternum VII slightly produced and rounded apically; sternum VIII forming simple paired sclerites that are narrowly connected medially. Aedeagus (Fig. 119): slender apical portion of tegmen with slight tooth at mid- length, with longitudinal carina and bluntly pointed apex; endophallic armature with numerous minute spinules.

Female. Identical with male for most external characters; elytral apices simple; both sternum and tergum VII simple.

Variation. Body length ( $\left.\jmath_{+}\right)$(2.2-2.5 mm; body colour brown to black, head sometimes nearly evenly rounded posteriorly; punctation of head and pronotum varying in prominence, mostly rather inconspicuous.

Differential diagnosis. Microhoria persica sp. nov. belongs to the M. terminata species-group. Externally it can be easily confused with $M$. kermanica sp. nov., showing only slight differences, e.g. the rather widely rounded head base and anterior margin of pronotum (the latter somewhat angled antero-laterally in dorsal view). On the other hand, it can be easily distinguished from the latter species by characters of the aedeagus: the endophallus with numerous minute spinules, the lack of paired hook-like sclerites and longer spines, and the simple apex of the tegmen (cf. Figs 119 versus 112 ).

Etymology. Named after the ancient empire Persia which once included the present-day region of Iran; adjective.

Distribution. Iran.

\section{Microhoria pinicola (Reitter, 1889)}

Anthicus pinicola Reitter, 1889: 258.

Microhoria pinicola: Telnov (1998): 170 (record Greece); CHANDLER et al. (2008): 442 (catalogue, distribution).

Microhoria feroni Bonadona, 1960: 51, Figs 1, 3, 5, syn. nov.

Type locality. Anthicus pinicola - Greece, Attica; Microhoria feroniGreece, Euboea Island, Rovies.

Type material. Anthicus pinicola - Lестотуре (herewith designated): o, 'Attica Reitter [p] // Graecia [h] // Paratypus 1889. Anthicus pinicola Reitter [p+h; red frame] // Coll. Reitter [p]' (HNHM). PARALECTOTYPE: 1 , same data, except 'Holotypus' in the 3rd label (HNHM).

Microhoria feroni - PARATYPE: đ', 'Ile d'Eubée a Roviès (Sporades) 10.VII.1956. [h] II Paratype [h; red label] // Microhoria (Platyhoria) feroni n sp. P. BONADONA det. [p+h]' (coll. Bonadona, MNHN).

Additional material. GREECE: Central Greece: 3 ô, Euboea, Pili, 105 m, 16.vi.-25.ix.2014, A. Sette lgt. (ADBC); $4 \delta$, Euboea, Pili, 100 m, 20.vi.2016, A. Sette lgt. (ADBC). Central Macedonia: 1 , Mount Menikio, 12.viii.2010, J. Halada lgt. (ADBC). EpIrus: $1 \hat{\delta}$,

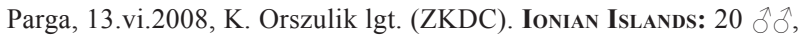
Corfu, Pelekito, 21.vi.2010, M. Pavesi lgt. (ADBC). Peloponnese: 4 ôे, Arcadia, Tyros, Paralia, 15.vii.1987, R. Schuh lgt. (ZKDC); 4 $\hat{\jmath}$ 1 , Corinthia, Gerania Region, NW of Perachora, $38^{\circ} 03^{\prime} \mathrm{N} 22^{\circ} 55^{\prime} \mathrm{E}$, 200 m, 16.vii.1990, M. \& R. Rausch lgt. (ZKDC); 3 $\delta$, Laconia, $1.4 \mathrm{~km} \mathrm{NW}$ of Grammousa, 10.vi.2016, B. Zbuzek lgt. (ZKDC). Thessaly: $1 \hat{\jmath}$, Trikala, Pili, 20.vi.2008, A. Fancello lgt. (ADBC). West Greece: 2 ô, Etolia-Akarnania, Astakos, 22.vi.-6.vii.2001, A. Sette lgt. (ADBC).

\section{Distribution. Greece.}

Remarks. ReITTER (1889) described Anthicus pinicola from an unstated number of specimens collected by $\mathrm{H}$. von Oertzen in Greece at three localities: Aegina, Attica, and Morea. The lectotype is designated herein for a male syntype from Attica (its paratype label is surely not original but added by curators). BonADONA (1960) described Microhoria feroni from two specimens originating from Euboea Island in Greece. Both species are conspicuous in having a unicolorous reddish body, and the male type specimens have identical aedeagi, including the rather 


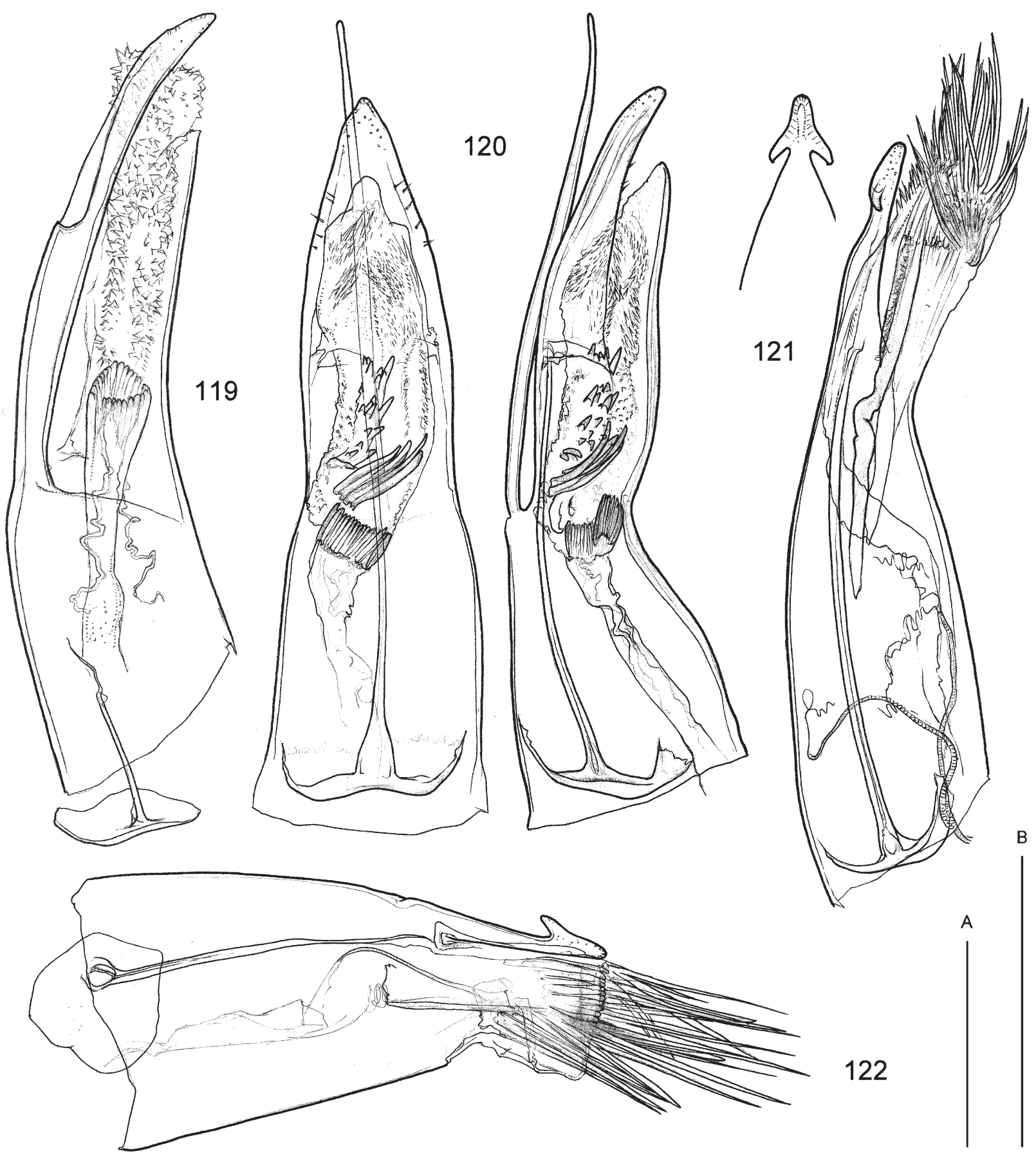

Figs 119-122. Aedeagus: 119 - Microhoria persica sp. nov., lateral view; 120 - M. sawda sp. nov., ventral (left) and lateral (right view); 121 - M. strejceki sp. nov., lateral view, and apex of tegmen in dorsal view; $122-$ M. truncatipennis (Pic, 1897) comb. nov., lateral view. Scale bars: 0.2 mm - A (Figs 120, 121), B (Figs 119, 122).

characteristic small lobule on the outer side of the narrowed, straightly projecting apical portion of the tegmen, and the endophallus with an apical tuft of simple, delicate spinules. Consequently, Microhoria feroni is proposed as a junior synonym of Anthicus pinicola.

The specimens collected by M. Pavesi at the locality Pelekito were captured by using traps with paper towels soaked with alcohol containing the exudates from freshly caught specimens of Meloe Linnaeus, 1759 (Degiovanni, pers. comm.); the specimens collected by A. Sette in Central and Western Greece Regions were trapped in cups holding wine vinegar (Degiovanni, pers. comm.).

\section{Microhoria sawda Kejval, sp. nov.}

(Fig. 120)

Type locality. Saudi Arabia, Riyadh Province, Salhoukh, wadi near dam, $25^{\circ} 05^{\prime} \mathrm{N} 46^{\circ} 20^{\prime} \mathrm{E}$, alt. $698 \mathrm{~m}$.

Type material. Holotyp: 'A, 'Saudi Arabia, Riyadh prov. 6.ii.2016,

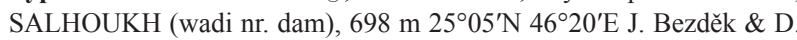
Král lgt. [p]' (NMPC). ParatyPes: $19 \delta 6 \% 9$, same data as holotype (NMPC, ZKDC); 2 \& 1 , 'Saudi Arabia, Riyadh prov. 2.ii.2016, WADI HANIFA, btw UYAYNA and SADUS (nr. dam), 24 ${ }^{\circ} 54^{\prime} \mathrm{N} 46^{\circ} 11^{\prime} \mathrm{E} 805$ m, J. Bezděk \& D. Král lgt. [p]' (NMPC).

Description. Male (holotype). Body length $3.1 \mathrm{~mm}$. Body black, elytra with brownish tinge posteriorly; legs 
brownish-black, tibiae and tarsi somewhat paler, antennae black, antennomeres II, III slightly brownish.

Head elongate, 1.3 times as long as wide, widely rounded posteriorly; eyes small, moderately convex. Surface moderately glossy, minutely punctate; punctures distinctly spaced; setation short, subdecumbent. Antennae moderately enlarged in apical half; antennomeres X 1.2 times, XI nearly 2.7 times as long as wide.

Pronotum 1.1 times as long as wide, moderately narrower than head including eyes, evenly rounded anteriorly, pronotal disc moderately convex, outline in dorsal view with lateral margins slightly narrowing posteriorly. Surface moderately glossy, punctate; punctation and setation as on head, with few very short erect setae.

Elytra 1.8 times as long as wide, somewhat flattened medially in basal half; humeri distinctly protruding; apices modified, channel of gland forming short tubular process. Surface moderately glossy, distinctly and densely punctate; punctation coarser and setation slightly longer than on head, with scattered, inconspicuous, short erect setae.

Legs slender, simple; all tibiae with paired terminal spurs.

Abdominal sternum VII widely rounded to subtruncate and slightly emarginate apically; sternum VIII forming paired, subtriangular sclerites that are distinctly setose posteriorly. Aedeagus (Fig. 120): apical portion of tegmen rather wide, nearly evenly narrowing towards bluntly pointed apex, with several short setae along margins, and with conspicuous, slender rod-like projection; endophallic armature with numerous robust spines (longer spines bunched) and delicate minute spinules.

Female. Identical with male for most external characters; elytral apices simple; sternum VII simple; tergum VII simple, evenly rounded apically.

Variation. Body length ( $\delta^{1}+$ ) 3.0-3.6 mm.

Differential diagnosis. Microhoria sawda sp. nov. belongs to the $M$. terminata species-group. It can be recognized by the elongate, subparallel body, posteriorly slightly narrowed and uniformly setose pronotum, and mainly by the characters of aedeagus (wider apical portion of tegmen, with some short setae laterally and with slender, rod-like projection).

Etymology. The species name sawda is derived from the Arabic word 'Sawaad' (black colour); refering to generally dark colouration of this species; noun in the nominative case, standing in apposition.

Distribution. Saudi Arabia.

\section{Microhoria strejceki Kejval, sp. nov. (Fig. 121)}

Type locality. Tajikistan, Aruk-Tau Mts, Gara-Vuti env., pr. Shaartuz, cca $600 \mathrm{~m}$.

Type material. HoLOTYPE: O', 'USSR-Tadžikistan 21.4.1978 Aruk-Tau (cca 600 m) Gara-Vuti env. (pr. Šaartuz) J. Strejček lgt. [p]' (NMPC). PARATYPES: $2 \hat{\delta}$, same data as holotype (ZKDC); $1 \hat{\jmath}$, 'USSR Tadžikistan Babatag Mts. 30.4.1977 J. Strejček lgt. [p]' (ZKDC); 2 우, 'USSR Tadžikistan Babatag Mts. 30.4.1977 Sv. Bílý lgt. [p]' (NMPC); 1 ô, 'USSR, Tardzjekistan, 1981 Hissar Mts., 1.300-1.600 m 50 km N Dushanbe, 19.6. GUSHARA, Varzob river Karel Majer leg. [p]'(ZKDC);
2 3. 'SU, Tadshikistan, Pamir Dschailgan, Muxu-Ufer b. Dep-Schaar, $2150 \mathrm{~m}$ NN 29.VI.1990, leg. Hartmann [h; partly illegible] // Microhoria nepticula Bonadona det. GUhmann1991 [p+h]' (ZSMC).

Description. Male (holotype). Body length $3.5 \mathrm{~mm}$. Head black; pronotum reddish, disc darkened medially; elytra yellowish, with brown apex, base, wide transverse band at about mid-length, and suture in basal half (narrowly connecting basal spot with band); femora brown, tibiae and tarsi yellowish to pale reddish; antennae reddish-brown, antennomeres I, VII-XI distinctly darkened.

Head moderately elongate, 1.3 times as long as wide, widely rounded posteriorly (posterior angles indistinct); eyes small, at most moderately convex. Surface glossy, minutely but distinctly punctate; punctures distinctly spaced, sparser medially; setation short, subdecumbent to appressed. Antennae moderately enlarged in apical half; antennomeres $\mathrm{X}$ as long as wide, XI 2.4 times as long as wide.

Pronotum 1.1 times as long as wide, moderately narrower than head including eyes, evenly rounded anteriorly, pronotal disc moderately convex, outline in dorsal view with lateral margins nearly straightly narrowing posteriorly. Surface glossy, minutely punctate; punctation and setation as on head.

Elytra 1.9 times as long as wide, subparallel, slightly impressed medially on basal half; humeri distinctly protruding; apices modified, channel of gland forming short tubular process. Surface moderately glossy, distinctly and densely punctate; punctation and setation slightly coarser than on head, with scattered, very short erect setae.

Legs slender, simple; all tibiae with paired terminal spurs.

Abdominal sternum VII slightly emarginate apically; sternum VIII forming paired subtriangular sclerites that are rounded and setose posteriorly; tergum VII and VIII simple. Aedeagus (Fig. 121): tegmen elongate, narrowed and triangular (arrowhead-like) apically; endophallic armature with pair of robust, longitudinal sclerites, and clustered slender spines.

Female. Identical with male for most external characters; elytral apices simple; sternum VII simple; tergum VII simple, evenly rounded apically.

Variation. Body length ( $1 \circ$ ) $3.1-3.9 \mathrm{~mm}$; pronotum entirely reddish or largely black, elytra with transverse band complete and connected with basal spot along suture, or widely interrupted medially (markings forming four widely separated spots).

Differential diagnosis. Microhoria strejceki sp. nov. belongs to the $M$. terminata species-group. At first sight it can be easily confused with the sympatric M. edmondi, but differs by the more widely rounded base of the head, less convex eyes, characters of the aedeagus (cf. Figs 121 versus 97), and by the simple tergum VII of the females (distinctly emarginate apically in M. edmondi).

Etymology. Named in honour of the late Czech entomologist Jaromír Strejček, who collected part of type series, including the holotype; noun in the genitive case, standing in apposition.

Distribution. Tajikistan. 


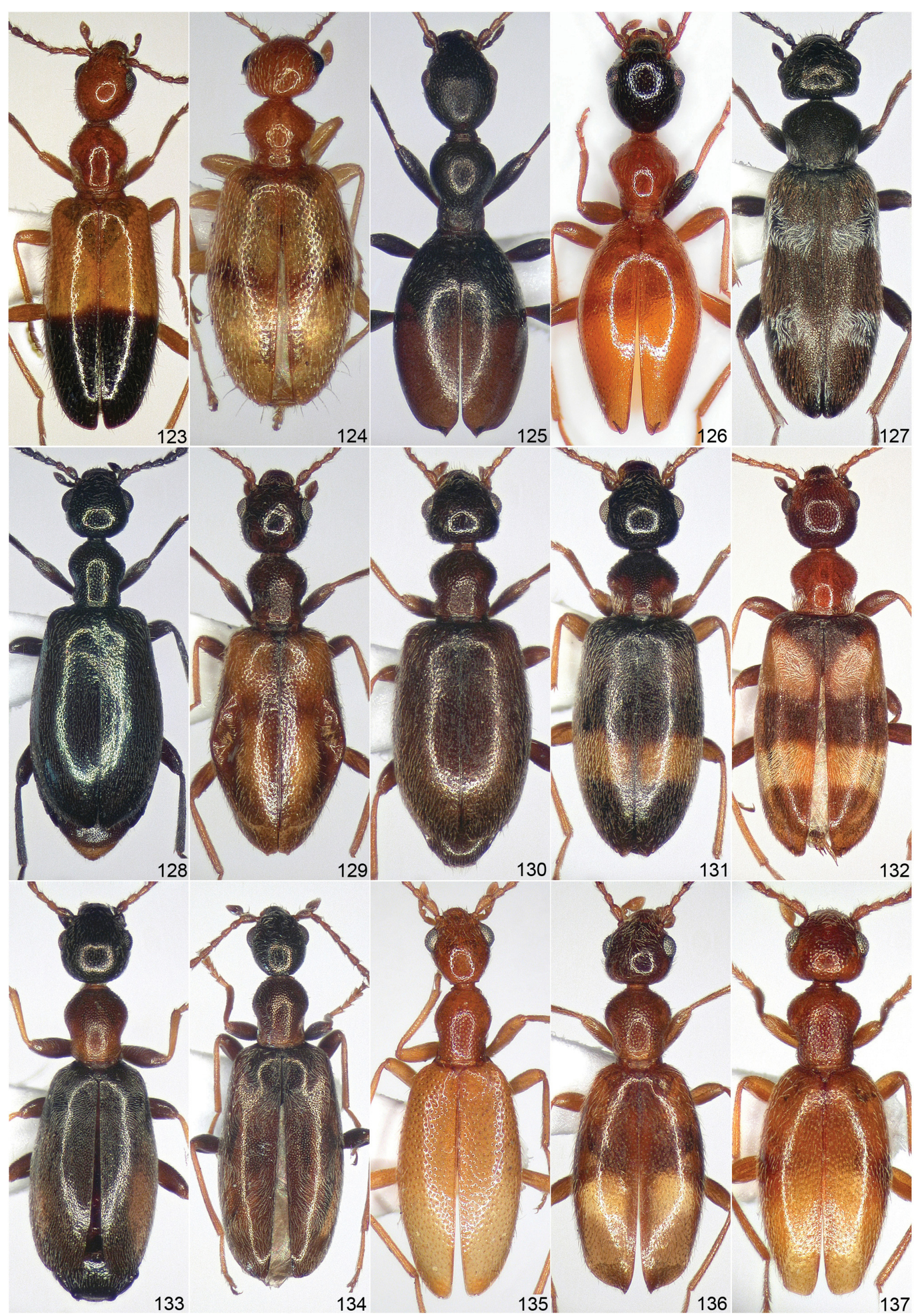

Figs 123-137. Habitus: 123 - Neocrohoria melanura (Fairmare \& Germain, 1863), O’Higgin prov., Cuesta Chada (ZKDC); 124 - Aulacoderus mutatus (Gemminger, 1870); 125 - A. tuberculifer (van Hille, 1985), Western Cape, Soutpan (ZKDC); 126 - Falsophilus minutus (Pic, 1894), Western Cape, Cape Point (ZKDC); 127 - Liparoderus insignis (Lucas, 1843), Spain, Farlete (ZKDC); 128 - Microhoria caeruleicolor (Pic, 1906) comb. nov.; 129 - M. fugiens (Marseul, 1896) comb. nov.; 130 - M. posthuma (Krekich-Strassoldo, 1931) comb. nov., India, Loharket (ZKDC); 131 - M. fasciata (Chevrolat, 1834); 132 - M. vosseleri (Pic, 1894); 133 - M. heydeni (Marseul, 1879) comb. nov.; 134 - M. longiceps (LaFerté-Sénectère, 1849) comb. nov.; 135 - M. proterva (Krekich-Strassoldo, 1931), syntype (BMNH); 136 - M. antalya sp. nov.; 137 - M. globipennis (Pic, 1897), Turkey, Şenköy (ZKDC). 
Microhoria truncatipennis (Pic, 1897) comb. nov.

(Figs 122, 155, 159)

Formicomus (Anthelephilus) truncatipennis Pic, 1897c: 61.

Formicomus (Anthelephilus) truncatipennis: WINKLER (1927): 836 (catalogue).

Formicomus truncatipennis: PIC (1911b): 21 (catalogue).

Anthelephila truncatipennis: CHANDLER et al. (2008): 424 (catalogue, distribution).

Anthicus Mouzafferi Pic, 1910: 42, syn. nov.

Anthicus Mouzafferi: PIC (1911b): 62 (catalogue).
Anthicus Mouzaffieri [misspelling]: WINKLER (1927): 842 (catalogue). Clavicollis mouzafferi: CHANDLER et al. (2008): 431 (catalogue, distribution); Telnov \& GHahari (2018): 483 (note).

Type locality. Formicomus truncatipennis - Central Asia ('Asie Centrale'); Anthicus mouzafferi - Iran ('Perse').

Type material. Formicomus truncatipennis - SYNTYPES: $1 \delta$ [torso, lacking head and pronotum; narrow triangular card], 'Asie Centrale [h] // Anthicus pres olivieri [h] // type [h; yellowish label] // TYPE [p; red label] // truncatipennis Pic [h]' (MNHN); 1 [narrow triangular card], '[plain label] // Asie Centrale [p] // type [h; yellowish label] // Stenidius

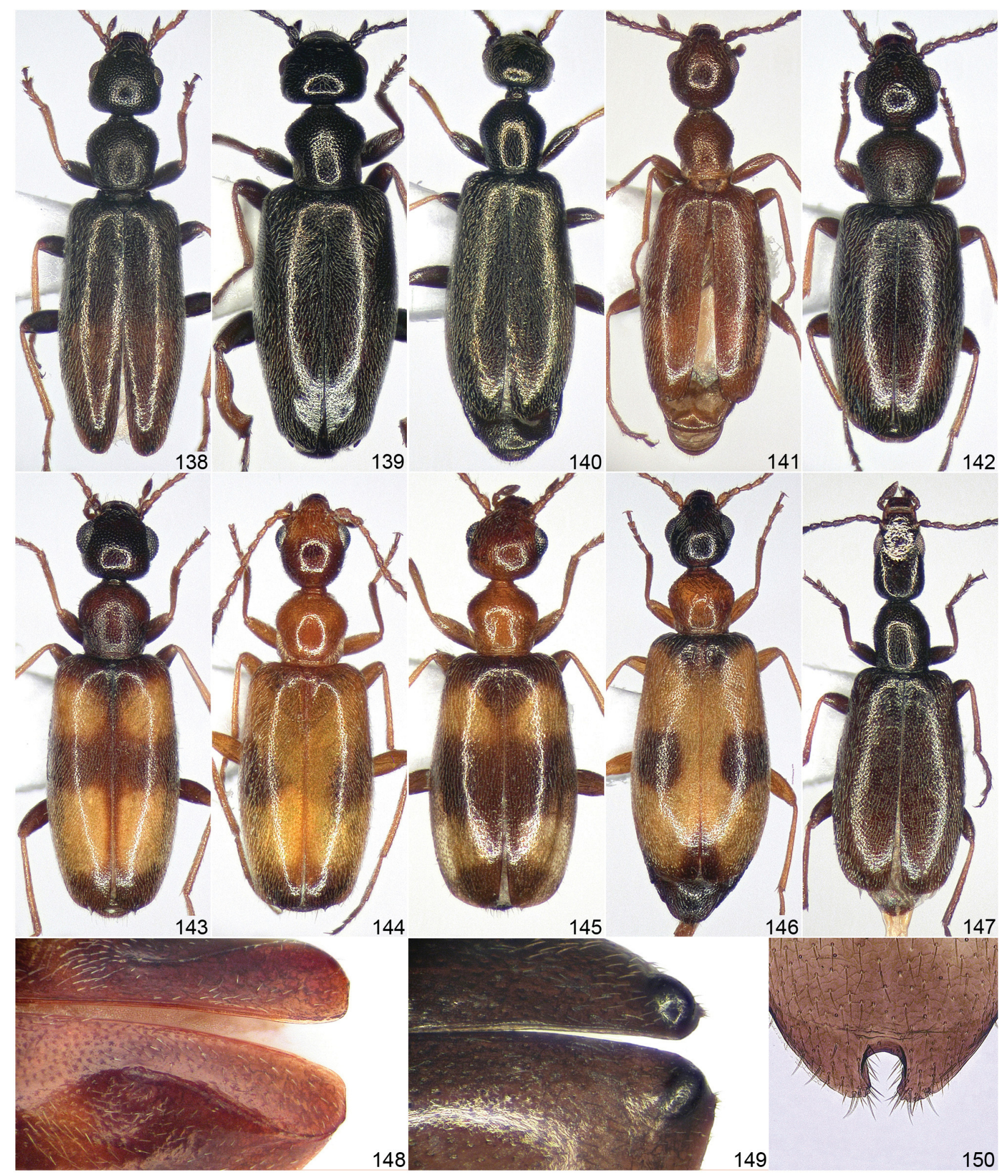

Figs 138-150. 138-147 - Habitus: 138 - Microhoria ocreata (LaFerté-Sénectère, 1847) comb. nov.; 139 - M. oedipus (Chevrolat, 1860); 140 - M. olivacea (LaFerté-Sénectère, 1849) comb. nov.; 141 - M. paupercula (LaFerté-Sénectère, 1849) comb. nov.; 142 - M. babaulti (Pic, 1921) comb. nov.; 143 - M. cervi sp. nov.; 144 - M. sulaimanica sp. nov., paratype; 145 - M. terminata (W. L. E. Schmidt, 1842); 146 - M. anahita sp. nov.; 147 - M. angelinii (Degiovanni, 2012) comb. nov.; 148 - M. apicordiger (Bonadona, 1958) comb. nov., apex of elytra; 150 - M. gibbipennis sp. nov., apex of elytra; $150-M$. angelinii, apex of female tergum VII. 
truncatipennis Pic [h]' (MNHN).

Anthicus mouzafferi - LeCtotyPe (herewith designated): + , "[small plain, goldish label] // 623. [h] // Persia [h] // type [h; yellowish label] // TYPE [p; red label] // mouzafferi Pic [h]' (coll. Pic, MNHN). PARALECTOTYPE: 1 , same data as lectotype, mounted on same card, see Remarks (coll. Pic, MNHN).

Additional material. IRAN: 1 , 'Persia' [Collection Jakob Sturm, $A$. mouzafferi det. Krekich] (ZSMC); 1 , Mazandaran prov., 40 km E from Firuzkuh Geduk, 30.vi.2004, C. Holzschuh lgt. (ZKDC).

Diagnosis. Microhoria terminata species-group; brownish-black, apterous species, with oval head, simple elongate pronotum (Fig. 159), and subtruncate elytral apices (Fig. 155). Male sternum VII moderately emarginate apically; sternum VIII forming paired, subtriangular sclerites; tergum VII and VIII simple; aedeagus (Fig. 122). Female sternum VII simple; tergum VII truncate and emarginate apically.

Distribution. Iran, Tajikistan.

Remarks. PIC (1897c) described Formicomus truncatipennis from two specimens provided by Otto Staudinger, and regarded both as females, probably due to the simple
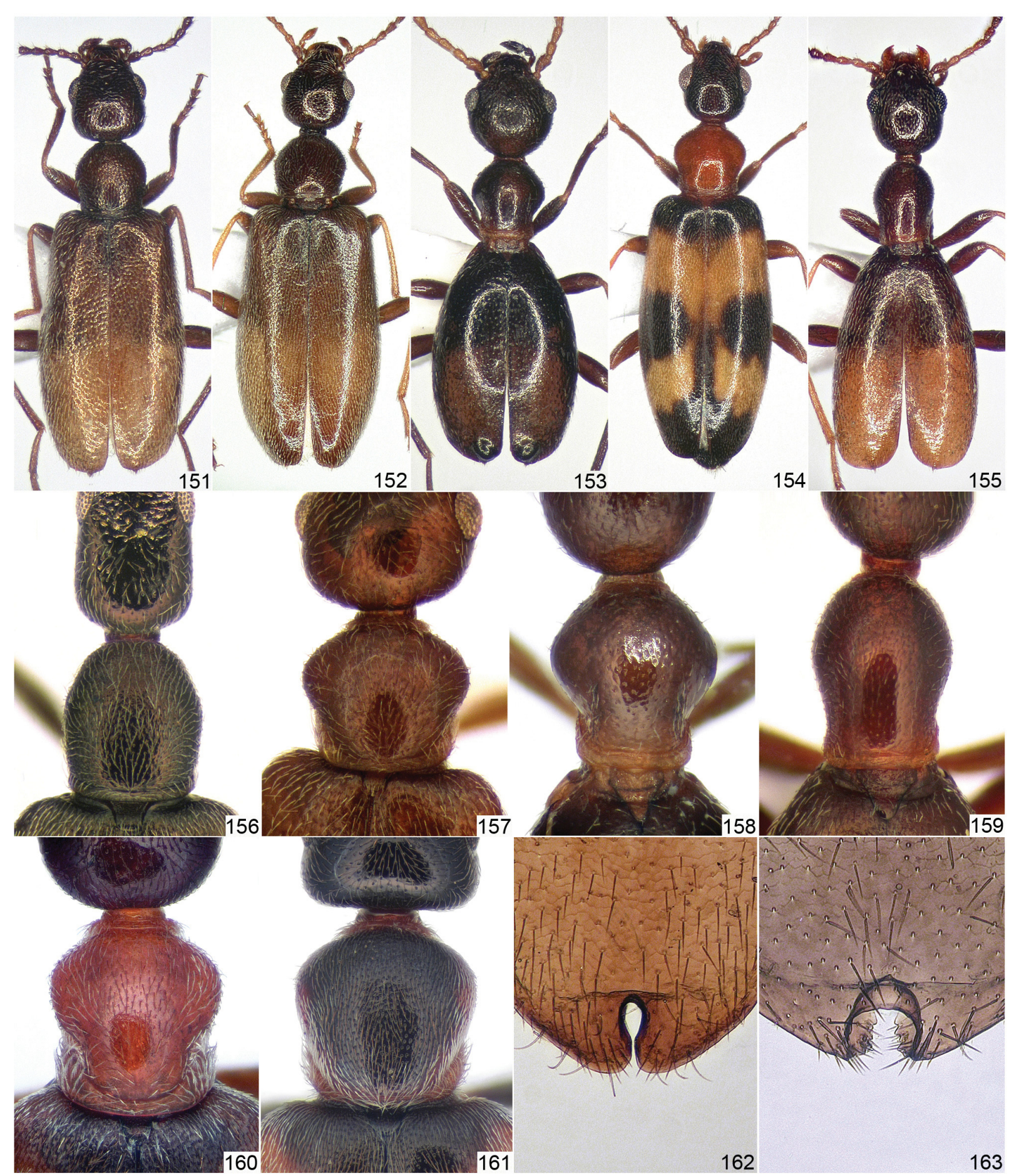

Figs 151-163. 151-155 - Habitus: 151 - Microhoria bacillisternum sp. nov.; 152 - M. garavuti sp. nov.; 153 - M. gibbipennis sp. nov.; 154 - M. heracleana sp. nov., paratype, Stomio (ZKDC); 155 - M. truncatipennis (Pic, 1897) comb. nov. 156-161 - pronotum and base of head and elytra: 156 - M. angelinii (Degiovanni, 2012) comb. nov.; 157 - M. persica sp. nov., paratype (ZKDC); 158 - M. gibbipennis sp. nov.; 159 - M. truncatipennis; 160 - M. vosseleri (Pic, 1894); 161 - Microhoria sp., Spain, Jarama River env., near Madrid (ZFMK). 162 - M. depressa (LaFerté-Sénectère, 1849), Azerbaijan, Zarat (ZKDC), apex of female tergum VII; 163 - M. gibbipennis sp. nov., apex of female tergum VII. 
front legs. PIC (1910) described Anthicus mouzafferi from an unstated number of specimens originating from 'Perse', and deposited the syntypes in his collection. The type material of both species was never examined, and especially the former species has been considered to be an enigmatic species of Anthelephila. Having examined the available syntypes (probably all) and additional specimens from Iran, we found the two species identical and are here placed in Microhoria.

The type specimens of Anthicus mouzafferi are mounted on a single card, both are females that face away from the pin. The syntype on the right from the pin base was found in better condition, and is herein selected as the lectotype.

\section{Species excluded from Microhoriini}

\section{Anthicus desertus Marseul, 1879}

Anthicus desertus Marseul, 1879: 134

Type locality. Russia, Siberia ('Sibérie Transbaïcale').

Type material. Syntypes, not examined (coll. Bonvouloir, MNHN).

Remarks. This species was recently listed under Clavicollis (CHANDLER et al. 2008). Its type material was never examined, however its distribution and some characters given in the original description (body 'densément ruguleux pointillé', base of head 'tronguée avec une petite sinuosité au milieu') suggest retention in its original genus Anthicus.

Nitorus niger (Uhmann, 1996) comb. nov.

Clavicomus niger Uhmann, 1996: 33, fig. 12.

Type locality. North Vietnam, Sapa (Cao Ca.), $22^{\circ} 20^{\prime} \mathrm{N} 103^{\circ} 50^{\prime} \mathrm{E}$. Type material. Holotype (NHMW) and 5 paratypes (NHMW, ZSMC).

Remarks. Based on examination of all the type specimens, which originate from the single locality, this species undoubtedly belongs to a different tribe, Anthicini. It is externally very similar to some species currently placed in Nitorus Telnov, 2007, and thus is tentatively placed in this genus.

\section{Nitorus laevipennis Marseul, 1877}

Anthicus laevipennis Marseul, 1877: 471.

Clavicollis laevipennis: TELNOV (2004): 129 (new combination); CHANDLER et al. (2008): 431 (catalogue, distribution).

Nitorus laevipennis: Telnov (2010): 11 (new combination).

Type locality. Japan, Nagasaki.

Remarks. This species was listed under Clavicollis in the last Palaearctic catalogue (CHANDLER et al. 2008), but was subsequently transferred to Nitorus by TELNOV (2010).

\section{Acknowledgements}

We have to thank mainly the following individuals for the loan of specimens in their care: Augusto Degiovanni (Bubano, Italy), Maxwell V. L. Barclay and Michael Geiser (BMNH), David Frank (Praha, Czech Republic); Maria Tavano and Roberto Poggi (MCSN), Azadeh Taghavian and Thierry Deuve (MNHN), Harald Schillhammer (NHMW), Jiř́ Hájek (NMPC), Stanislav
Benedikt (Plzeň, Czech Republic), Dirk Ahrens (ZFMK), Christoffer Fägerström (MZLU), and Katja Neven and Michael Balke (ZSMC).

SEM photomicrographs were valuable in assisting our understanding the morphology of the mesothorax. Most specimen images were produced by Carli Langevin, summer intern, under the direction of Mark Townley and Nancy Cherim (Instrumentation Center, University of New Hampshire, USA). For their time and support we sincerely thank all three individuals and the Center Director, Shawn Banker. Some images were produced by Martina Tesařová (Institute of Parasitology, Biology Centre CAS, České Budějovice, Czech Republic), and Aleš Bezděk (Institute of Entomology, ditto) was also very helpful in this matter, by arranging a visit of the first author. Furthermore, Dmitry Telnov (BMNH) kindly provided photos of the holotype of Microhoria taurica for comparison, Benito Campo (Zaragoza, Spain) provided macro photo of a living Liparoderus venator, and Ahmet Ömer Koçak (Yuzuncu Yil University, Van, Turkey) was helpful in explaining the type locality of Microhoria inobscura.

Claudia Hemp (University of Bayreuth, Bayreuth, Germany) is here recognized for her critical earlier work on the defensive compounds of Anthicidae, and we sincerely thank her for her courtesy in providing unpublished information of the anatomy of the mesothoracic glands. Lastly we would like to thank our three reviewers, Darren Pollock (University of New Mexico, USA), Daniel K. Young (University of Wisconsin, USA), and Dmitry Telnov (BMNH) for their time invested in checking the manuscript.

\section{References}

ABDULLAH M. 1965a: Protomeloe argentinensis, a new genus and species of Meloidae (Coleoptera), with remarks on the significance of cantharidin and the phylogeny of the families Pyrochroidae, Anthicidae, Meloidae and Cephaloidae. Annals and Magazine of Natural History, 13th Series 7 [1964]: 247-254.

ABDULLAH M. 1965b: Protomeloe crowsoni, a new species of a new tribe (Protomeloini) of the blister beetles (Coleoptera, Meloidae), with remarks on a postulated new pheromone (cantharidin). Entomologisk Tidskrift 86: 43-48.

ALONSO-ZARAZAGA M. A. 2013: Case 3624 A proposal for the rejection of 38 names in Anthicidae (Coleoptera). Bulletin of Zoological Nomenclature 70: 171-184.

ANGELINI F., AUDISIO P., BOLOGNA M. A., DE BIASE A., FRANCISCOLO M. E., NARDI G., RATTI E. \& ZAMPETTI M. F. 1995: Coleoptera Polyphaga XII (Heteromera escl. Lagriidae, Alleculidae, Tenebrionidae). In: MINELLI A., RUFFO S., \& LA POSTA S. (eds): Checklist delle specie della fauna Italiana, 57. Calderini, Bologna, 30 pp.

AUDISIO P. \& VIGNA TAGLIANTI A. 2010: Insecta Coleoptera. Biologia Marina Mediterranea 17 (Supplementum 1): 547-571.

BAUDI DI SELVE F. 1877: Eteromeri delle famiglie susseguenti a quella dei tenebrioniti nei limiti della fauna Europea e Circummediterranea. Atti della Reale Accademía delle Scienze di Torino 12: 571-729.

BOCÁK L. 1993: Anthicidae. Pp. 113-114. In JELÍNEK J. (ed.): Checklist of Czechoslovak Insects IV (Coleoptera). Seznam československých brouků. Folia Heyrovskyana Supplementum 1: 1-172.

BOLIVAR y URRUTIA D. I. 1896: [note at meeting]. Anales de la Sociedad Española de Historia Natural 24: 182-184.

BONADONA P. 1952: Notes sur les Anthicidae paléarctiques. Revue Française d'Entomologie 19: 233-237.

BONADONA P. 1955: Les Microhoria de France [Col., Anthicidae]. Revue Française d'Entomologie 21: 101-118. 
BONADONA P. 1956: Anthicides recueillis par. F. Pierre dans le Sahara algérien [Coleoptera]. Revue Française d'Entomologie 23: 116-120.

BONADONA P. 1958a: Faune de Madagascar, VI. Insectes Coléoptères Anthicidae. Publications de l'Institut de Recherche Scientifique, Tananarive, $153 \mathrm{pp}$.

BONADONA P. 1958b: Notes sur les Anthicidae paléarctiques [Coleoptera]. Revue Française d'Entomologie 25: 287-297.

BONADONA P. 1960: Notes sur les Anthicidae paléarctiques (Coleoptera). Revue Française d'Entomologie 27: 51-57.

BONADONA P. 1961: Les Tomoderini de l'Afrique noire et de la région Malgache (Coleoptera Anthicidae). Annales du Musée Royal de l'Afrique Centrale, Tervuren, Série $8^{\circ}$ : Sciences Zoologiques 91: 1-78.

BONADONAP. 1964: Note sur les Anthicidae paléarctiques [Col.]. Revue Française d'Entomologie 31: 225-249.

BONADONA P. 1971: Les Notoxinae de France (Col. Anthicidae). L'Entomologiste 27: 132-148.

BONADONA P. 1974: La classification des Anthicidae de la faune de France (Coleoptera). L'Entomologiste 30: 101-111.

BONADONA P. 1976: Les Anthicidae de la faune de France (Troisième partie). L'Entomologiste 32: 105-129.

BONADONA P. 1988: Notes sur les Anthicidae paléarctiques (Insecta Coleoptera). Biocosme Mésogéen 5: 13-22.

BONADONA P. 1990a: Les Anthicidae de la faune de France (septième partie). Bulletin Mensuel de la Société Linnéenne de Lyon 59: 9-24.

BONADONA P. 1990b: Les Anthicidae de la faune de France (huitième et dernière partie). Bulletin Mensuel de la Société Linnéenne de Lyon 59: 363-386.

BONADONA P. 1991: Les Anthicidae de la faune de France (Coleoptera). Société linnéenne de Lyon, Lyon, $155 \mathrm{pp}$.

BONADONA P. 2013: Les Anthicidae de la faune de France (Coleoptera). Mémoires de la Société Linnéenne de Lyon 5: 1-126 pp.

BOUCHARD P., BOUSQUET Y., DAVIES A. E., ALONSO-ZARAZAGA M. A., LAWRENCE J. F., LYAL C. H. C., NEWTON A. F., REID C. A. M., SCHMITT M., ŚLIPIŃSKI S. A., \& SMITH A. B. T. 2011. Family-group names in Coleoptera (Insecta). ZooKeys 88: 1-972.

BUCCIARELLI I. 1977: Coleotteri anticidi della Laguna di Venezia. Lavori - Società Veneta di Scienze Naturali 2: 15-21.

BUCCIARELLI I. 1980: Fauna d'Italia XVII. Coleoptera, Anthicidae. Calderini, Bologna, viii +240 pp.

CARRELL J. E. \& EISNER T. 1974: Cantharidin: potent feeding deterrent to insects. Science 183: 755-757.

CHANDLER D. C. 1976: Use of cantharidin and meloid beetles to attract Anthicidae (Coleoptera). Pan-Pacific Entomologist 52: 179-180.

CHANDLER D. C. 1977: New Mecynotarsus with a key to the New World species (Coleoptera: Anthicidae). Coleopterists Bulletin 31: 363-370.

CHANDLER D. C. 2002: 117. Anthicidae Latreille, 1819. Pp. 549-558. In: ARNETT R. H. Jr., THOMAS M. C., SKELLY P. E. \& FRANK J. H. (eds): American Beetles, Volume 2: Polyphaga: Scarabaeoidea through Curculionoidea. CRC Press, Boca Raton, London, New York, Washington, D.C., $861 \mathrm{pp}$.

CHANDLER D. S. 2010: 11.26. Anthicidae Latreille, 1819. Pp. 729-741. In: LESCHEN R. A. B., BEUTEL R. G. \& LAWRENCE J. F. (volume eds): Coleoptera, beetles. Volume 2: Morphology and systematics (Elateroidea, Bostrichiformia, Cucujiformia partim). In: KRISTENSEN N. P. \& BEUTEL R. G. (eds): Handbook of zoology. A natural history of the phyla of the animal kingdom. Volume IV. Arthropoda: Insecta. Part 38. Walter de Gruyter, Berlin, New York, xiii + 786 pp.

CHANDLER D. S., NARDI G. \& TELNOV D. 2004: Nomenclatural notes on the Palaearctic Anthicidae (Coleoptera). Mitteilungen der Internationalen Entomologischen Vereins e. V. 29: 109-173.

CHANDLER D. S., UHMANN G., NARDI G. \& TELNOV D. 2008: Family Anthicidae Latreille, 1819. Pp. 421-455. In: LÖBL I. \& SMETANA A. (eds): Catalogue of Palaearctic Coleoptera. Volume 5. Tenebrionoidea. Apollo Books, Stenstrup, 670 pp.

CHEVROLAT L. A. A. 1877: Description d'un sous-genre nouveau de la coléoptères hétéromères de la famille des Anthicides et indication des espèces que s'y rapportent. Annales de la Société Entomologique de France, Série 5 7: 167-169.

CHOBAUT A. 1895: Note sure des Anthicus Fairmairei Bris. trouvés sur le corps d'un Meloë rugosus Marsh. (Col.). Bulletin des Séances de la Société Entomologique de France 1895: ccclxxvii-ccclxxviii.
CUÉNOT L. 1890: Le sang des Meloe et le role de la cantharidine dans la biologie des coléoptères vésicants. Bulletin de la Société Zoologique de France 15: 126-128.

COLOMBINI I., CHELAZZI L., FALLACI M., LUCARELLI E. \& MASCAGNI A. 1991: La coleotterofauna del tombolo antistante la Laguna di Burano (GR): dinamica di popolazione e zonazione delle cinque famiglie più numerose. Redia 74: 87-109.

DEGIOVANNI A. 2012: Una nuova species della Turchia del genere Tenuicollis Marseul, 1879. Quaderno di Studi e Notizie di Storia Naturale della Romagna 36: 97-103.

DEGIOVANNI A. 2016: Four new species of Endomia from Africa (Coleoptera, Anthicidae). Annali del Museo Civico di Storia Naturale “G. Doria” 108: 219-234.

DE MARZO L. 1992: Le ghiandole odorifere in Formicomus pedestris (Rossi) (Coleoptera Anthicidae). Bolletino della Società Entomologica Italiana 124: 12-16.

DE MARZO L. 1996: Anatomia dei genitali interni e modalità di inseminazione in alcuni coleotteri anticidi. Entomologica 30: 147-165.

DE MARZO L. 2006: Nuove segnalazioni di Anthicidae in possesso di ghiandole mesosternali (Coleoptera). Naturalista Siciliano, Serie IV 30: 29-33.

DESBROCHERS DES LOGES J. 1868: Description de deux coléoptères nouveaux des environs de Bône. Bulletin de l'Académie d'Hippone 4 [1865]: 77-80.

DESBROCHERS DES LOGES J. 1875: Anthicides nouveaux. Pp. 42-49. In: Opuscules Entomologiques (Coléoptères). $1^{\mathrm{er}}$ Cahier [1874-1875], A. Gaudon, Paris, 56 pp.

DETTNER K. 1997: Inter- and intraspecific transfer of toxic insect compound cantharidin. Pp. 115-145. In: DETTNER K., BAUER G. \& VÖLKL W. (eds): Vertical food web interactions. Evolutionary patterns and driving forces. Ecological Studies 130: i-xxi + 1-390.

ELMALI M. 1997: Anthicus unicolor (Coleoptera: Anthicidae), a new predator of Diuraphis noxia (Homoptera: Aphididae) from Turkey. Entomological News 108: 208-212.

FORCHHAMMER P. 1986: Seasonal and daily variations in activity of ant-like flower-beetles (Anthicidae) collected in Serowe, Botswana 1982-83. Botswana Notes and Records 17: 163-174.

FUENTE J. M. DE LA 1932: Catálogo sistemáticogeográfico de los coléopteros observados en la Peninsula Ibérica, Pirineos y Baléares. Boletín de la Sociedad Entomológica de España 15: 104-119.

GOUVÈRS J. \& PONEL P. 2014: Anthicidae Latreille, 1819. Pp. $557-$ 561. In: TRONQUET M. (ed.): Catalogue des Coléoptères de France. Association Roussillonnaise d'Entomologie, Perpignan, 1052 pp.

GÖRNITZ K. 1937: Cantharidin als Gift und Anlockungsmittel für Insekten. Arbeiten über Physiologische und Angewandte Entomologie aus Berlin-Dahlem 4: 116-157.

GUYON G. 1848: Insectivorous propensity of Notoxus monoceros. The Zoologist: a Popular Miscellany of Natural History 6: 2000.

HASHIMOTO K. \& HAYASHI F. 2014: Cantharidin world in nature: a concealed arthropod assemblage with interactions via the terpenoid cantharidin. Entomological Science 17: 388-395.

HASHIMOTO K. \& HAYASHI F. 2016: Cantharidin world on islands: species diversity of canthariphilous arthropods in the Izu-Ogasawara Arc. Entomological Science 19: 432-439.

HASHIMOTO K., SUGAWARA H. \& HAYASHI F. 2016: Sclerotised spines in the female bursa associated with male's spermatophore production in cantharidin-producing false blister beetles. Journal of Insect Physiology 93-94: 18-27.

HEMP C. 1994: Anthiciden und Cantharidin. Ein Beiträg zur chemischen Ökologie, Bionomie und Phylogenie der Ameisenkäfer (Coleoptera: Anthicidae). Dissertation [unpublished] zur Erlangung des Doktorgrades der Fakultät Biologie, Chemie und Geowissenschaften der Universität Bayreuth, Bayreuth, 131 pp + 33 unnumbered pages.

HEMP C. \& DETTNER K. 1997: Morphology and chemistry of mesothoracic glands in anthicid beetles (Coleoptera: Anthicidae). Entomologia Generalis 22: 97-108.

HEMP C. \& DETTNER K. 2001: Compilation of canthariphilous insects. Beiträge zur Entomologie 51: 231-245.

HEMP C., DETTNER K., UHMANN G. \& HEMPA. 1997: A contribution to the biology of the African canthariphilous anthicids Formicomus 
rubricollis LaFerté, 1848 and F. gestroi Pic, 1894. Mitteilungen der Münchner Entomologische Gesellschaft 87: 81-96.

HEMP C., HEMP A. \& DETTER K. 1999: Canthariphilous insects of East Africa. Journal of East African Natural History 88: 1-15.

HEYDEN L. F. J. D. von 1883: Anthicidae. Pp. 139-141. In: HEYDEN L. F. J. D. von, REITTER E. \& WEISE J. (eds): Catalogus Coleopterorum Europae et Caucasi. Editio Tertia. Libraria Nicolai, Berlin, 228 pp.

HEYDEN L. F. J. D. von 1891: Anthicidae. Pp. 265-268. In: REITTER E. (ed.): Catalogus Coleopterorum Europae, Caucasi et Armeniae rossicae. M. Büsing, Mödling bei Wien, i-viii + 420 pp.

HOBERLANDT L. 1974: Results of the Czechoslovak-Iranian entomological expedition to Iran. No. 1: Introduction. Acta Entomologica Musei Nationalis Pragae, Supplementum 6: 9-20.

HOBERLANDT L. 1981: Results of the Czechoslovak-Iranian entomological expedition to Iran. Introduction to the Second expedition 1973. Acta Entomologica Musei Nationalis Pragae 40: 5-32.

HOBERLANDT L. 1983: Results of the Czechoslovak-Iranian entomological expedition to Iran. Introduction to the Third expedition 1977. Acta Entomologica Musei Nationalis Pragae 41: 5-24.

HOLZ C., STREIL G., DETTNER K., DÜTEMEYER J. \& BOLAND W. 1994: Intersexual transfer of a toxic terpenoid during copulation and its paternal allocation to developmental stages: quantification of cantharidin in cantharidin-producing oedemerids (Coleoptera: Oedemeridae) and canthariphilous pyrochroids (Coleoptera: Pyrochroidae). Zeitung für Naturforschung 49C: 856-864.

HORION A. 1956: Faunistik der mitteleuropäischen Käfer. Band V: Heteromera. Entomologische Arbeiten aus dem Museum G. Frey, Tützing bei München, xv +336 pp.

HORN W., KAHLE I., FRIESE G. \& GAEDIKE R. 1990: Collectiones entomologicae. Ein Kompendium über den Verbleib entomologischer Sammlungen der Welt bis 1960. Akademie der Landwirtschaftwissenschaften der Deutschen Demokratischen Republik, Berlin, 573 pp.

ICZN [= International Commission on Zoological Nomenclature] 2016: Opinion 2377 (Case 3624) A proposal for the rejection of 38 names in Anthicidae (Coleoptera): approved. Bulletin of Zoological Nomenclature 73: 65-69.

JIANG M., LÜ S. \& ZHANG Y. 2017: The potential organ involved in cantharidin biosynthesis in Epicauta chinensis Laporte (Coleoptera: Meloidae). Journal of Insect Science 17: 1-9.

KEJVAL Z. 2015: Falsophilus gen nov. from southern Africa (Coleoptera: Anthicidae). Klapalekiana 51: 175-199.

KEJVAL Z. 2017: The Palaearctic species of Aulacoderus LaFerté-Sénectère (Coleoptera: Anthicidae). Klapalekiana 53: 55-133.

KEJVAL Z. 2018: New synonymy in Cyclodinus and Microhoria (Coleoptera: Anthicidae). Klapalekiana 54: 197-205.

KREKICH-STRASSOLDO H. von 1911: Gli Anticidi del Litorale e della Dalmazia. Bollettino della Società Adriatica di Scienze Naturale in Trieste 8: $63-79+$ pl. 1 .

KREKICH-STRASSOLDO H. vON 1919. Über Anthicus humilis Germ. und verwandte Arten. Koleopterologische Rundschau 8: 60-76.

KREKICH-STRASSOLDO H. von 1913: Neue Anthiciden und Mitteilungen über die Verbreitung bekannter Anthiciden. Wiener Entomologische Zeitung 32: 223-232.

KREKICH-STRASSOLDO H. vON 1929: Revision der paläarktischen Anthicus-Arten der Gruppe 'Bifossicolles' (Gruppe XVIII in Marseuls Monographie). Koleopterologische Rundschau 15: 151-189.

KREKICH-STRASSOLDO H. vON 1931: Beiträge zur Kenntnis indischer Anthiciden II. Folia Zoologica et Hydrobiologica 3: $1-41+3$ pls.

KUBISZ D. \& SZWAŁKO P. 1998: Klucze do oznaczania owadów Polski Część XIX Chrząszcze - Coleoptera z. 80. Nakwiatkowate - Anthicidae. Polskie Towarzystwo Entomologiczne, Toruń, 37 pp.

LAFERTÉ-SÉNECTÈRE F. T. DE 1847: [new taxa of Anthicidae]. Pp. 365-381 + pl. 32. In: LUCAS P. H.: Exploration scientifique de l'Algérie pendant les années 1840, 1841, 1842 publiée par ordre du gouvernement et avec le concours d'un Commission Académique. Sciences physiques Zoologie. Vol. II. Histoire naturelle des animaux articulés. Cinquième classe. Insectes. Premier ordre. Les coléoptères. Imprimerie Nationale, Paris [1849], 590 pp +47 pls.

LAFERTÉ-SÉNECTÈRE F. T. DE 1849a: Anthicus (Troisième Division). In: GUÉRIN-MÉNEVILLE F.-E. (ed.): Species et iconographie générique des animaux articulés ou representation des genres, avec leur description et celle de toutes les espèces de cette grande division du règne animal. Première Partie: Insectes Coléoptères (1846-1849). Livraison 8, No. 29. Fain et Thunot, Paris, pp 184-231+ 1 pl.

LAFERTÉ-SÉNECTÈRE F. T. DE 1849b: Anthicus (Quatrième Division). In: GUÉRIN-MÉNEVILLE F.-E. (ed.): Species et iconographie générique des animaux articulés ou representation des genres, avec leur description et celle de toutes les espèces de cette grande division du règne animal. Première Partie: Insectes Coléoptères (1846-1849). Livraison 9, No. 30. Fain et Thunot, Paris, pp 133-181 + 1 pl.

LAFERTÉ-SÉNECTÈRE F. T. DE 1849c: Monographie des Anthicus et genres voisins, coléoptères hétéromères de la tribu des trachélides (1848). De Sapia, Paris, xxii + 340 pp + pls 17-32.

LAWRENCE J. F. \& ŚLIPIŃSKI A. 2013: Australian beetles. Vol. 1. Morphology, classification and keys. CSIRO Publishing, Collingwood VIC., viii + 561 pp.

LAWRENCE J. F., ŚLIPIŃSKI A., SEAGO A. E., THAYER M. K., NEWTON A. F. \& MARVALDI A. E. 2011: Phylogeny of the Coleoptera based on morphological characters of adults and larvae. Annales Zoologici 61: 1-217.

MARSEUL S. A. DE 1877: Coléoptères du Japon recueillis par M. Georges Lewis. 2. mémoire. Énumération des hétéromères avec la description de espèces nouvelles. 2. Partie. Annales de la Société Entomologique de France, Série 56 [1876]: 465-486.

MARSEUL S. A. DE 1879: Monographie des Anthicides de 1'Ancien-Monde. L'Abeille, Journal d'Entomologie 17: 1-268 + pls 1-2.

MCCORMICK J. P. \& CARREL J. E. 1987: Cantharidin biosynthesis and function in meloid beetles. Pp. 307-350. In: PRESTWICH G. D. \& BLOMQUIST G. J. (eds): Pheromone Biochemistry. Academic Press, New York, 586 pp.

MIN H.-K., PARK J.-K. \& CHO Y.-B. 2012: The first record of Anthicine species (Coleoptera: Anthicidae) in Korea. Journal of Korean Nature 5: 273-276.

NARDI G. 2003: Notes on some Microhorini (Coleoptera, Anthicidae). Bolletino dell'Associazione Romana di Entomologia 58: 53-75.

NARDI G. 2004: [New names]. In: CHANDLER D. S., NARDI G. \& TELNOV D.: Nomenclatural notes on the Palaearctic Anthicidae (Coleoptera). Mitteilungen der Internationalen Entomologischen Vereins e. V. 29: 109-173.

NARDI G. \& MIFSUD D. 2003: A review of the Anthicidae of the Maltese Islands (Central Mediterranean). Fragmenta Entomologica 35: 77-127.

NIKBAKHTZADEH M. R., DETTNER K., BOLAND W., GÄDE G. \& DÖTTERL S. 2007: Intraspecific transfer of cantharidin within selected members of the family Meloidae (Insecta: Coleoptera). Journal of Insect Physiology 53: 890-899.

PIC M. 1893: Anthicides nouveaux. L'Échange, Revue Linnéenne 9: 15-16.

PIC M. 1894: Catalogue geographique des anthicides de France, Corse, Algérie et Tunisie (Suite). Revue Scientifique du Bourbonnais et du Centre du France 7: 69-79.

PIC M. 1895: [Diagnoses de plusieurs coléoptères rapportés de Syrie par M. C. Delagrange]. Bulletin de la Société Entomologique de France 1894: cclxxiv-cclxxv.

PIC M. 1896: Xylophilides et anthicides recueillis en Algérie (Mai-Juin 1896). Revue Scientifique du Bourbonnais et du Centre du France 9: 162-169.

PIC M. 1897a: Descriptions des coléoptères. La Feuille des Jeunes Naturalistes, Série 3 27: 119-120.

PIC M. 1897b: Descriptions de coléoptères. Comptes Rendus de Séances et des Excursions de la Société d'Histoire Naturelle d'Autun 10: 295-300.

PIC M. 1897c: Descriptions de coléoptères. Miscellanea Entomologica 5: 61-63.

PIC M. 1898: Anthicides (Col. hétéromères) africains nouveaux des collections du Muséum de Paris. Bulletin du Muséum d'Histoire Naturelle 4: 67-72.

PIC M. 1901: Xylophilides et Anthicides Capturés en Italie et Grèce, du 17 avril au 14 juin 1901. Revue Scientifique du Bourbonnais et du Centre de la France 14: 173-182.

PIC M. 1904: Coléoptères nouveaux de la Turquie d'Asie. L'Échange, Revue Linnéenne 20: 73-74. 
PIC M. 1906: Anthicides et ptinides d'Algérie et de Tunisie (Col.) récoltés par M. le Capitaine Vibert. Bulletin de la Société Entomologique de France 1906: 282-285.

PIC M. 1908: Descriptions ou diagnoses et notes diverses (Suite). L'Échange, Revue Linnéenne 24: 65-66.

PIC M. 1910: Descriptions ou diagnoses et notes diverses (Suite). L'Échange, Revue Linnéenne 26: 41-43.

PIC M. 1911a: Descriptions ou diagnoses et notes diverses (Suite). L'Échange, Revue Linnéenne 27: 97-98.

PIC M. 1911b: Anthicidae. Pars 36. In: SCHENKLING S. (ed.): Coleopterorum Catalogus. W. Junk, Berlin, 102 pp.

PIC M. 1912: Descriptions ou diagnoses et notes diverses (Suite). L'Échange, Revue Linnéenne 28: 41-43.

PIC M. 1938: Notes diverses, nouveautés (Suite). L'Échange, Revue Linnéenne 54: 9-11.

PIC M. 1941: Opuscula martialis. L'Échange, Revue Linnéenne. Numéro Spécial 2: 1-16.

PIC M. 1957: [new taxa]. In: PIC M. \& HAWKINS C. N.: 29. Coleoptera: Anthicidae. British Museum (Natural History) Expedition to South-west Arabia 1937-8. [1941-1957] 1: 435-450.

REITTER E. 1889: Berichte über die von E. v. Oertzen in Jahre 1887 in Griechenland u. Klein-Asien gesammelten Coleopteren. IX. Neue Arten aus verschiedenen Familien. Deutsche Entomologische Zeitschrift 1889: 251-259.

REITTER E. (ed.) 1891: Catalogus Coleopterorum Europae, Caucasi et Armeniae rossicae. Büsing, Mödling bei Wien, viii +420 pp.

REITTER E. (ed.) 1906: Catalogus Coleopterorum Europae, Caucasi et Armeniae rossicae. Second edition. Oskar Hensel, Gottesberg, 774 pp.

SAHLBERG J. R. 1903a: Coleoptera Levantina mensibus Februario et Martio 1896 Palaestina et Aegypto inferiore collecta. Öfversigt af Finska Vetenskaps-Societetens Förhandlingar 45A(18) [1902-1903]: $1-14$.

SAHLBERG J. R. 1903b: Coleoptera Numido-Punica mensibus Martio, Aprili et Majo 1899 in Tunisia et Algeria orientali collecta. Öfversigt af Finska Vetenskaps-Societetens Förhandlingar 45A (19) [1902-1903]: 1-70.

SAHLBERG J. R. 1913a: Coleoptera mediterranea et rosso-asiatica nova et minus cognita maxima ex parte itineribus annis 1895-1896, 1898-1899 et 1903-1904 collecta. Öfversigt af Finska VetenskapsSocietetens Förhandlingar 55A (8) [1912-1913]: 1-88.

SAHLBERG J. R. 1913b: Messis nova hiemalis Coleopterorum Corcyreum. Öfversigt af Finska Vetenskaps-Societetens Förhandlingar 55A (12) [1912-1913]: 1-28.

SAHLBERG J. R. 1913c: Coleoptera mediterranea orientalia, quae in Aegypto, Palaestina, Syria, Caramania atque in Anatolia occidentali anno 1904 collegerunt John Sahlberg et Unio Saalas. Öfversigt af Finska Vetenskaps-Societetens Förhandlingar 55A (19) [1912-1913]: $1-281$.

SANZ DE DIEGO D. M. 1880: [meeting note]. Actas de la Sociedad Española de Historia Natural 9: 38-39.

SCHÜTZ C. \& DETTNER K. 1992: Cantharidin-secretion by elytral notches of male anthicid species (Coleoptera: Anthicidae). Zeitschrift für Naturforschung 47C: 290-299.

SIERRA J. R., WOGGON W.-D. \& SCHMID H. 1976: Transfer of cantharidin (1) during copulation from the adult male to the female Lytta vesicatoria ('Spanish flies'). Experientia 32: 142-144.

TAKADA K., TANABE S., TAKABA S. \& NAKAMURA K. 2006: Seasonal occurrence and spatial distribution of some anthicid species (Coleoptera, Anthicidae) in a rural area in Kakuma, Kanazawa, temperate zone of Japan. Elytra (Tokyo) 34: 363-373.

TELNOV D. 1998: Paläarktische Anthicidae des Zoologischen Museums Kopenhagen (Insecta: Coleoptera). Mitteilungen des Internationalen Entomologischen Vereins e. V. 22: 165-171.

TELNOV D. 1999: Weitere Anthicidae verschiedener Regionen aus dem Zoologischen Museum Kopenhagen (Insecta Coleoptera). Bulletin de la Société Royale Belge d'Entomologie 135: 72-81.

TELNOV D. 2002: Vorlaufige Auflistung der Anthicidae (Coleoptera) von Afghanistan, mit Beschreibung einer neuen Art. Latvijas Entomologs 39: 20-29.

TELNOV D. 2003: Trictenotomidae und Anthicidae (Insecta: Coleoptera) des Himalayas und angrenzender Regionen, Teil 1. Systematik, Fau- nistik, Zoogeographie. Pp. 279-303. In: HARTMAN M. \& BAUMBACH H. (eds): Biodiversität und Naturausstattung im Himalaya. Verein der Freunde und Förderer des Naturkundemuseums Erfurt e. V., $389 \mathrm{pp}+16 \mathrm{pls}$

TELNOV D. 2004: [New names, new combinations]. In: CHANDLER D. S., NARDI G. \& TELNOV D.: Nomenclatural notes on the Palaearctic Anthicidae (Coleoptera). Mitteilungen der Internationalen Entomologischen Vereins e. V. 29: 109-173.

TELNOV D. 2010: Nomenclatural notes on Anthicidae and Pyrochroidae (Coleoptera). 3. Latvijas Entomologs 48: 8-16.

TELNOV D. 2018a: Nomenclatural Notes on Anthicidae and Pyrochroidae (Coleoptera). 6. Baltic Journal of Coleopterology 18: 219-278.

TELNOV D. 2018b: Descriptions of two new Australian genera of Anthicidae (Insecta: Coleoptera). Baltic Journal of Coleopterology 18: $199-218$

TELNOV D. 2019. Neocrohoria gen. nov., a new Anthicidae (Insecta: Coleoptera) genus from Chile. Acta Biologica Universitatis Daugavpiliensis 19: 1-8.

TELNOV D. \& GHAHARI H. 2018: An annotated checklist of the Anthicidae and pediline Pyrochroidae (Insecta: Coleoptera) of Iran, with thirteen new country records. Zootaxa 4497: 451-491.

TEZCAN S., UHMANN G. \& KESKIN B. 2002: Notes on the ant-like flower beetles (Coleoptera Anthicidae, Anthicinae) of the ecologically managed cherry orchards of western Turkey. Baltic Journal of Coleopterology 2: 77-82.

TYLDEN W. 1865: Curious habit of Notoxus monocerus. Entomologist's Monthly Magazine 2: 118-119.

UHMANN G. 1976: Die Gattungen der Anthicidae und ihre systematische Anordnung. Entomologische Blätter 72: 166-182.

UHMANN G. 1978: Die Gattungen der Anthicidae und ihre systematische Anordnung. Teil 2. Die Systematische Anordnung. Entomologische Blätter 74: 75-80.

UHMANN G. 1985: Paläarktische Anthiciden (Coleoptera) des Ungarischen Naturwissenschaftlichen Museums Budapest. Folia Entomologica Hungarica 46: 177-203.

UHMANN G. 1989: Anthicidae (Coleoptera) der orientalischen Region aus dem Naturhistorischen Museum in Genf, II. Revue Suisse de Zoologie 96: 243-252.

UHMANN G. 1992: Die Anthicidae der Iberischen Halbinsel. Mitteilungen der Münchener Entomologischen Gesselschaft 82: 87-180.

UHMANN G. 1996: Anthiciden aus dem Naturhistorischen Museum in Wien (Coleoptera, Anthicidae). Entomologische Blätter 92: 19-36.

UHMANN G. 1998: Anthicidae (Insecta: Coleoptera) from Saudi Arabia with the decription of a new species. Fauna of Arabia 17: 93-105.

UHMANN G. 2000: Anthicidae (Coleoptera) aus verschiedenen Regionen. Annales Historico-Naturales Musei Nationalis Hungarici 92: $145-160$.

UHMANN G. 2007: Die Anthicidae Latreille 1819 (Coleoptera: Tenebrionoidea) von Australien ohne Formicomini. 68. Beitrag zur Kenntnis der Anthicidae. Coleoptera, Schwanfelder Coleopterologische Mitteilungen 11: 1-107.

UHMANN G., CHIKATUNOV V. \& PAVLÍČEK T. 2005: Catalogue of the beetles (Coleoptera) in Israel and adjacent areas: 4. Anthicidae. Biocosme Mésogéen Revue 22: 1-64.

VAN HILLE J. C. 1954: Cantharidin and Anticidae [sic]. South African Journal of Science 51: 154-155.

VAN HILLE J. C. 1961: Chapter III. Coleoptera: Anthicidae. Pp. 217-258. In: HANSTRÖM B., BRINCK P. \& RUDEBECK G. (eds): South African Animal Life, Volume 8. Almqvist \& Wiksells, Uppsala, 557 pp.

VAN HILLE J. C. 1971: Anthicidae (Coleoptera) from Northern Zululand. Transactions of the Royal Society of South Africa 39: 367-391.

VAN HILLE J. C. 1984: Monograph of Aulacoderus la Ferté, a subgenus of Anthicus Paykull (Coleoptera: Anthicidae). Annals of the Cape Provincial Museums (Natural History) 15: 1-171.

VAN HILLE J. C. 1985: Descriptions of new species of Anthicus Paykull (Aulacoderus La Ferté) from southern Africa (Coleoptera: Anthicidae). Annals of the Transvaal Museum 34: 55-121.

WERNER F. G. 1966a: A revision of Acanthinus (Coleoptera: Anthicidae). I. The bimaculifer-group. Annals of the Entomological Society of America 59: 509-513. 
WERNER F. G. 1966b: A revision of Acanthinus (Coleoptera: Anthicidae). II. The angusticollis-group. Annals of the Entomological Society of America 59: 746-751.

WERNER F. G. 1966c: A revision of Acanthinus (Coleoptera: Anthicidae). III. The spinicollis-group. Annals of the Entomological Society of America 59: 1267-1276.

WERNER F. G. 1967a: A revision of Acanthinus (Coleoptera: Anthicidae). IV. Annals of the Entomological Society of America 60: 255-273.

WERNER F. G. 1967b: A revision of Acanthinus (Coleoptera: Anthicidae). V. The striatopunctatus-group and some related forms. Annals of the Entomological Society of America 60: 535-549.

WERNER F. G. 1967c: A revision of Acanthinus (Coleoptera: Anthicidae). VI. Annals of the Entomological Society of America 60 1217-1234.

WERNER F. G. 1970a: A revision of Acanthinus (Coleoptera: Anthicidae). VII. Annals of the Entomological Society of America 63: 111-128.

WERNER F. G. 1970b: A revision of Acanthinus (Coleoptera: Anthicidae). VIII. The Australian species. Annals of the Entomological Society of America 63: 486-490

WERNER F. G. 1970c: A revision of Acanthinus (Coleoptera: Anthicidae). IX. The leporinus, scitulus, cuyabanus, and myrmecops-groups. Annals of the Entomological Society of America 63: 719-731.
WERNER F. G. 1970d: A revision of Acanthinus (Coleoptera: Anthicidae). X. Albicinctus-group and conclusion. Annals of the Entomological Society of America 63: 859-876.

WERNER F. G. 1974: A review of the Chilean Anthicidae (Coleoptera). Revista Chilena de Entomologia 8: 27-34.

WERNER F. G. \& CHANDLER D. S. 1995: Anthicidae (Insecta: Coleoptera). Fauna of New Zealand 34. Manaaki Whenua Press, Lincoln, $59 \mathrm{pp}$.

WINKLER A. 1927: Anthicidae. Pp. 833-851. In: Catalogus coleopterorum regionis palaearcticae. Albert Winkler Verlag, Wien [1927-1932], $1698 \mathrm{pp}$.

YOUNG D. K. 1984a: Cantharidin and insects: an historical review. Great Lakes Entomologist 17: 187-194.

YOUNG D. K. 1984b: Field records and observations of insects associated with cantharidin. Great Lakes Entomologist 17: 195-199.

ZAHRADNÍK P. 2017: Seznam brouků (Coleoptera) České republiky a Slovenska. Check-list of beetles (Coleoptera) of the Czech Republic and Slovakia. Lesnická práce, Kostelec nad Černými lesy, 539 pp. 